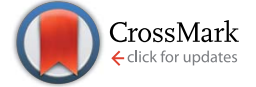

Cite this: Nat. Prod. Rep., 2015, 32, 1207

Received 25th February 2015

DOI: 10.1039/c5np00025d

www.rsc.org/npr

\title{
Structural aspects of phenylglycines, their biosynthesis and occurrence in peptide natural products
}

\author{
Rashed S. Al Toma, ${ }^{a}$ Clara Brieke, ${ }^{b}$ Max J. Cryle ${ }^{\star b}$ and Roderich D. Süssmuth ${ }^{\star a}$
}

\begin{abstract}
Covering up to February 2015
Phenylglycine-type amino acids occur in a wide variety of peptide natural products, including glycopeptide antibiotics and biologically active linear and cyclic peptides. Sequencing of biosynthesis gene clusters of chloroeremomycin, balhimycin and pristinamycin paved the way for intensive investigations on the biosynthesis of 4-hydroxyphenylglycine ( $\mathrm{Hpg}$ ), 3,5-dihydroxyphenylglycine (Dpg) and phenylglycine (Phg) in recent years. The significance and importance of this type of unusual non-proteinogenic aromatic amino acids also for medicinal chemistry has drawn the attention of many research groups and pharmaceutical companies. Herein structures and properties of phenylglycine containing natural products as well as the biosynthetic origin and incorporation of phenylglycines are discussed.
\end{abstract}

1 Introduction

2 Structure and properties of Phg, Hpg and Dpg

3 Phenylglycines in peptide natural products

3.1 Phg-containing peptides

3.2 Hpg and Dpg-containing peptides

3.2.1 Linear peptides

3.2.2 Cyclic peptides

$4 \quad$ Biosynthesis of phenylglycines

4.1 Phg biosynthesis

4.2 Hpg biosynthesis

4.3 Dpg biosynthesis

5 Biosynthesis of phenylglycine-containing peptides

5.1 Phenylglycine incorporation into non-ribosomal peptides

5.1.1 Phenylglycine selection and epimerization

5.1.2 Acceptance of alternative substrates by phenylglycine activating A-domains

5.2 Phenylglycine modifying enzymes

5.2.1 Oxidative coupling

5.2.2 Halogenation

5.2.3 Alkylation

5.2.4 Glycosylation

5.2.5 Sulfation

5.2.6 Miscellaneous/combined tailoring reactions: nocardicin A

6 Significance, importance and occurrence in medicinal chemistry

${ }^{a}$ Institut für Chemie, Technische Universität Berlin, 10623 Berlin, Germany. E-mail: suessmuth@chem.tu-berlin.de

${ }^{b}$ Max Planck Institute for Medical Research, Department of Biomolecular Mechanisms, 69120 Heidelberg, Germany. E-mail: Max.Cryle@mpimf-heidelberg.mpg.de

$\begin{array}{ll}7 & \text { Conclusions } \\ 8 & \text { Acknowledgements } \\ 9 & \text { Notes and references }\end{array}$

\section{Introduction}

A great many fundamental processes in the cell are based on the interaction of peptides and proteins, which are composed of the repertoire of 20 so-called canonical amino acids (cAA). Generally, the biosynthesis of these peptides and proteins is based on mechanisms of ribosomal synthesis. ${ }^{1}$ The alphabet of the cAAs has recently been extended by two additional amino acids, selenocysteine (abbreviated as Sec or U, in older publications as Se-Cys) as the $21^{\text {st }}$ proteinogenic amino acid, which is used as a building block for selenoproteins in all kingdoms of $\operatorname{life}^{2}$ and pyrrolysine (Pyl or O) as the $22^{\text {nd }}$ proteinogenic amino acid, which in 2002 was discovered to be used by Methanosarcina barkeri in the active site of a methyl-transferase enzyme. Pyl is encoded by the amber stop codon $\mathrm{UAG}^{3-5}$ and also used by some methanogenic archaea as well as the Gram-positive bacterium Desulfitobacterium hafniense as a part of a methane-producing enzyme complex. ${ }^{6}$ The structural complexity in the bacterial and fungal world is further increased by posttranslational modifications of the canonical amino $\operatorname{acids}^{\mathbf{1}}$ to a multitude of additional amino acid modifications.

An alternative biosynthesis route for assembly of peptides is non-ribosomal peptide biosynthesis. In a similar manner to ribosomally synthesized and post-translationally modified peptides (RiPPs) biosynthesis, genes are assembled in gene clusters which harbor a variety of genes coding for non- 
ribosomal peptide synthetases (NRPSs), amino acid biosynthesis genes, tailoring enzymes, as well as genes for export and resistance. The NRPSs are multimodular giant enzymes, in which one module is typically dedicated to the activation and coupling of one amino acid. Of particular importance are the adenylation (A) domains as essential constituents of these modules. The A-domains perform the recognition and activation of a specific amino acid. The amino acids to be activated can be proteinogenic or non-proteinogenic. In the latter case, the gene cluster or the genome of the producing organism must contain the biosynthesis genes for the corresponding non-proteinogenic amino acid. Structural diversity during non-ribosomal biosynthesis is further attained either by in cis acting domains (methylation, epimerization, cyclization, etc.) or by tailoring enzymes, performing methylations, $\beta$-hydroxylations, oxidation reactions and halogenations acting in trans. Methylations have been observed at the $\beta$-carbon atom of some amino

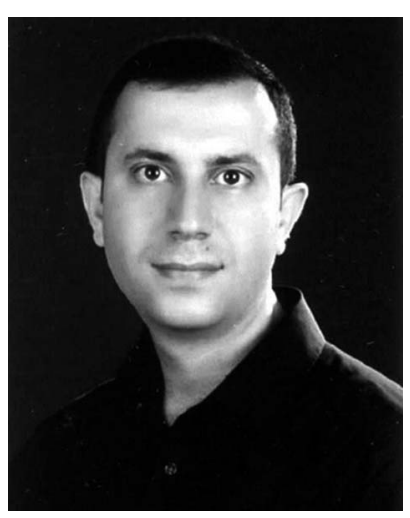

Rashed Al Toma, an agricultural engineer from Damascus University in horticulture and plant tissue culture. Between 2006 and 2010 he was a supervising engineer of plant biotechnology laboratory at the national commission for biotechnology in Syria. In 2009 he obtained an MSc in biotechnology with Khalil Al Maarri (Damascus), Wim Vanden Berghe and Guy Haegeman (Gent), where he screened medicinal plants against cancer cells and bacteria. In 2010 he started his PhD with Roderich Süssmuth at TU-Berlin as a BIG-NSE fellow with an Erasmus Mundus fellowship. He studies in vivo incorporation of noncanonical amino acids into lantibiotics and lasso peptides.

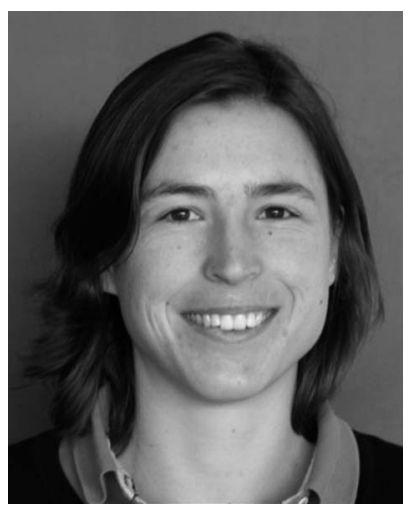

Clara Brieke studied biomedical chemistry at the universities of Mainz and London. For her PhD, she moved to Prof. Heckel's group at the University of Frankfurt focusing on photoregulation methods and nucleic acid chemistry. In 2012 she joined the group of Dr Cryle at the Max Planck Institute for Medical Research in Heidelberg, where she entered the field of non-ribosomally derived natural products. Her research activities mainly focus on the synthesis of biosynthetic intermediates of glycopeptide antibiotics and the exploration of enzymatic oxidative cross coupling reactions in their biosynthesis. acids like Asp in friulimicin, ${ }^{7}$ Glu in daptomycin ${ }^{8}$ and Phe in hormaomycin. ${ }^{9}$ Such $\beta$-hydroxylations are catalyzed either by nonheme iron-containing $\alpha$-ketoglutarate-dependent dioxygenases ${ }^{10,11}$ or cytochrome $\mathrm{P} 450$ monooxygenases ${ }^{12,13}$ and a prominent example is $\beta$-hydroxytyrosine in various glycopeptide antibiotics, such as vancomycin. ${ }^{\mathbf{1 4}}$ Likewise halogenations of proteinogenic amino acids have been described for glycopeptide antibiotics. ${ }^{15}$

A remarkable family of non-proteinogenic amino acids which are recruited by NRPSs to build up peptide structures are the phenylglycines (Scheme 1), consisting of phenylglycine (Phg), 4-hydroxyphenylglycine (Hpg) and 3,5-dihydroxyphenylglycine (Dpg) as the most important representatives. Phenylglycine-type amino acids occur in various natural products, e.g. in pristinamycins (Phg), ${ }^{16,17}$ or in almost all glycopeptide antibiotics (Hpg and Dpg). They can formally be regarded as truncated versions of Phe or Tyr which lack the methylene

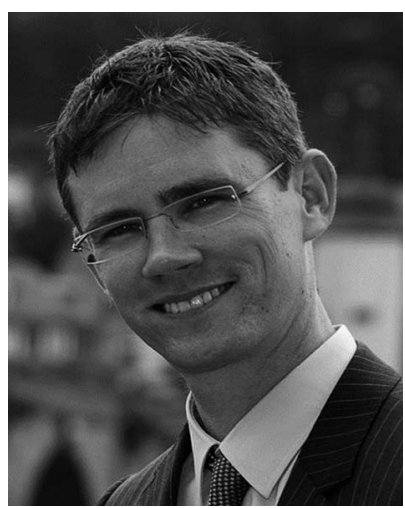

Max Cryle obtained his PhD in organic chemistry from the University of Queensland in Brisbane, Australia in 2006. Following the completion of his PhD he moved to the Max Planck Institute for Medical Research in Heidelberg, Germany as a Cross Disciplinary Fellow of the Human Frontiers Science Program to study Carrier Protein/Cytochrome P450 complexes. In 2011 he was funded through the Emmy Noether program to lead an independent group with a focus on the biosynthesis of glycopeptide antibiotics. His group currently applies a combination of approaches including organic synthesis, biochemistry and structural biology to investigate antibiotic biosynthesis.

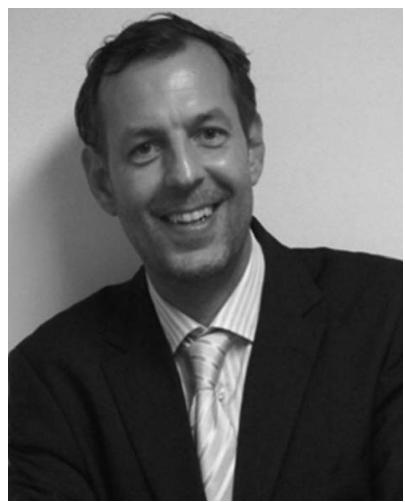

Roderich Süssmuth is the Rudolf Wiechert Professor of Biological Chemistry at the Technische Universität Berlin. He obtained his PhD degree in chemistry in 1999 from the Eberhard Karls Universität Tübingen with Günther Jung. In 2000, he was a Feodor-Lynen-Fellow of the Alexander von Humboldt-Foundation with Carlos Barbas III and Richard Lerner. Subsequently he became an Assistant Professor in Tübingen with an Emmy-Noether fellowship granted by the DFG, and then moved in 2004 to the TU Berlin where he is full professor. His research is focused on antibiotics, biosynthetic assembly lines, host-pathogen interactions, medicinal chemistry of peptides, enzymes and enzyme inhibitors. 


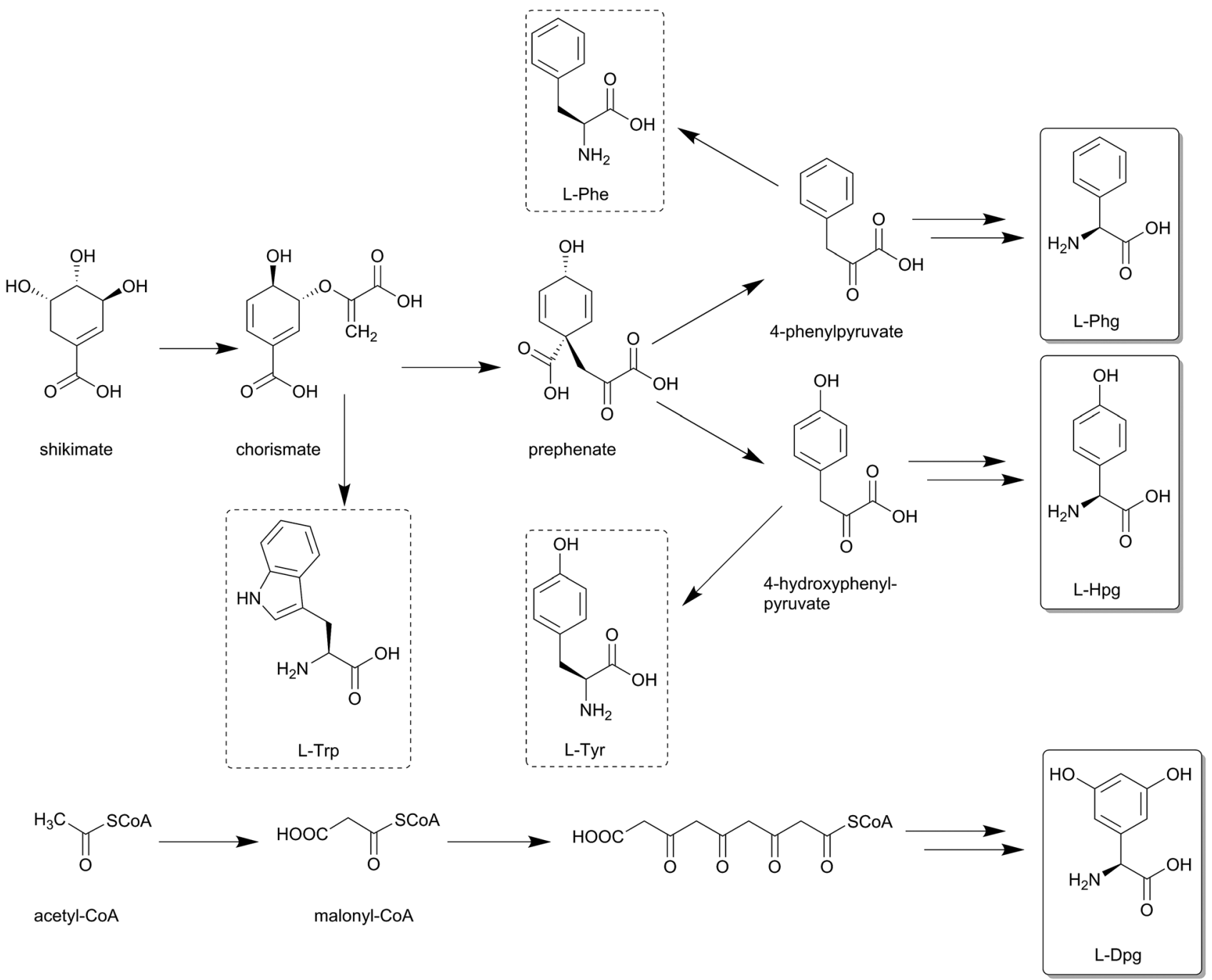

Scheme 1 Shared biosynthesis scheme for phenylglycines and the aromatic amino acids Phe, Tyr and Trp. While Phg and Hpg originate from chorismate branching off into the biosyntheses of Phe and Tyr, the amino acid Dpg is directly assembled from acetyl-CoA. Detailed insights into the biosynthesis of Phg, Hpg and Dpg are discussed in Section 4.

group in contrast to the methylene-extended versions, i.e. the homoamino acids. $^{18}$ Respective examples are homophenylalanine (homoPhe), in pahayokolides A and $\mathrm{B},{ }^{19}$ homotyrosine (homoTyr) in cyanopeptolins as well as anabaenopeptins, ${ }^{20}$ or 3,4-dihydroxyhomotyrosine in echinocandin $\mathrm{B}^{21}$ In this review we highlight some structural aspects of Phg, Hpg and Dpg, discuss their occurrence in various natural products as well as their biosynthesis, modification and incorporation into peptides.

\section{Structure and properties of Phg, Hpg and Dpg}

Steric and electronic aspects play an important role for conformation and reactivity of phenylglycine-containing peptides and thus it is pertinent to discuss these influences.

Remarkably, in phenylglycines the bulky aromatic sidechain is directly attached to the $\alpha$-carbon. This is in stark contrast to the proteinogenic aromatic amino acids, which all bear a $\beta$ methylene spacer between the $\alpha$-carbon and the aromatic group. Accordingly, phenylglycines have, assuming that the conformation of the peptide backbone is fixed, strongly restricted degrees of freedom for the aromatic side chain. Furthermore, electronic effects of substituents at the aromatic rings influence reactivity and physical properties. In general, phenylglycines appear more prone to racemization than other $\alpha$-amino acids. $^{22,23}$

In the literature, two basic mechanisms of racemization for amino acids are discussed. According to the first mechanism, it is believed that deprotonation occurs at the $\alpha$-carbon due to acidic nature of the $\alpha$-proton stabilizing an enolate-like structure, which ultimately leads to racemization upon reprotonation. Alternatively, deprotonation may occur at the amide proton forming an enolate upon rearrangement, leading to racemization. ${ }^{22}$ Interestingly, Phg, Hpg and Dpg undergo basecatalyzed racemization at the $\alpha$-position at much higher rate 
compared to Phe/Tyr and also compared to other proteinogenic amino acids. Experimentally, it was found that Phg has a ninefold higher rate of racemization compared to alanine. ${ }^{22,23} \mathrm{~A}$ 4hydroxy group substitution on phenylglycine (Hpg) should decelerate the racemization rate, which can be attributed to the mesomeric effect $(+\mathrm{M})$ (Scheme 2) decreasing the acidity of the $\alpha$-carbon. Electron withdrawing substituents in this position, e.g. a nitro group, should dramatically increase racemization. Due to the $m$-position, the phenol substituents of Dpg have a significantly reduced M-effect compared to Hpg. Rather - Ieffects could induce faster racemization. In addition, one has to consider that the electronic effects of the aromatic sidechain are conformation-depend, i.e. that rotation of the aromatic ring (IV) out of the plane $(\mathrm{V})$ leads to lowered orbital overlap and thus less influence on racemization rate of the $\alpha$-carbon.

The racemization-prone nature of phenylglycines is a wellknown phenomenon and has been described for synthesis applications during deprotection ${ }^{24}$ and macrocyclization reactions of amino acids and peptides, which greatly limits the selection of protecting groups, and further requires the careful selection of reaction conditions. This indicates the importance of structural features and of electronic effects on the stability of phenylglycines as well as of peptides derived from them. In addition, electron donating effects from hydroxyl and other substituents on the aromatic ring may influence $\pi-\pi$ stacking, as well as capabilities for formation of H-bonds.

While the electronic nature and influence of phenylglycines within a peptide context is rather poorly understood, it is apparent that these amino acids play a particular role for both structure and bioactivity. One example for the importance of the $\mathrm{Hpg}$ residue was performed at [L-Dap $\left.{ }^{2}\right]$ ramoplanin $\mathrm{A} 2$ aglycon by an alanine scan, ${ }^{25}$ a commonly used method to systematically replace and hence assess every amino acid position of a peptide by Ala. By means of this method the minimal inhibitory

a)

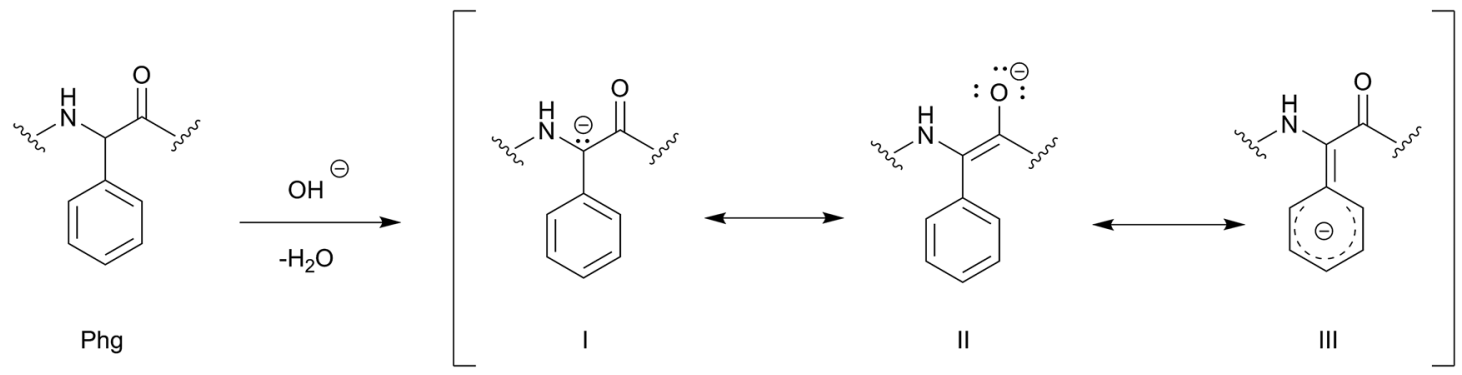

b)<smiles>[M]CCCCCC(=O)C(=O)c1ccc(S)cc1</smiles><smiles>CCNC(=O)C(CC)c1cccc(S)c1</smiles>

e.g. $\mathrm{S}=\mathrm{OH}$

c)<smiles>CCNC(=O)C(CC)c1ccc(S)cc1</smiles>

IV

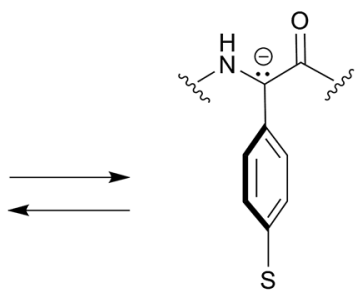

V

d)<smiles>[3H]C(=O)C(NCC)c1ccc(O)cc1</smiles>

Hpg<smiles></smiles>

Phg<smiles></smiles>

Dpg

Scheme 2 Proposed racemization mechanism of phenylglycines due to stereochemical and conformational influences. (a) The carbanion structure (I) and the enolate structure (II) postulated also for proteinogenic amino acids is further stabilised by delocalisation of the negative charge in the aromatic ring (III); (b) electron donating and electron withdrawing substituents (S) stabilize or destabilize the carbanion structure thus influencing racemisation rates. Substituents in $p$-position are expected to exert a stronger effect compared to $m$-substituents; (c) rotation of the aromatic ring (IV) out of plane (V) interrupts communication between $\pi$-orbitals of the aromatic ring and is expected to strengthen resistance against racemisation; (d) the rate of racemization increases in the order $\mathrm{Hpg}<\mathrm{Phg}<\mathrm{Dpg}$. 
concentration (MIC) decreased 13 to 74 times fold depending on the position of $\mathrm{Hpg}$ which had been exchanged with Ala. ${ }^{25} \mathrm{~A}$ similar experiment was carried out for the peptide antibiotic feglymycin, where an assessment of contributions of Hpg and Dpg to the antimicrobial activity was performed. ${ }^{26}$

\section{Phenylglycines in peptide natural products}

Phenylglycines occur in various forms as constituents of peptide natural products and thus contribute to novel - and even medically exploited - bioactivities. With regard to structural aspects, the number of phenylglycine building blocks varies, from a single occurrence to multiple times in different peptides. Among phenylglycine-containing peptides linear structures, head-to-tail cyclizations or side chain-bridges directly involving phenylglycines have been described. In addition, both enantiomeric forms of phenylglycines, i.e. L or D configuration, are represented in various peptides. In the following sections we will suggest a classification of peptides according to characteristic structural features.

\subsection{Phg-containing peptides}

The amino acid phenylglycine has been reported in the early 1960-70s as a constituent of the peptide antibiotics virginiamycin $\mathrm{S}^{27-29}$ produced by Streptomyces virginiae, streptogramin B (also known as pristinamycin IA and mikamycin IA) ${ }^{30-34}$ produced by various species of the Streptomyces genus (e.g. Streptomyces diastaticus, and Streptomyces graminofaciens), ${ }^{35}$ and pristinamycin $\mathbf{I}^{\mathbf{2 8 , 3 6 - 3 9}}$ produced from Streptomyces pristinaespiralis (Scheme 3). The structure elucidation of these compounds has been performed by identification of hydrolysis products, ${ }^{27,28,40-42}$ while the configuration of these compounds has been determined by mass spectrometry and X-ray crystallography. ${ }^{28,43}$ Pristinamycin I, virginiamycin S and streptogramin B are heptameric cyclic peptide antibiotics synthesized by NRPSs $^{28,37}$ which share the same core structure. Pristinamycin I for example consists of seven amino acids, five of them are noncanonical residues including L-hydroxypicolinic acid (L-Hpa), L-aminobutyric acid (L-Apa), 4- $\mathrm{N}-\mathrm{N}$-dimethylaminoL-phenylalanine (L-DAMPA), 4-oxo-L-pipecolic acid (L-Pip) and L-phenylglycine (L-Phg). ${ }^{17,28}$ Virginiamycin S has exactly the same structure as pristinamycin I with the exception that it contains L-Phe instead of L-DAMPA (Scheme 3).

Virginiamycin $\mathrm{S}$ has antimicrobial activities against a broad spectrum of Gram-positive bacteria, and was used as an antibiotic for poultry feeds in order to stimulate growth. ${ }^{\mathbf{4 4 , 4 5}}$ The use of virginiamycin increased from 1995 to 1997 as growth promoter for pigs, which in turn caused an increase in virginiamycin-resistant Enterococcus faecium isolates from $27.3 \%$ in 1995 to $66.2 \%$ in 1997 in Denmark. In the beginning of 1998, the Danish government banned its use, and the occurrence of virginiamycin-resistance decreased to $33.9 \%$ in $2000 .{ }^{46}$ Similar results have been reported from Norway and Finland. ${ }^{\mathbf{4 7}}$ Streptogramins (including virginiamycin $\mathrm{S}$ and pristinamycin I) inhibit bacterial protein synthesis in Gram-positive bacteria targeting the $23 \mathrm{~S}$ ribosomal RNA by binding to the P-binding site of the 50S ribosomal subunit. This prevents the elongation of the protein chains by the ribosome, ultimately leading to the premature release of peptides. ${ }^{35}$

Pristinamycin I exhibits antimicrobial activities against erythromycin-resistant staphylococci and streptococci, as well as against methicillin-resistant Staphylococcus aureus (MRSA). This peptide, which has moderate bacteriostatic effects, ${ }^{17}$ is synthesized together with the polyunsaturated cyclopeptide/ macrolactone pristinamycin II, a streptogramin group A member. The producing strain Streptomyces pristinaespiralis synthesizes both compounds in an approximate $1: 3$ ratio. $^{28}$ Both compounds, pristinamycin I and II, act in a synergistic manner rendering bactericidal affects. In spite of its poor

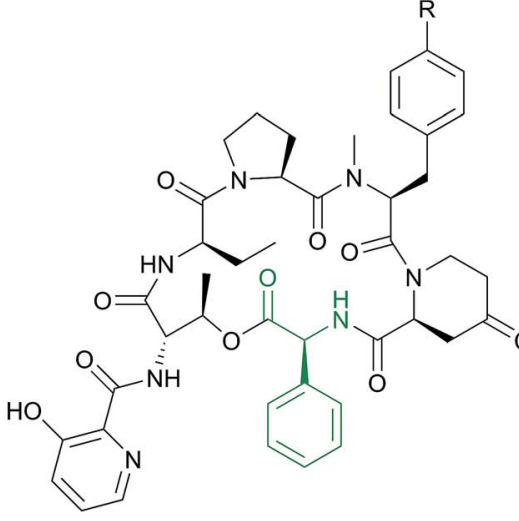

$\mathrm{R}=\mathrm{N}\left(\mathrm{CH}_{3}\right)_{2}:$ Pristinamycin IA / Streptogramin B $\mathrm{R}=\mathrm{H}$ : Virginiamycin $\mathrm{S} 1$

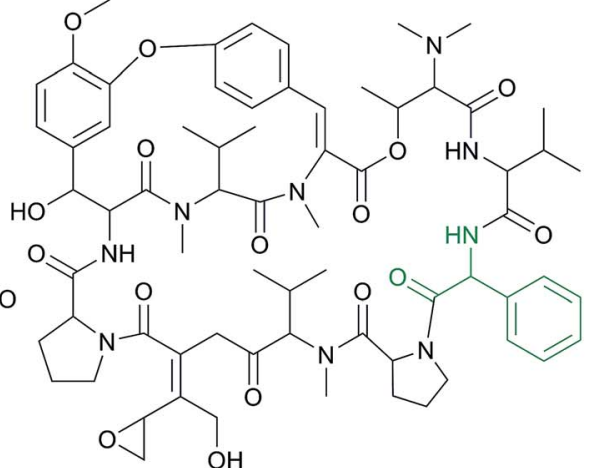

Dityromycin

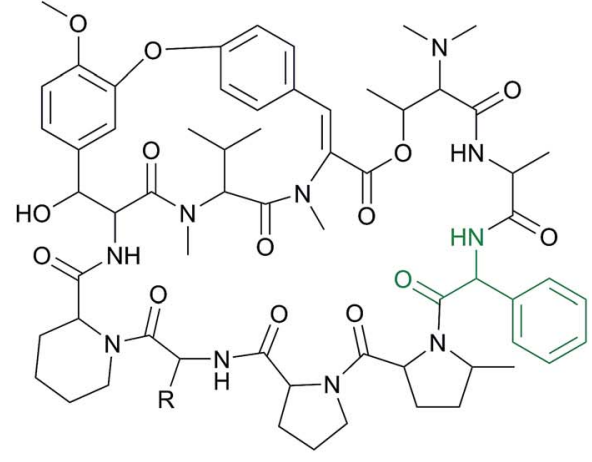

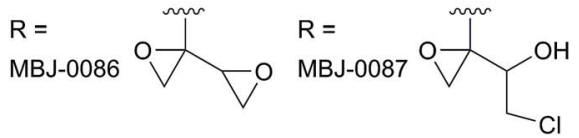

Scheme 3 Structures of the Phg-containing peptides: pristinamycin IA/streptogramin B, virginiamycin S1, the bicyclic peptides dityromycin, MBJ-0086 and MBJ-0087. 
solubility $\left(10^{-4} \mathrm{mg} \mathrm{ml}{ }^{-1}\right.$ water $),{ }^{28}$ which limits its usage in intravenous formulations, it is sometimes used as a therapeutic drug in human medicine against multi-resistant Gram-positive bacteria, such as the semisynthetic streptogramin Synercid (Pfizer) which is a mixture of quinupristin (a pristinamycin I derivative) and dalfopristin (a pristinamycin II derivative). ${ }^{\mathbf{2 9 , 4 8}}$ Dalfopristin binds to the 23S ribosomal RNA of the 50S ribosomal subunit and changes its conformation, which enhances the binding of quinopristin 100 fold.${ }^{17}$ Pristinamycin I is used as an alternative to rifampicin, fusidic acid or linezolid in the treatment of methicillin-resistant Staphylococcus aureus MRSA, drug-resistant Streptococcus pneumoniae and vancomycin-resistant Enterococcus faecium as well as some Gram-negative bacteria, such as Haemophilus spp..$^{1,49-52}$

In addition to the monocyclic peptides mentioned above, a bicyclic peptide named dityromycin is also a Phg-containing peptide (Scheme 3). ${ }^{53,54}$ Dityromycin is produced by Streptomyces sp. strain AM-2504, and shows antimicrobial activities against Gram-positive bacteria including Bacillus, Clostridium, and Corynebacterium. ${ }^{55}$ Its structure was elucidated by NMR spectroscopy and FAB-MS, and finally confirmed by fragment synthesis. ${ }^{53}$ Nevertheless, its stereochemistry has not yet been clarified. The structure of GE82832, synthesized by Streptosporangium cinnabarinum (strain GE82832) is highly related to that of dityromycin and has a mass difference of $2 \mathrm{Da}$, which might result from an additional yet undetermined position of a double bond.$^{54}$ Furthermore, GE82832 consists of two bioactive isomeric components (A and B) with the same molecular weight (1286 Da) which may be due to the occurrence of diastereomers. ${ }^{56}$ Dityromycin and GE82832 inhibit bacterial protein synthesis in vitro and in vivo by targeting the small ribosomal subunit and inhibiting the EF-G-catalyzed translocation of the elongation step. ${ }^{\mathbf{5 4 5 7}}$ Recently, two new bicyclic depsipeptides, named MBJ-0086 and MBJ-0087, have been isolated from the culture broth of Sphaerisporangium sp. $3226 .{ }^{58}$ They have very similar structure to dityromycin and GE82832 peptides (Scheme 3). Their structures were elucidated by NMR spectroscopy and high-resolution-ESI-LC-MS. MBJ-0086 shows a high antimicrobial activity against Bacillus subtilis with an MIC value of $1.1 \mu \mathrm{M}$, in comparison to $24 \mu \mathrm{M}$ for MBJ-0087. Both compounds have no cytotoxicity against human ovarian adenocarcinoma SKOV-3 cells $\left(\mathrm{IC}_{50}>50 \mu \mathrm{M}\right)$ nor antimicrobial activity against Micrococcus luteus $\left(\mathrm{IC}_{50}>50 \mu \mathrm{M}\right) .^{58}$ As the above-mentioned Phg-containing natural products are the only examples of Phg found in nature, this amino acid appears to be the least represented among all phenylglycines.

\subsection{Hpg and Dpg-containing peptides}

Non-substituted phenylglycines are comparatively rare in peptide natural products, and they do not occur accompanied by other phenylglycines. However, it is quite remarkable that there have been several peptides described with the concomitant presence of Hpg and Dpg. Furthermore, the structural diversity of Hpg- and Dpg-containing peptides is much more pronounced, possibly also due to the H-bonding properties of the phenolic groups, which expands the options for molecular interactions. However, the amino acid 3-hydroxyphenylglycine rarely occurs in nature, and the only example of a known natural product is forphenicine (4-formyl-3-hydroxyphenylglycine), an inhibitor of alkaline phosphatase produced by Actinomyces fulvoviridis var. acarbodicus. ${ }^{\mathbf{5 9 , 6 0}}$ Another rare natural derivative of phenylglycine is $m$-carboxyphenylglycine, which was isolated from bulbs of Iris tingitana var. Wedgewood. ${ }^{61}$

3.2.1 Linear peptides. Peptide natural products with a linear architecture containing $\mathrm{Hpg}$ include members of the $\beta$ lactam-type compounds of microbial origin, such as the monocyclic $\beta$-lactam antibiotics nocardicin A-G (Scheme 4). ${ }^{\mathbf{6 2 , 6 3}}$ They have been isolated from Nocardia uniformis ssp. tsuyamanensis ATCC 21806, with nocardicin A as the most abundant component out of seven from the nocardicin A-G series. ${ }^{\mathbf{6 2 , 6 4 , 6 5}}$ The structure elucidation of the nocardicins was performed by ${ }^{1} \mathrm{H}$ and ${ }^{13} \mathrm{C}$ NMR spectroscopy, complemented by hydrolysis and derivatization studies. ${ }^{62}$ Structurally, the nocardicins vary in their amine oxidation state and the presence or absence of an ether-linked homoseryl (hSer) side chain. Remarkably, all nocardicin structures contain the Hpg motif in a twofold manner. One Hpg constitutes the C-terminus of nocardicin whereas the other $\mathrm{Hpg}$, which is attached to the N-terminus of the lactam, is masked as an oxime and, in addition, is etherified in the phenolic side chain with hSer in case of nocardicin A and $\mathrm{C}$ (Scheme 4). The simplest member of the nocardicin family is nocardicin G, which is derived from the tripeptide core D-Hpg-LSer-D-Hpg. Nocardicin G was shown to be incorporated intact into nocardicin $\mathrm{A}$, which was confirmed by preparation of a doubly labeled $\left({ }^{13} \mathrm{C},{ }^{15} \mathrm{~N}\right)$ sample of nocardicin $\mathrm{G}$, and subsequent feeding into a growing culture of Nocardia uniformis ssp. tsuyamanensis ATCC $21806 .{ }^{66}$ Nocardicin has a modest activity against a wide spectrum of Gram-negative bacteria, e.g. Proteus vulgaris IAM-1025 ( $\mathrm{MIC}=3.13 \mu \mathrm{g} \mathrm{ml}^{-1}$ ) and Pseudomonas aeruginosa IAM-1095 ( $\left.\mathrm{MIC}=400 \mu \mathrm{g} \mathrm{ml}^{-1}\right)$, and possesses at the same time $\beta$-lactamase resistance. ${ }^{\mathbf{6 3 , 6 7}}$

Some other $\beta$-lactam linear peptides, which are structurallyrelated to nocardicin A are chlorocardicin and the formadicins. Chlorocardicin, was isolated from Streptomyces sp. (SK\&F-AAH873) from a soil sample collected from the root zone of a cactus in Pima County, Arizona. ${ }^{68,69}$ The structure was elucidated by high resolution FAB-MS and ${ }^{1} \mathrm{H}$ and ${ }^{13} \mathrm{C}$ NMR analysis. ${ }^{69}$ The only difference to the nocardicin A structure is an additional chlorine atom, resulting in 3-chloro-4-hydroxy phenylglycine instead of the C-terminal Hpg moiety (Scheme 4). The antibacterial activities against Gram-negative bacteria, e.g. Klebsiella pneumoniae were similar to nocardicin A in M9 medium, and eightfold higher in complex media (Müller-Hinton broth MHB; MIC $\left.=25 \mu \mathrm{g} \mathrm{ml}^{-1}\right) .{ }^{68}$ Chlorocardicin exhibits low activity against Staphylococcus aureus, whereas nocardicin A is not active. ${ }^{68}$ The formadicins were isolated from Flexibacter alginoliquefaciens sp. nov. YK-498 (ref. 70) in four variants: formadicin A-D with a homologous structure to norcardicin A. Additional structural modifications are a formylamino group at the 3- or 12-position ( $\mathrm{R}^{2}$ and $\mathrm{R}^{1}$ respectively in the structure of formadicins in Scheme 4), as well as $\beta$-D-glucoronidation at the phenolic group in formadicins $\mathrm{A}$ and $\mathrm{B} .^{71}$ 


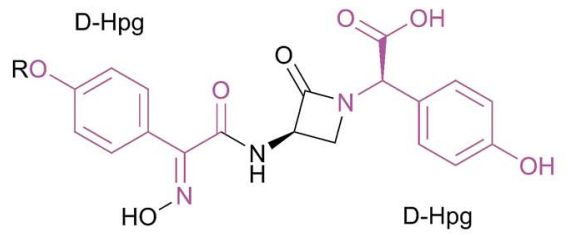

Nocardicin $A$ and $E$

$A: R=$ homoserine

$E: R=H$<smiles>N[C@@H](CCOc1ccc(/C(=N/O)C(=O)N[C@@H]2CN(C(C(=O)O)c3ccc(O)c(Cl)c3)C2=O)cc1)C(=O)O</smiles>

Chlorocardicin<smiles>[R9]c1ccc([C@H](N)C(=O)N[C@@H]2CN([C@H](C(=O)O)c3ccc(O)cc3)C2=O)cc1</smiles>

Nocardicin C and G

$\mathrm{C}: \mathrm{R}=$ homoserine

$G: R=H$<smiles>[R7]Oc1ccc(C(C(=O)O)N2C[C@]([R2])(NC(=O)[C@H]([R1])c3ccc(OCC[C@H](N)C(=O)O)cc3)C2=O)cc1</smiles>

Formadicins $A, B, C$, and $D$ $A: R^{1}=\mathrm{OH}, \mathrm{R}^{2}=\mathrm{NHCHO}, \mathrm{R}^{3}=\mathrm{D}$-glucoronic acid $B: R^{1}=\mathrm{NHCHO}, \mathrm{R}^{2}=\mathrm{H}, \mathrm{R}^{3}=\mathrm{D}$-glucoronic acid C: $\mathrm{R}^{1}=\mathrm{OH}, \mathrm{R}^{2}=\mathrm{NHCHO}, \mathrm{R}^{3}=\mathrm{H}$ D: $\mathrm{R}^{1}=\mathrm{NHCHO}, \mathrm{R}^{2}=\mathrm{H}, \mathrm{R}^{3}=\mathrm{H}$

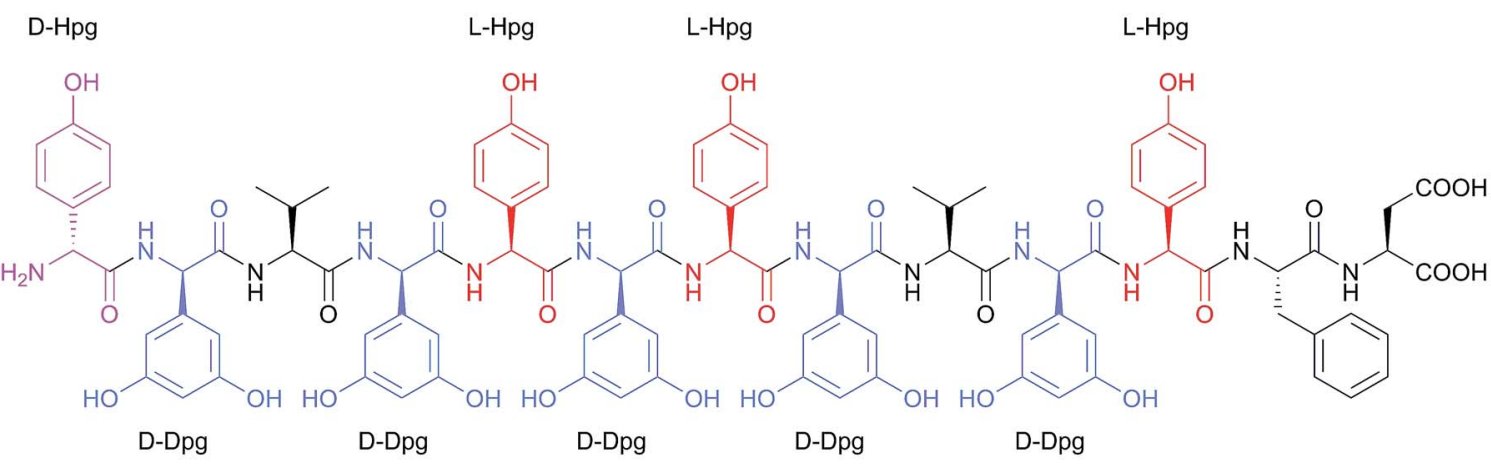

Feglymycin

Scheme 4 Structures of Hpg- and Dpg-containing linear peptides: nocardicin A, C, E, and G, chlorocardicin, formadicin A-D, and feglymycin.

Formadicins $\mathrm{A}$ and $\mathrm{C}$ contain two residues of $\alpha, 4$ dihydroxybenzeneacetic acid instead of the N-terminal D-Hpg residue. Formadicins have antibacterial activities similar to that of nocardicin A, and they exhibit high activity against some Pseudomonas and Proteus species. Generally, the formadicins C and D display higher antimicrobial activities than formacidins A and B. ${ }^{\text {7o }}$ A linear peptide which contains both amino acids, Hpg and Dpg, is feglymycin (Scheme 4). The peptide was isolated from Streptomyces DSM 11171 (ref. 72 and 73) and its structure was solved by NMR spectroscopy ${ }^{72}$ and later by X-ray crystallography. ${ }^{74}$ It is a 13 mer peptide consisting of four $\mathrm{Hpg}$ (one $\mathrm{D}-\mathrm{Hpg}$ and three L-Hpg) and five D-Dpg residues. With exception of the N-terminal D-Hpg the molecule displays a long stretch of alternating $\mathrm{D}^{-}$and L-configured amino acid residues. In the crystal the peptides form a $\pi$-helical homodimeric cylinder where the aromatic side chains of Hpg and Dpg point to the outside. The lids of the cylinder are formed by the side chains of Phe. ${ }^{74}$ While feglymycin shows antibacterial activity only against Gram-positive bacteria it inhibits peptidoglycan biosynthesis enzymes MurA and MurC (E. coli and Staphylococcus aureus) of Gram positive and Gram negative bacteria (Scheme 4). ${ }^{26}$ Furthermore, feglymycin has been reported to inhibit HIV replication in the low $\mu \mathrm{M}$ range $\left(\mathrm{EC}_{50}=0.8-3.2 \mu \mathrm{M}\right)$ in addition to the inhibition of the formation of syncitia, which results from cell-to-cell transfer between HIV-infected T cells and healthy $\mathrm{CD} 4^{+} \mathrm{T}$ cells as well as the DC-SIGN-mediated viral transfer to $\mathrm{CD} 4^{+} \mathrm{T}$ cells. Feglymycin acts as gp120/CD4 binder by interacting with the heavily glycosylated viral envelope protein gp120, as determined by surface plasmon resonance (SPR) spectroscopy, thus inhibiting HIV entry to $\mathrm{CD} 4^{+} \mathrm{T}$ cells via CCR5 and/or CXCR4 chemokine receptors. ${ }^{75}$ Finally, the total synthesis of the 13 amino acid antiviral peptide antibiotic feglymycin and its enantiomer was performed by fragment condensation. This study was motivated by the difficulty in assembling a large number of phenylglycines while suppressing racemization and epimerization, respectively. Structure-activity-relationship (SAR) studies with 
truncated synthetic peptides shed light on structural features relevant to the molecular mode of action of feglymycin. ${ }^{73} \mathrm{~A}$ further Ala-scan of feglymycin revealed contributions of amino acid side chains to the activity in antibacterial and antiviral assays. ${ }^{26}$

The Ala-scan showed a significant decrease in MICs, 4-16 times lower when D-Dpg was exchanged with D-Ala. Interestingly, $\mathrm{D}^{-\mathrm{Hpg}^{1}}{ }^{1}$ and $\mathrm{L}-\mathrm{Hpg}^{5}$ were even more critical for the antimicrobial activities. ${ }^{26}$
3.2.2 Cyclic peptides. The formation of rings is a widely distributed principle of nature to fix peptides in certain conformations, which are crucial to exert biological activity. Hence, it is not surprising that a considerable number of cyclic peptides containing phenylglycines have been identified.

The lipoglycodepsipeptide antibiotic ramoplanin (Scheme 5), formerly called A-16686, ${ }^{76,77}$ was isolated from the liquid culture of Actinoplanes strain ATCC33076. ${ }^{76,78}$

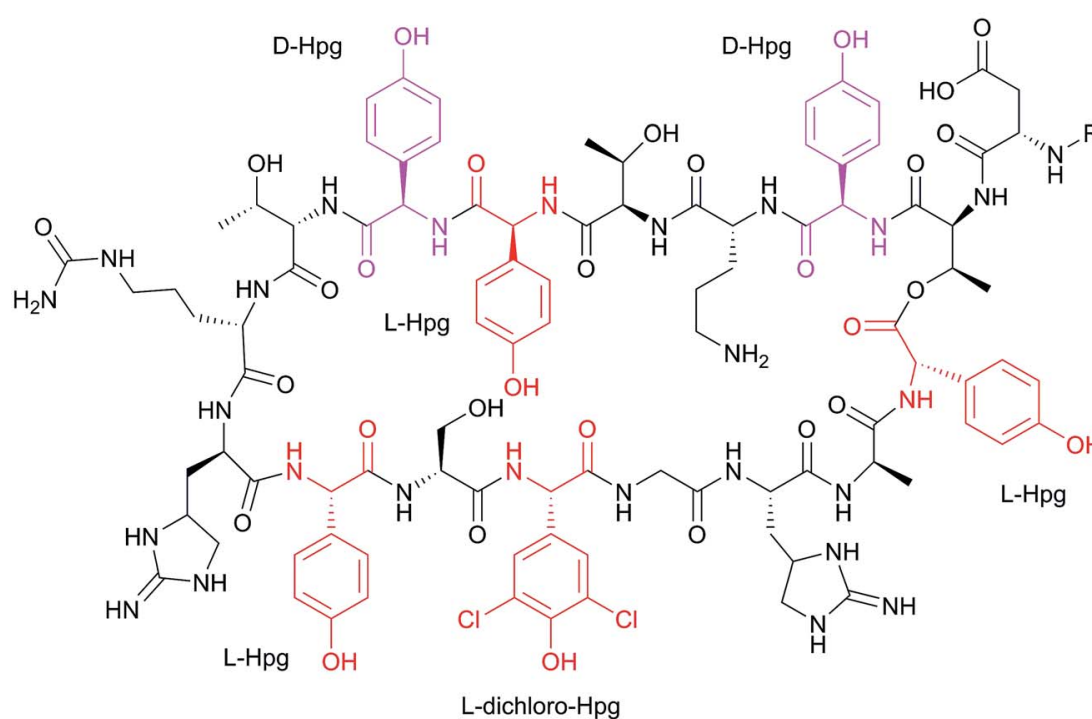

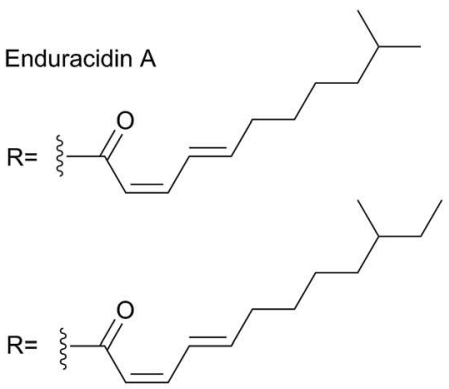

Enduracidin B

L-dichloro-Hpg

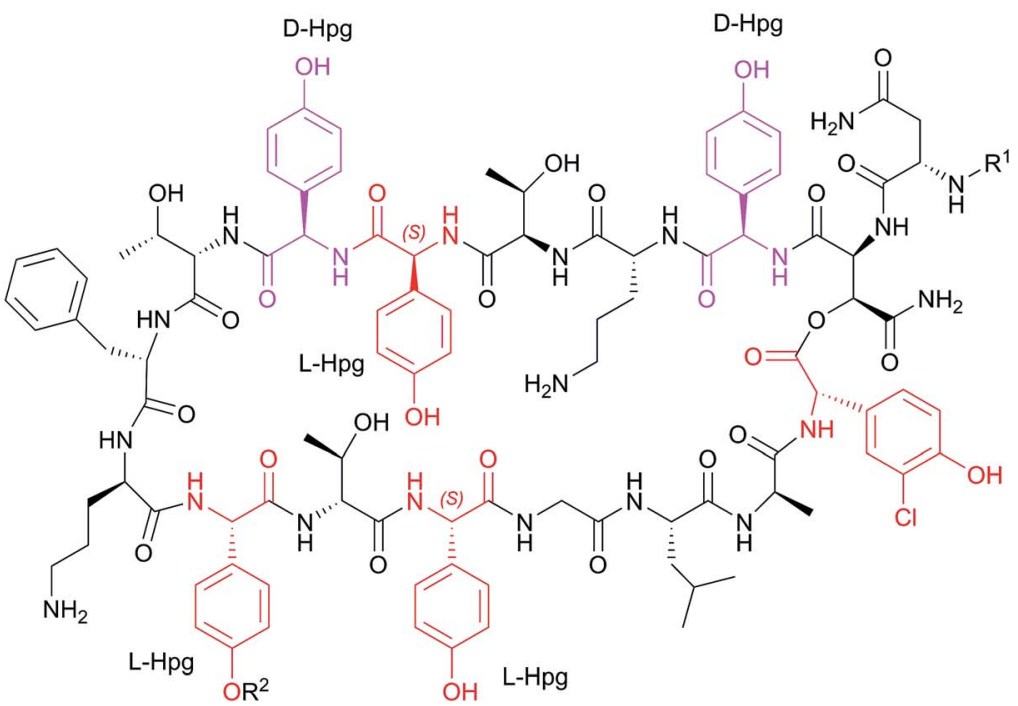

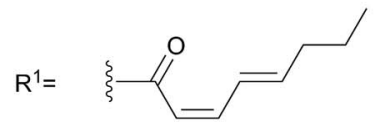

Ramoplanin A1

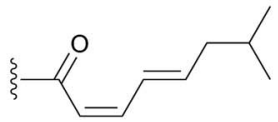

Ramoplanin A2

Ramoplanose

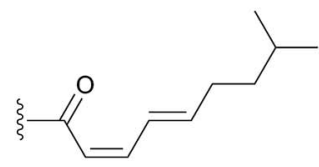

Ramoplanin A3
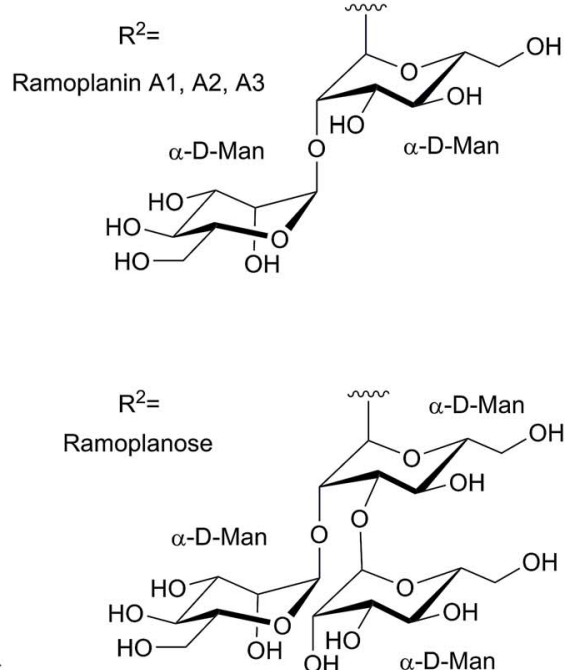

$R^{2}=H$

Scheme 5 Structures of Hpg-containing cyclic peptide antibiotics, enduracidins A and B, ramoplanin (A1, A2, A3), ramoplanose, and ramoplanin aglycon. 
Ramoplanin, produced as a complex of three compounds $\mathrm{A} 1-\mathrm{A} 3,{ }^{77,79,80}$ has excellent antibacterial activities against Grampositive bacteria (2-10 times more active than vancomycin against 500 strains), particularly against Staphylococci (including methicillin-resistant isolates), vancomycin-resistant Enterococci VRE (MIC $=0.5 \mu \mathrm{g} \mathrm{ml}{ }^{-1}$ ), Streptococci, Actinomyces and Gram-positive anaerobes. ${ }^{251}$ It shows excellent therapeutic activities against experimental septicemias in the mouse and exhibits a lack in the cross-resistance with other clinically used antibiotics. ${ }^{76,78}$ The main mode of ramoplanin action is changing the bacterial peptidoglycan architecture, thus inhibiting bacterial cell wall integrity by interrupting the late stage membrane-associated glycosyltransferase reactions catalyzed by transglycosylases and MurG. ${ }^{81-83}$ Because of its highly potent antimicrobial activity, ramoplanin reached phase I clinical trials in the early 90ies and since 2001 is in phase III clinical trials for the temporary suppression of VRE gastrointestinal carriage and for the treatment of Clostridium difficileassociated diarrhea. In 2001 the FDA put ramoplanin A2 on a fast-truck status for the prevention of VRE and treatment of C. difficile colitis. ${ }^{\mathbf{8 0 8 1 , 8 3 - 8 5}}$ Ramoplanin A1-A3 structures were elucidated in 1989 by means of chemical degradation, mass spectrometry as well as ${ }^{1} \mathrm{H}$ and ${ }^{13} \mathrm{C}$ NMR studies. ${ }^{77,79}$ They are macrocyclic peptides consisting of 17 amino acids, 12 of them are non-proteinogenic amino acids, and seven display D-configuration. All ramoplanins contain five 4-Hpg residues, two of them with D-configuration. In addition they contain an L-3-chloro-4-Hpg (L-Chp17) residue (Scheme 5). Ramoplanins A1-A3 only differ in the lipid side chains attached to the N-terminus of Asn ${ }^{1}{ }^{25,77,79-81}$

The ramoplanose structure (ramoplanin aglycon) was elucidated in 1991 by means of FAB-MS, amino acid analysis, chiral GC, and NMR spectroscopy ${ }^{86}$ and subsequently corrected in 1996 by 2D NMR spectroscopy; from these data a 3D structure model has also been derived. ${ }^{\mathbf{8 1 , 8 7}}$ This $3 \mathrm{D}$ structure is characterized by two antiparallel $\beta$-strands $\left(\mathrm{L}-3-\mathrm{OH}-\mathrm{Asn}^{2}\right.$ to $\mathrm{D}-\mathrm{Hpg}^{7}$, and $\mathrm{D}^{-} \mathrm{Orn}^{10}$ to $\mathrm{Gly}^{14}$ ) stabilized by six transannular hydrogen bonds and a cluster of hydrophobic aromatic side chains $\left(\mathrm{D}-\mathrm{Hpg}^{3}, \mathrm{~L}-\mathrm{Phe}^{9}\right.$ and $\left.\mathrm{L}-\mathrm{Chp}^{17}\right)$. This provides a U-shape topology to the $\beta$-sheet with a reverse $\beta$-turn formed by $\mathrm{L}_{\text {-Thr }}{ }^{8}$ and $\mathrm{L}-\mathrm{Phe}^{9}$ at one end and a more flexible connecting loop (L-Leu ${ }^{15}$ to L-Chp ${ }^{17}$ ) at the other end. ${ }^{25,81,87,88}$ The total synthesis of ramoplanin A2 and ramoplanose was achieved in 2002 by assembly and cyclization of three peptide subunits in a solution phase approach. ${ }^{88}$ Structure-activity relationship (SAR) studies by Boger and coworkers were performed by an Ala-scan on the derivative $\left[\mathrm{L}-\mathrm{Dap}^{2}\right]$ ramoplanin $\mathrm{A} 2$ aglycon. ${ }^{25}$ This study showed that for Hpg substitutions the MIC decreased between 13 to 74 times upon substitution with Ala, depending on the positions of Hpg within the molecule. Nevertheless, the most critical residue for its activity was D-Orn ${ }^{10}$ where the MIC decreased three order of magnitude when substituted with Ala. ${ }^{25}$

The peptide antibiotics enduracidin $A$ and $B^{82,89,90}$ (Scheme 5) and janiemycin have similar amino acid compositions, ${ }^{\mathbf{9 1}, 92}$ and show similar core structures compared to ramoplanin. Enduracidin A and B were isolated from mycelium of Streptomyces fungidicus B-5477.90 The structure of enduracidin was determined by Hori and coworkers in the early 70s by NMR spectroscopic studies, ${ }^{93-95}$ while the $3 \mathrm{D}$ solution conformation was determined in 2005 by NMR spectroscopy and molecular dynamics. ${ }^{89}$ Enduracidins are cyclodepsipeptides composed of 17 amino acids, of which 16 form a macrolactam. The $\mathrm{N}$ terminus is acylated with cis,trans-fatty acids (Scheme 5), which is the discriminating feature of enduracidin A and B. ${ }^{89}$ Apart from significant similarities between enduracidin and ramoplanin the former contains the characteristic amino acid enduracididine (End) at position 10 and 15 and citrulline ( $\mathrm{Cit}^{9}$ ) replacing $\mathrm{Phe}^{9}, \mathrm{Orn}^{10}$ and $\mathrm{Leu}^{15}$ in ramoplanin. The structures further differ in D-mannosylation of ramoplanin at $\mathrm{Hpg}^{11}$ as well as in the length of the acyl chain. ${ }^{89}$ Structural similarities between enduracidin and ramoplanin point to a similar mechanism of action, i.e. binding to the peptidoglycan lipid intermediate and a common bioactive antibiotic pharmacophore. ${ }^{\mathbf{8 1 , 8 2}}$ The total synthesis of enduracidin has not yet been achieved; enduracididin (End) has been synthesized previously by Tsuji and coworkers in 1975. ${ }^{96}$ Enduracidin shows in vitro and in vivo antibacterial activities against a wide spectrum of Gram-positive bacteria including MRSA causing human urinary tract and skin infections, ${ }^{97}$ as well as Neisseria gonorhoeae, with a minimal inhibitory concentration $(\mathrm{MIC})<0.05 \mu \mathrm{g} \mathrm{m}{ }^{-1} \cdot{ }^{98-103}$ Although enduracidins are known since the 1960s, they have more recently been revisited for their potential as pharmaceutically used antibacterial compounds. In addition, enduracidin hydrochloride has been reported to be used for animal production in order to increase animal weight in pigs and chicken, and to improve feed conversion ratio in these animals. ${ }^{104}$

Janiemycin is a cell wall biosynthesis inhibitor peptide isolated from Streptomyces macrosporeus. It has a structure related to the peptide antibiotic ramoplanin A2, and shares a similar amino acid composition with enduracidin. ${ }^{92,105,106}$ Until now a detailed structure analysis of janiemycin has not been performed. Application of janiemycin on Gram-positive and Gramnegative bacteria results in accumulation of lipid intermediates. ${ }^{92,105}$ Based on amino acid similarities of janiemycin to ramoplanin A2 and to enduracidin, it is proposed that janiemycin might also inhibit transglycosylases and/or MurG by binding to lipid I and/or lipid II. ${ }^{\mathbf{8 1}}$

The calcium dependent peptide antibiotic CDA (Scheme 6) has first been described by B. Rudd in 1978 as produced by Streptomyces coelicolor A3(2). ${ }^{\mathbf{1 0 7}}$ This peptide was called CDA because it kills bacteria only in the presence of calcium ions, where it produces transmembrane channels to conduct monovalent cations. ${ }^{\mathbf{1 0 8 , 1 0 9}}$ The CDA structure was elucidated by Jung and co-workers ${ }^{\mathbf{1 1 0}}$ by means of amino acid analysis, Edman degradation and 2D NMR spectroscopy. CDA occurs also in various natural subtypes (CDA1b, CDA2a, CDA2b, CDA3a, CDA3b, CDA4a and CDA4b) and their production depends on the culture medium used. ${ }^{\mathbf{1 1 1}, \mathbf{1 1 2}}$ With regard to the structure, CDA is an 11mer cyclic lipopeptide with the C-terminus attached to the side chain of $\mathrm{Thr}^{2}$. An epoxyhexanoyl residue is attached to the N-terminus of Ser ${ }^{1}$. Further structural characteristics of this molecule are D-4-Hpg at position 6, D-3-hydroxyasparagine at position 9, and four acidic amino acids (L-Asp at 


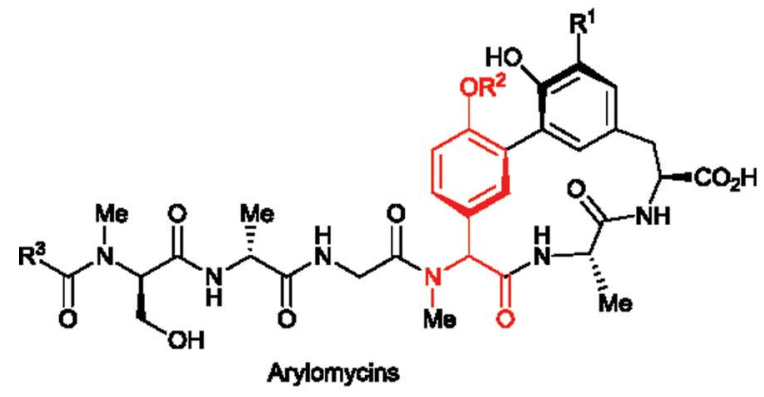

$$
\begin{aligned}
& \mathbf{R}^{1}=H_{1} \mathbf{R}^{2}=H_{1} \mathbf{R}^{3}=\text { iso-C12: Arylomycin } A 2 \\
& \mathbf{R}^{1}=\mathrm{NO}_{2}, \mathbf{R}^{2}=\mathrm{H}, \mathbf{R}^{3}=\text { iso-C12: Arylomycin B2 } \\
& \mathbf{R}^{1}=\mathrm{H}_{1} \mathbf{R}^{2}=\text { deoxy- } \alpha \text {-mannose, } \mathbf{R}^{3}=\text { iso-C16: Arylomycin C16 }
\end{aligned}
$$

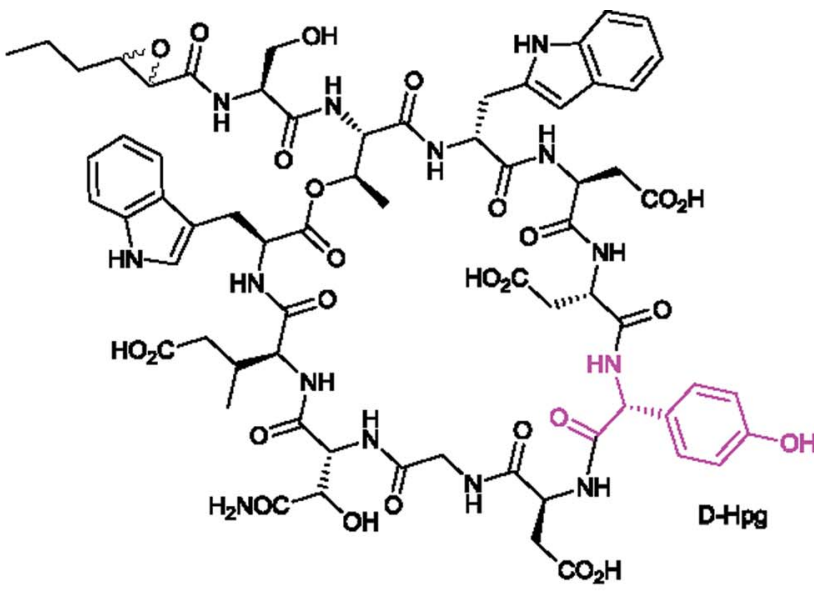

CDA

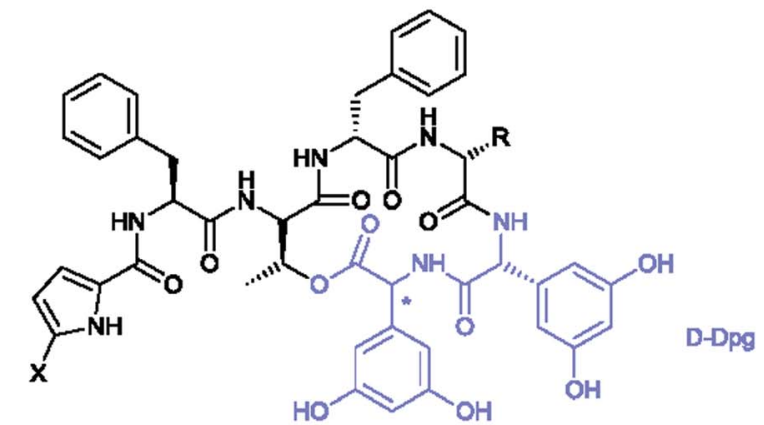

Cochinmicins

I: $\mathrm{X}=\mathrm{H}_{1} *=R$

III: $\mathrm{X}=\mathrm{Cl}, *=R$

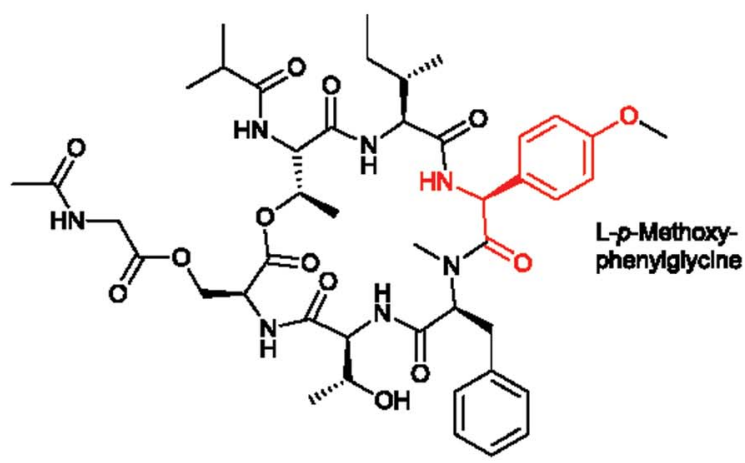

Xanthostatin

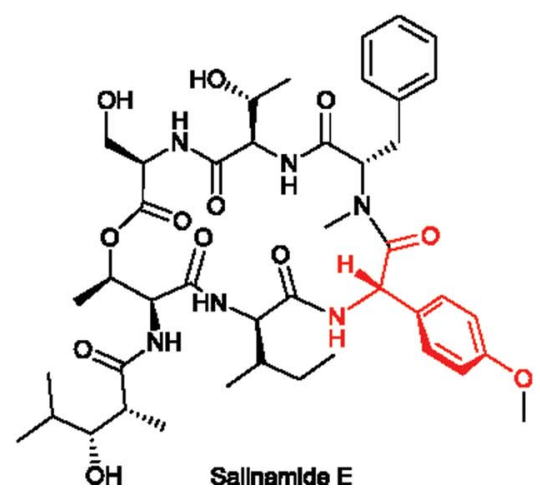

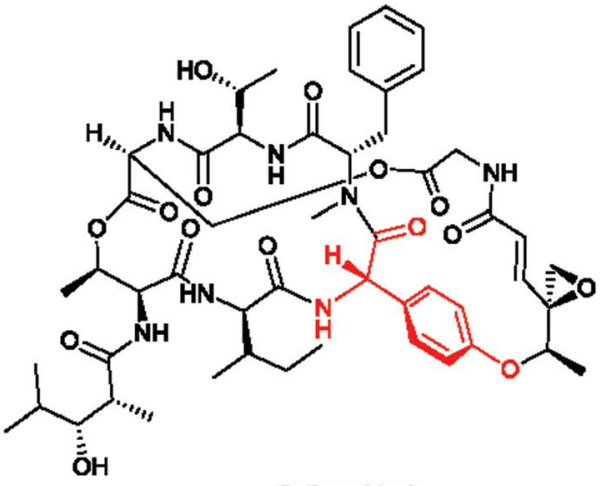

Sallnamlde A

Scheme 6 Structures of Hpg-and/or Dpg-containing cyclic peptide antibiotics CDA, cochinmicins I, II, and III, xanthostatin, and salinamides A and $\mathrm{E}$, arylomycins $\mathrm{A} 2$, B2, and $\mathrm{C} 16$.

positions 4, 5 and 7, and one L-3-methyl-Glu at position 10$).{ }^{110}$ CDA displays antimicrobial activities against a variety of Grampositive bacteria, and multicellular bacteria from the Streptomyces genus, except for five strains closely related to the wild type producing organism Streptomyces coelicolor A3(2). ${ }^{\mathbf{1 0 8}}$ There are obvious structural similarities of CDA to related lipocyclopeptides such as the marketed antibacterial daptomycin
(Cubicin ${ }^{\mathrm{TM}}$, injectable form) and to friulimycin. ${ }^{113,114}$ Main structural similarities are the 10 mer peptide macrocycle as a central element. However, neither daptomycin nor friulimycin contain the D-4-Hpg in their structures. Both CDA and friulimycin possess three residues of Asp at position 4, 5 and 7, where $\mathrm{Asp}^{4}$ in friulimycin is $\beta$-methylated. ${ }^{\mathbf{1 1 4}}$ Daptomycin contains also Asp at position 7, and two other Asp residues but in 
different positions compared to CDA. Nevertheless, both peptide antibiotics CDA and daptomycin contain L-3-methyl-Glu at the preliminary position in their macrocyclic rings. ${ }^{\mathbf{1 1 0 , 1 1 3}}$

The peptide antibiotics arylomycin A and B, isolated and characterized from Streptomyces sp. Tü 6075 by the groups of Fiedler \& Jung in $2002,{ }^{\mathbf{1 1 5}, 116}$ were shown to bind and inhibit bacterial type I signal peptidase (SPase) in vitro. ${ }^{116-118}$ The total synthesis of arylomycin has been achieved by Romesberg and coworkers in $2007,{ }^{119}$ followed by the synthesis of various derivatives including arylomycin $\mathrm{A}-\mathrm{C}_{16} \cdot{ }^{119-124}$ Recently, a new arylomycin derivative (arylomycin A6) was isolated from Streptomyces parvus HCCB10043 and its structure was elucidated by HR-ESI-MS, fatty acid analysis and 1D- and 2D-NMR spectroscopy. ${ }^{125}$ Together with their synthetic derivatives (e.g. arylomycin $\mathrm{C}_{16}$ ) (Scheme 6), they contain N-methylated-Hpg in their ring structures and show a remarkably wide spectrum of activities against both Gram-positive and Gram-negative bacteria. ${ }^{120,122,123}$ The antimicrobial activities (MIC) of natural arylomycin A2 and of synthetic arylomycin $\mathrm{C}_{16}$ against Staphylococcus epidermidis are $\sim 1.0-0.25 \mu \mathrm{g} \mathrm{ml}{ }^{-1}$, respectively. ${ }^{119,126}$

The cyclodepsipeptides cochinmicin I, II and III (Scheme 6), isolated from Microbispora sp. ATCC 55140, ${ }^{127}$ have been reported as endothelin antagonists. The structures contain two D-Dpg residues (cochinmicin I and III), and L-Dpg and D-Dpg residues (cochinmicin II), respectively. ${ }^{\mathbf{1 2 8}}$ The structures were elucidated by mass spectrometry, 1D and 2D NMR spectroscopy in the early 1990 s. $^{\mathbf{1 2 8}}$

The antagonism of these compounds to the endothelin (ET) receptors could potentially be used for treatment of various diseases caused by elevated levels of endothelin, e.g. cyclosporine-induced nephrotoxicity, myocardial infarction, uremia, diabetes, systemic hypertension, endotoxic shock, cardiac ischemia, post-ischemic renal failure and compromised renal flow. ${ }^{127}$

The natural product xanthostatin (Scheme 6) is a cycloheptadepsipeptide which was isolated from Streptomyces spiroverticillatus. ${ }^{129}$ Characteristic features of the structure are a $p$-methoxyphenylglycine and a macrolactone formed by the sidechain of $\mathrm{Thr}^{1}$ with a modified $\mathrm{Ser}^{7}$ at the Cterminus. ${ }^{\mathbf{1 3 0}}$

Remarkably, xanthostatin has a highly specific antimicrobial activity against Xanthomonads and has been described as bacteriostatic against Xanthomonas oryzae $\left(\mathrm{MIC}=2 \mu \mathrm{g} \mathrm{ml}{ }^{-1}\right.$ ) and Xanthomonas campestris pv. citri $\left(\mathrm{MIC}=4 \mu \mathrm{g} \mathrm{ml}^{-1}\right)$. The latter phytopathogenic strain affects citrus plants ('citrus canker') causing necrosis on citrus fruits, leafs, and stems, and is considered a plant disease that is difficult to control. ${ }^{\mathbf{1 3 1}}$

Salinamides A-F (Scheme 6) are antibacterial and antiinflammatory depsipeptides isolated from Streptomyces sp. CNB-091. The Streptomyces strain has been isolated from the surface of the jellyfish Cassiopeia xamachana. ${ }^{\mathbf{1 3 2 - 1 3 4}}$ Salinamides are macrolactone heptapeptides with the ring formed between the side chain of $\mathrm{Thr}^{1}$ and the C-terminus of $\mathrm{Ser}^{7}$ (salinamide E). The cyclic structure may be extended by another cycle (salinamide A) consisting of an unusual ester in the sidechain of $\mathrm{Ser}^{7}$ and an ether with the OH-group of $\mathrm{Hpg}^{3}$. The total synthesis of salinamide A has been reported by Tan and Ma in
2008. ${ }^{135}$ Salinamides A and B show moderate antibiotic activities against Gram-positive bacteria and anti-inflammatory activities in a phorbol ester-induced mouse ear edema assay. ${ }^{\mathbf{1 3 2}}$ Salinamide A and B exhibit strong transcription inhibition activity by targeting bacterial RNA polymerases of $E$. coli (Gramnegative) and Staphylococcus aureus (Gram-positive) while they do not inhibit human RNA polymerase I, II and III. ${ }^{\mathbf{1 3 6 , 1 3 7}}$

The largest group of antibacterial peptides containing Hpg and Dpg are the glycopeptide antibiotics (GPA). In these peptides the amino acids 4-hydroxyphenylglycine (Hpg) and 3,5dihydroxyphenylglycine (Dpg) are essential elements of all typeI to type IV glycopeptide antibiotics, since they are involved in side-chain cross-links and thus are crucial for the overall conformation of the molecules. ${ }^{138}$ Vancomycin, ${ }^{139}$ balhimycin, ${ }^{140}$ chloroeremomycin ${ }^{\mathbf{1 4 1}}$ (all type I), actinoidin (type II), ${ }^{\mathbf{1 4 2 , 1 4 3}}$ ristocetin (type III), ${ }^{\mathbf{1 4 4 , 1 4 5}}$ and teicoplanin (type IV) ${ }^{\mathbf{1 4 6}}$ are the most prominent members of this compound class. Glycopeptide antibiotics have been classified into five types, ${ }^{23}$ four of them (type I-IV) have antimicrobial activities, while the last one (type V) with complestatin, ${ }^{147}$ and the anti-HIV antibiotic chloropeptin ${ }^{\mathbf{1 4 8}}$ exhibit antiviral activities inhibiting the binding of the human immunodeficiency viral glycoprotein (HIV-1/gp120) to the T-cell CD4 receptor. ${ }^{148,149}$ Type V GPA kistamicin ${ }^{150}$ exhibits a moderate antibacterial activity against Gram-positive bacteria but no activity against Gram-negative bacteria. ${ }^{\mathbf{1 5 0}}$ Furthermore, kistamicin shows stronger anti-influenza virus activity than ribavirin. ${ }^{151}$

The antimicrobial activities of type I-IV compounds arise from their highly complex and rigid structures, which perform non-covalent binding of the glycopeptide backbone via five hydrogen bonds to the amide bonds and C-terminal end of the Lys-D-Ala-D-Ala peptide of the peptidoglycan..$^{23,152,153}$ As the main mode of action, the binding of the substrate prevents subsequent crosslinking of peptidoglycan by transpeptidases. The common structure of type I-IV GPAs is a heptapeptide backbone containing three to five phenylglycine-derivatives (type I or type IV, respectively). The backbone is modified by one biaryl- (A-B ring) and two diarylether side-chain cyclizations (C-O-D and D-O-E rings) of the aromatic amino acids (Scheme 7), forming a cup-shaped cavity to accommodate the Lys-D-Ala-D-Ala peptide.

These cyclizations are formed by cross-linking of the aromatic amino acids $\beta$-hydroxytyrosine ( $\beta$-Hty), 3-chloro- $\beta$ hydroxytyrosine (Cht), tyrosine (Tyr), D-4-hydroxyphenylglycine (Hpg), and L-3,5-dihydroxyphenylglycine (Dpg) (see Section 5.2.1). When $\mathrm{Hpg}^{4}$ forms a DE-biaryl ring with $\mathrm{Trp}^{2}$, type $\mathrm{V}$ glycopeptides are obtained that display antiviral activities. Dpg is present in all GPA members of type I-IV and some GPAs of type V, such as kistamicin A \& kistamicin B, while Hpg is a constituent of all of these GPAs (Scheme 7). A comprehensive understanding of the mechanistic assembly of glycopeptide antibiotics and their non-proteinogenic building blocks, particularly of Hpg and Dpg as essential components of vancomycin and teicoplanin, might aid in the development of new biologically active drugs. Hence, Hpg and Dpg biosynthesis pathways have been a matter of interest for many research groups over the past 15 years. 

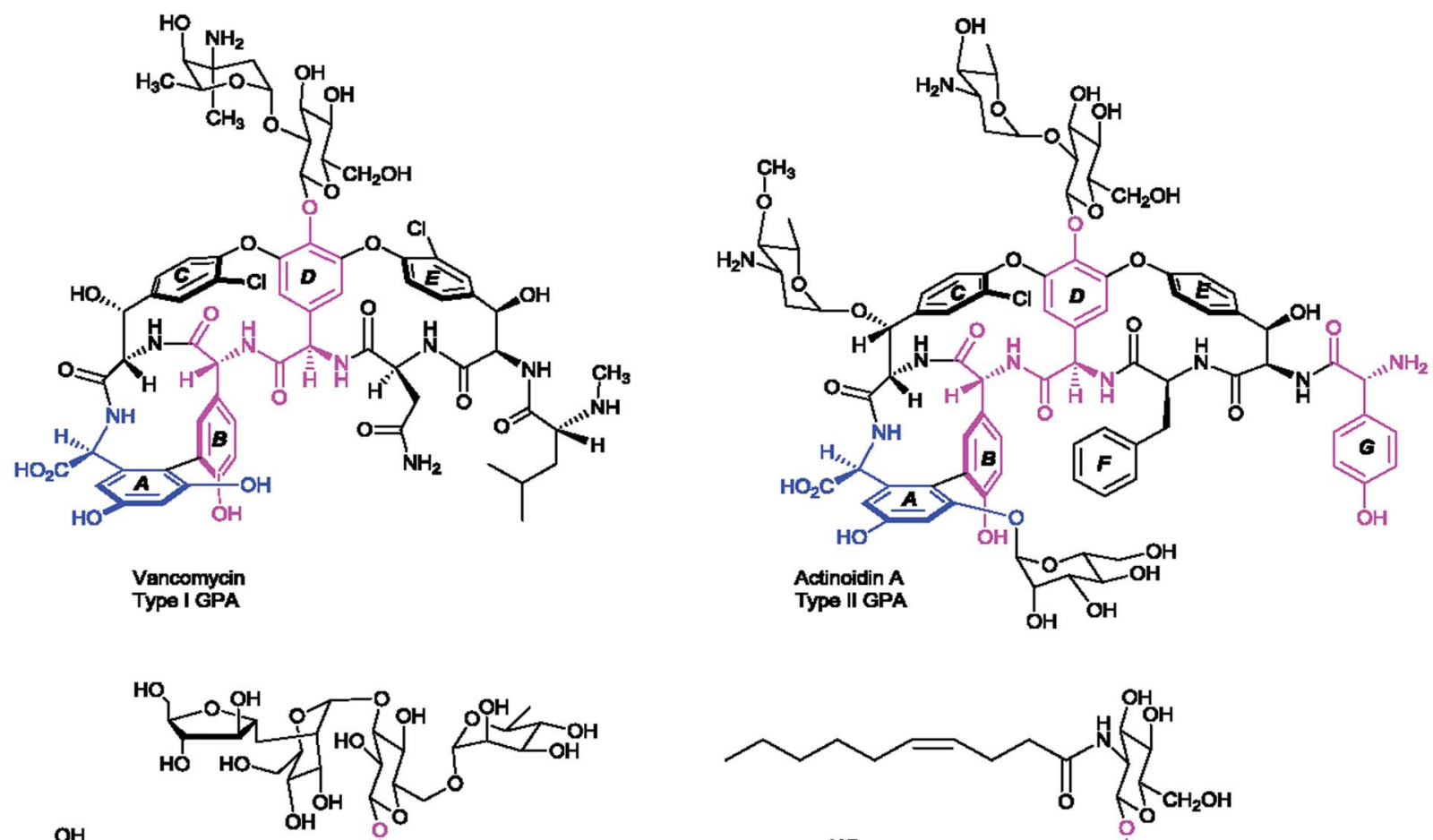<smiles>CCCCC/C=C/CCC(=O)NC1(O)C2OOC2(CO)C1(O)O</smiles>
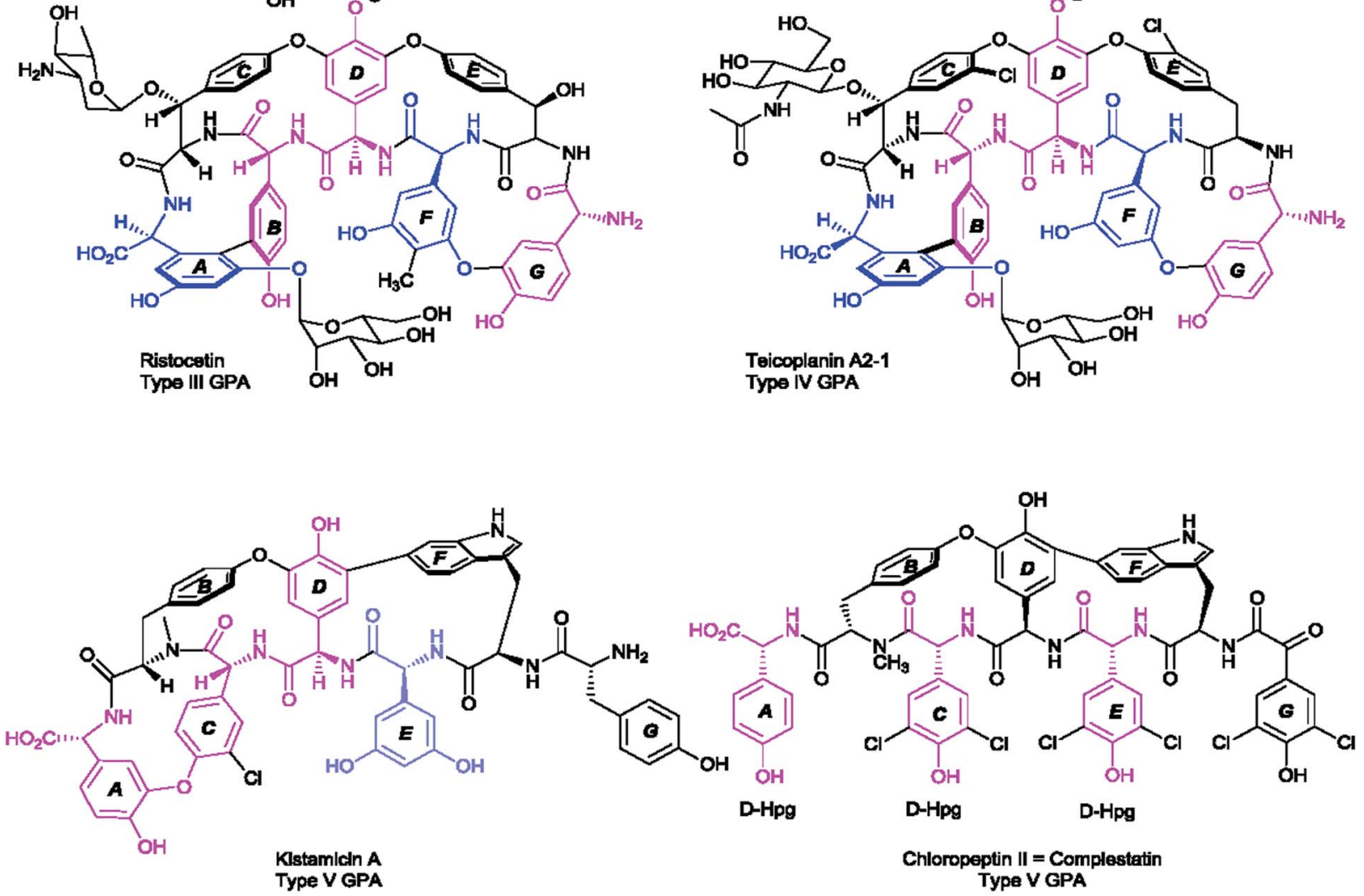

Scheme 7 Positions of D-4-hydroxyphenylglycine ( $\mathrm{Hpg}$ ) (coloured pink) and 3,5-dihydroxyphenylglycine (Dpg) (coloured blue) according to the different types of glycopeptide antibiotics (GPA). Due to convention the $\mathrm{N}$-terminus is placed to the right. The rings are named as ring A-G.

\section{Biosynthesis of phenylglycines}

The biosyntheses of Hpg and Dpg have been intensively investigated over the past years. The sequencing of the chloroeremomycin biosynthesis gene cluster in 1998 by van
Wageningen and coworkers was an important step, ${ }^{141}$ since it allowed first insights into putative genes functions involved into the assembly of these amino acids.

Further complete (or partial) sequencing for some other glycopeptides biosynthesis gene clusters such as balhimycin, ${ }^{154}$ 
teicoplanin, ${ }^{\mathbf{1 5 5}}$ complestatin, ${ }^{\mathbf{1 5 6}}$ A47934 (ref. 157) and A40926 (ref. 158) contributed in shedding light on different stages of Hpg and Dpg biosynthesis pathways. Scheme 8 shows the distribution of Phg, Hpg, and/or Dpg biosynthesis genes within some of the most relevant gene clusters of natural products.

\subsection{Phg biosynthesis}

Although phenylglycine is structurally the simplest member among the phenylglycines, its biosynthesis genes were not identified until 2011. ${ }^{159}$ The characterization of the pristinamycin biosynthesis gene cluster of Streptomyces pristinaespiralis led to the identification of an operon-like structure of five genes pglA-E. ${ }^{17}$ These genes exhibited similarities to some of the enzymes involved in Hpg- and Dpg- biosynthesis, ${ }^{17}$ with overlapping start and stop codons, suggesting that these are translationally coupled. ${ }^{159}$ Phg is suggested to be synthesised from phenylpyruvate, which is converted into phenylacetyl-CoA by PglB and PglC. These two enzymes are assumed to work together as a pyruvate dehydrogenase-like complex. ${ }^{159}$

This assumption is based on high similarities of the $p g l B$ and pglC gene products (57\% and 70\% respectively) to the $\alpha$ - and $\beta$ - subunits of pyruvate dehydrogenase from Mycobacterium avium. ${ }^{159,160}$ The gene expression of $p g l A$ gene results in the hydroxylacyl-dehydrogenase PglA which converts phenylacetylCoA into benzoylformyl-CoA.

Based on sequence comparisons using Blast data ${ }^{\mathbf{1 6 1}}$ PglA was found being related to DpgC of A. balhimycina (47\% identity, $62 \%$ similarity), a key enzyme in the biosynthesis of Dpg, which converts 3,5-dihydroxyphenylacetyl-CoA into 3,5-dihydroxyphenylglyoxylate (see below Section 4.3). ${ }^{\mathbf{1 5 9 , 1 6 2}}$

Due to this similarity, PglA was proposed to have a comparable function to DpgC by catalyzing a similar oxygenation reaction during Phg biosynthesis. ${ }^{159}$ The product of $p g l D$ gene was found to have moderate similarity (53\%) to a type II thioesterase of Amycolatopsis mediterranei, suggesting that PglD may have a function as the hydrolytic thioesterase releasing phenylglyoxylate and CoA from benzoylformyl-CoA. ${ }^{159}$

A basic local alignment of $p g l E$ gene product showed $67 \%$ similarity to the phenylglycine aminotransferase (Pgat) of Amycolatopsis balhimycina, suggesting that $\mathrm{PglE}^{\mathbf{1 5 9}}$ may convert benzoylformate into phenylglycine (Scheme 9). ${ }^{159}$ All biosynthetic assumptions were confirmed by gene insertion
Pristinamycin

Nocardicin A

Arylomycin

Enduracidin

Ramoplanin

CDA

Complestatin

Chloroeremomycin

Balhimycin

Feglymycin

Teicoplanin
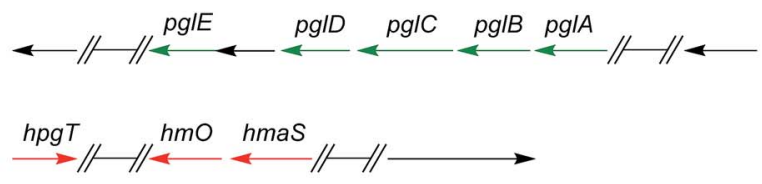

$1 K B$
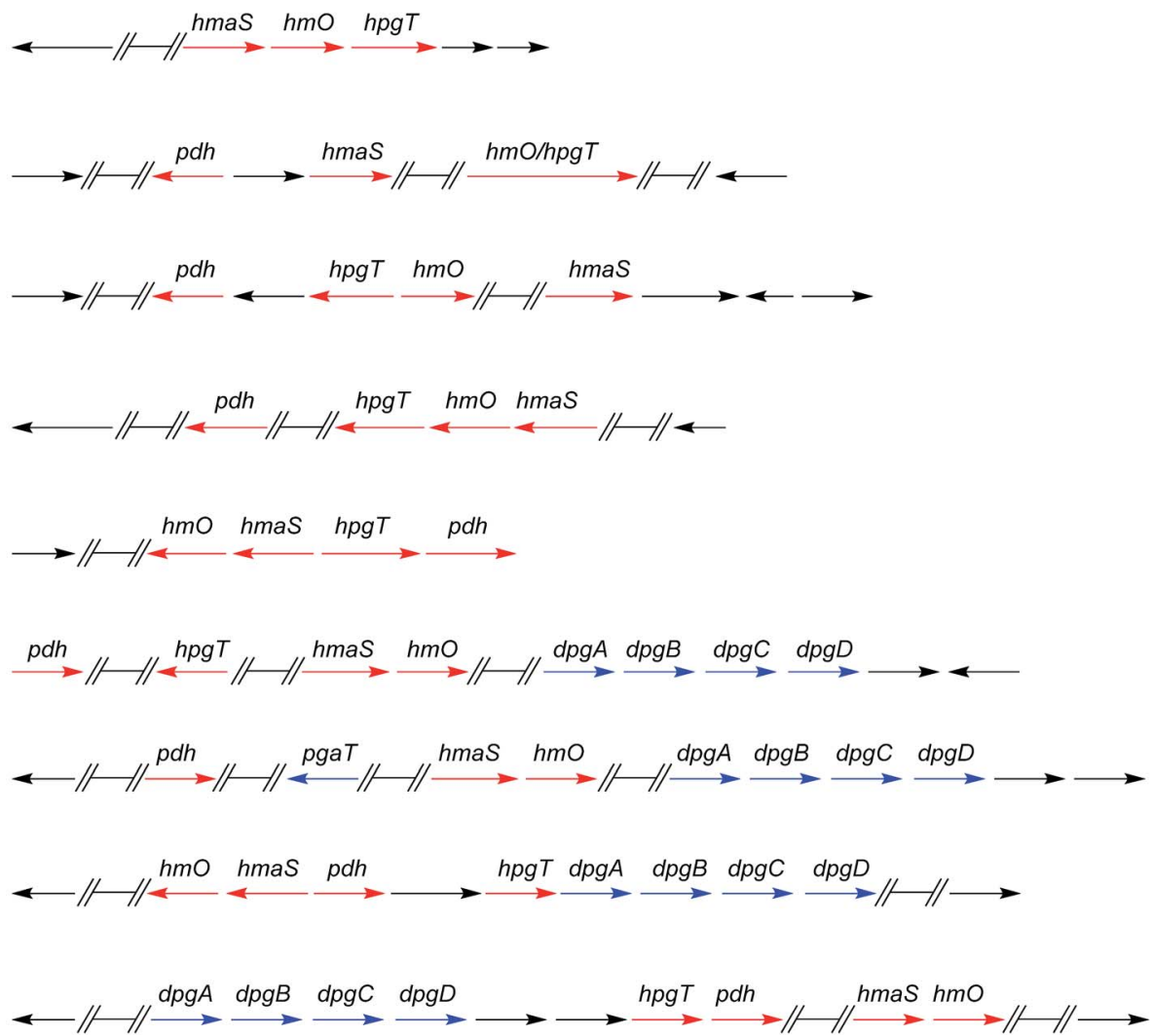

Scheme 8 Biosynthesis gene clusters of the important peptide antibiotics illustrating the distribution of biosynthesis genes of Phg ( $p g l A$, $p g l B$, pglC, pglD, and pglE; coloured green), Hpg (pdh, hmaS, hmO, and hpgT; coloured red), and Dpg (dpgA, DpgB, dpgC, and dpgD; coloured blue). 
mutagenesis studies and L-Phg feeding experiments in S. pristinaespiralis $\mathrm{pgl}$ mutants. ${ }^{159}$ Nevertheless no in vitro protein investigations have been performed to date.

\subsection{Hpg biosynthesis}

The genes of the L-4-hydroxyphenylglycine (Hpg) biosynthesis pathway were initially assigned based on the data from the chloroeremomycin biosynthesis gene cluster of Amycolatopsis orientalis. ${ }^{\mathbf{1 6 3 - 1 6 5}}$ Studies of different glycopeptide antibiotic biosynthesis gene clusters, such as balhimycin, complestatin and calcium-dependent antibiotic (CDA), as well as other compounds like ramoplanin, and nocardicin confirmed essentially identical pathways for Hpg biosynthesis. ${ }^{112,138,154,156,166,167}$ In early work on the origin of $\mathrm{Hpg},\left[{ }^{13} \mathrm{C}\right]$-tyrosine or $\left[{ }^{2} \mathrm{H},{ }^{13} \mathrm{C}\right]$ tyrosine were fed to growing cultures in radioactive labeling studies, ${ }^{\mathbf{1 6 8 - 1 7 1}}$ which determined Tyr as a precursor for $\mathrm{L}-4$ hydroxyphenylglycine. Biochemically, prephenate is converted into L-4-hydroxyphenylpyruvate by the action of prephenate dehydrogenase Pdh (Scheme 10).

The subsequent step is performed by L-4-hydroxymandelate synthase HmaS, an enzyme closely related to 4-hydroxyphenylpyruvate dioxygenase $\mathrm{HppD}^{\mathbf{1 7 2}}$ - both members of the $\alpha$ keto acid-dependent non-heme iron-dependent dioxygenases. ${ }^{173-175}$ This iron-dependent 4-hydroxyphenylpyruvate decarboxylating hydroxylase catalyzes the conversion of 4hydroxyphenylpyruvate into L-4-hydroxymandelate by hydroxylating the benzylic position of 4-hydroxyphenylpyruvate (Scheme 11). ${ }^{138,163,164,176,177}$ The dioxygenation activity of HmaS was confirmed by performing a reaction under $\left[{ }^{18} \mathrm{O}_{2}\right]$ atmosphere in vitro, whereupon one oxygen atom was incorporated into the carboxyl group and the other oxygen atom into the benzylic hydroxyl group. ${ }^{163}$ Subsequently L-4-hydroxymandelate oxidase $\mathrm{HmO}$, an FMN dependent enzyme, catalyzes the oxidation of $\mathrm{L}^{-}$ 4-hydroxymandelate to 4-hydroxybenzoylformate. Interestingly, this enzyme is unable to oxidize the D-isomer of L-4-hydroxymandelate, illustrating its stereospecificity. $\mathrm{HmO}$ has amino acid sequence homology with glycolate oxidase (GO, 50\% homology, present in the cytosol of the cell) and with mandelate dehydrogenase ( $\mathrm{MDH}, 52 \%$ homology, a membrane bound enzyme), which both use FMN as a cofactor. ${ }^{164}$

The reaction sequence is finalized by a transamination reaction catalyzed by $\mathrm{L}$-4-hydroxyphenylglycine transaminase
HpgT, which requires pyridoxal phosphate (PLP) as a coenzyme to exert its catalytic activity. HpgT has amino acid sequence homology to various amino acid transaminases. In addition HpgT showed substrate promiscuity by its ability to accepting a variety of amino donors, ${ }^{\mathbf{1 6 4}}$ as well as its ability of utilizing both L-4-hydroxyphenylglycine and L-3,5-dichloro-4-hydroxyphenylglycine in the reverse direction in complestatin biosynthesis. ${ }^{\mathbf{1 3 8 , 1 5 6}}$ The catalytic activity of HpgT played a critical role in establishing an economical three-enzyme cycle for $\mathrm{L}-4$ hydroxyphenylglycine biosynthesis (Scheme 10), since the reductive amination reaction converts L-4-hydroxybenzoylformate into L-4-hydroxyphenylglycine, and the amino donor co-substrate converts L-Tyr into one equivalent of 4-hydroxyphenylpyruvate, which is returned into the enzymatic cycle to serve as a substrate for Hmas catalyzing a further round of L-4-hydroxyphenylglycine biosynthesis. This also explains why labelling studies suggested L-Tyr as a precursor for L-4-hydroxyphenylglycine biosynthesis in glycopeptide antibiotics. $^{164,168-171}$

\subsection{Dpg biosynthesis}

The gene functions of 3,5-dihydroxyphenylglycine (Dpg) biosynthesis pathway (Scheme 12) were assigned in the course of investigating the balhimycin biosynthesis gene cluster from Amycolatopsis mediterranei DSM5908. ${ }^{154,175,178-181}$ Homologous biosynthesis pathways are found in all other glycopeptide biosynthesis gene clusters, e.g. chloroeremomycin (Scheme 10a). ${ }^{163-165}$ BLAST searches for genes with similarities to $d p g A$ from the balhimycin biosynthesis gene cluster revealed a gene encoding for gerberin chalcone synthase 2 (GCHS2), a plant polyketide synthase (PKS) of the chalcone synthase-type (CHS) from Gerbera hybrid (Asteraceae). The enzyme uses acetyl-CoA and malonylCoA to synthesize the carbon-skeleton of gerberin, a 2-hydroxypyrone plant secondary metabolite. ${ }^{\mathbf{1 7 5 , 1 8 2}}$ Significant sequence similarities were particularly found for key amino acids in the active site shown to be required for activity of GCHS2. ${ }^{183}$ Further similarities of DpgA to other proteins (45-49\%) were all chalcone synthase-related $\mathrm{PKSs}^{184}$ such as Streptomyces coelicolor. ${ }^{185}$

Heterologous expression in Streptomyces lividans or in Escherichia coli combined with in vitro studies of DpgA using radioactively labeled acetyl-CoA and malonyl-CoA esters as substrates showed that DpgA is a type III PKS. Accordingly, four

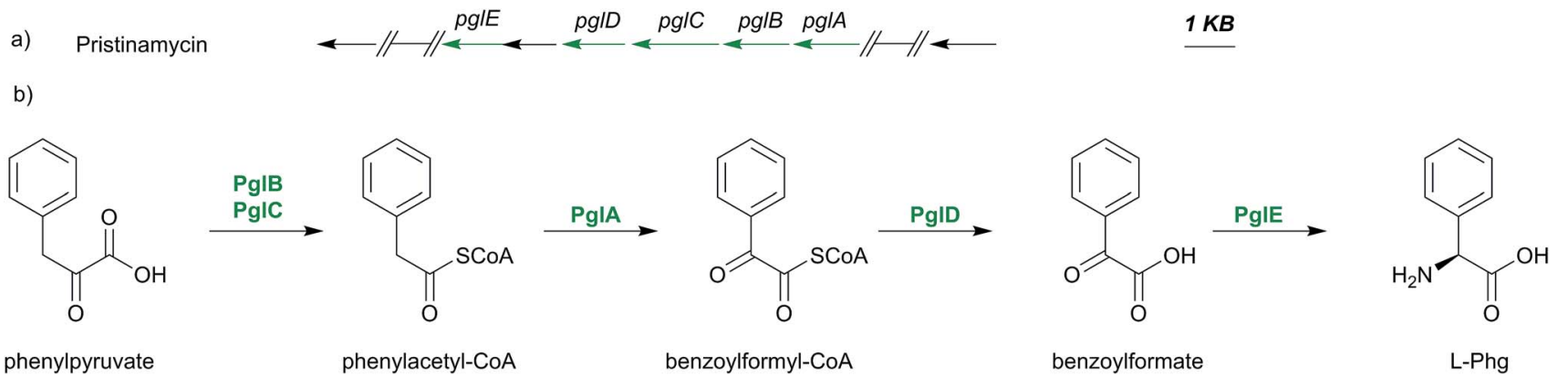

Scheme 9 Biosynthesis pathway of L-phenylglycine (Phg): a) portion of the pristinamycin biosynthesis gene cluster (pglA,pglB, pglC, pglD and pglE) from Streptomyces pristinaespiralis representing genes for b) the assembly of phenylglycine starting from phenylpyruvate. 
a)

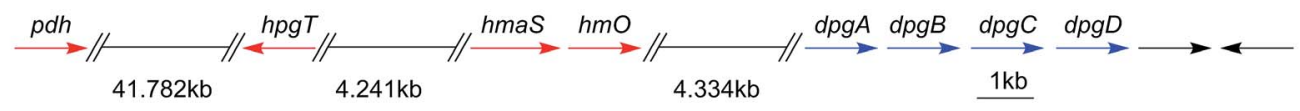

b)

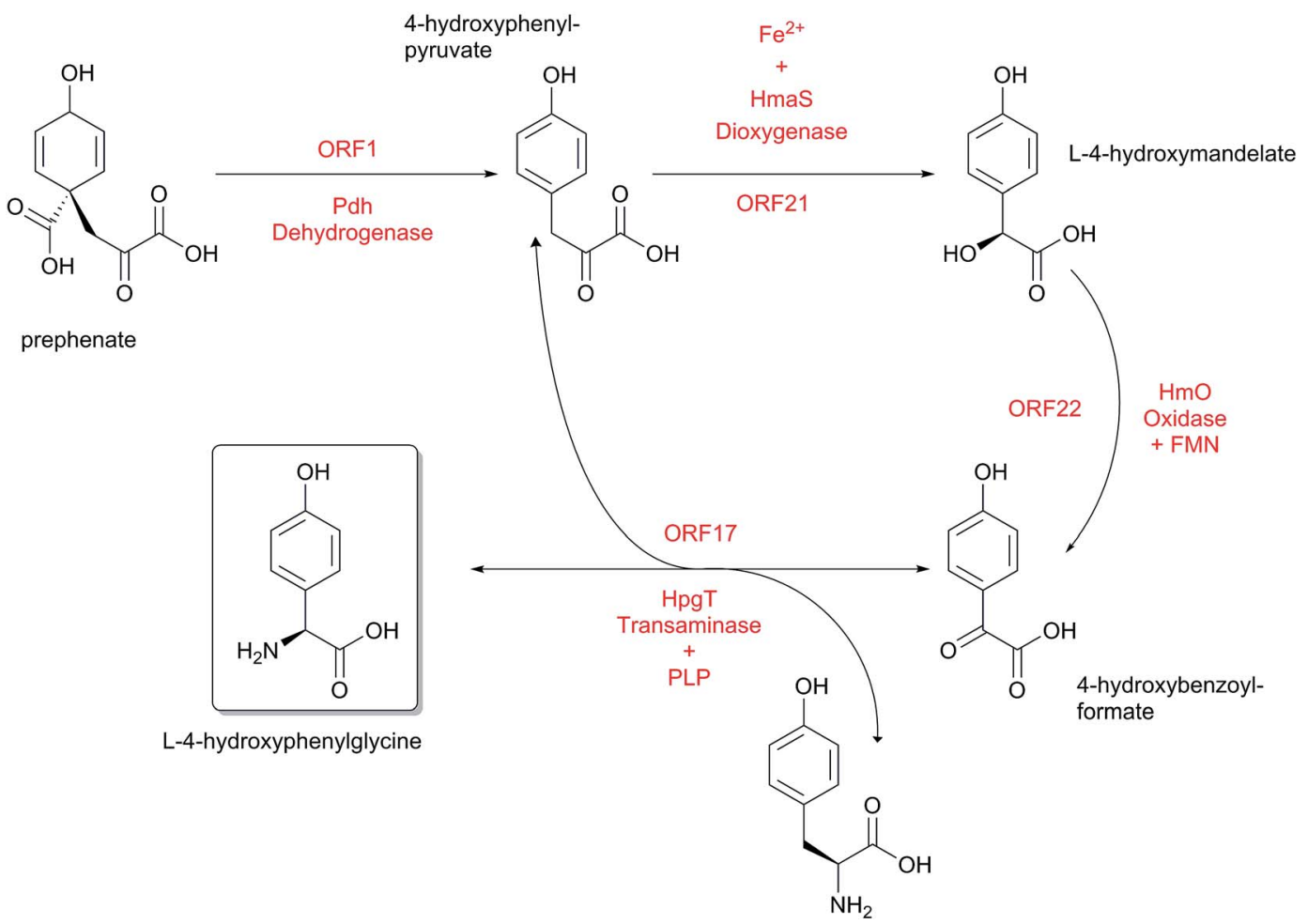

L-tyrosine

Scheme 10 Biosynthesis pathway of L-4-hydroxyphenylglycine (Hpg). (a) Chloroeremomycin biosynthesis gene cluster from Amycolatopsis orientalis with genes for L-4-hydroxyphenylglycine $(\mathrm{Hpg})$ biosynthesis ( $p d h, h p g T$, hmaS and $h m O)$. Numbers indicate ORFs starting from the first gene in the gene cluster. (b) L-4-hydroxyphenylglycine ( $\mathrm{Hpg})$ biosynthesis catalytic cycle. Pdh is prephenate dehydrogenase, HmaS is L-4hydroxymandelate synthase, $\mathrm{HmO}$ is L-4-hydroxymandelate oxidase, $\mathrm{HpgT}$ is 4-hydroxybenzoylformate/L-4-tyrosine transaminase, PLP is pyridoxal phosphate.

molecules of malonyl-CoA are assembled in a decarboxylating Claisen condensation to yield (1,3-dihydroxy-5-oxo-cyclohex-3enyl)acetyl-CoA, a precursor of 3,5-dihydroxyphenylacetic acid (Scheme 12). ${ }^{175,186,187}$
In in vitro experiments, DpgA showed the conversion of the above-mentioned precursor into 3,5-dihydroxyphenylacetylCoA (DPA-CoA), but in an extremely slow manner that was difficult to detect. However, formation of DPA-CoA was<smiles>O=C(O)C(=O)Cc1cc(O)ccc1O</smiles>

Scheme 11 Comparison of the products of the iron-dependent dioxygenases HmaS and HppD starting from the same substrate 4hydroxyphenylpyruvate. 
a)

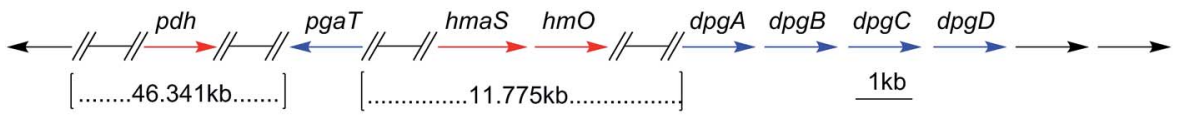

b)

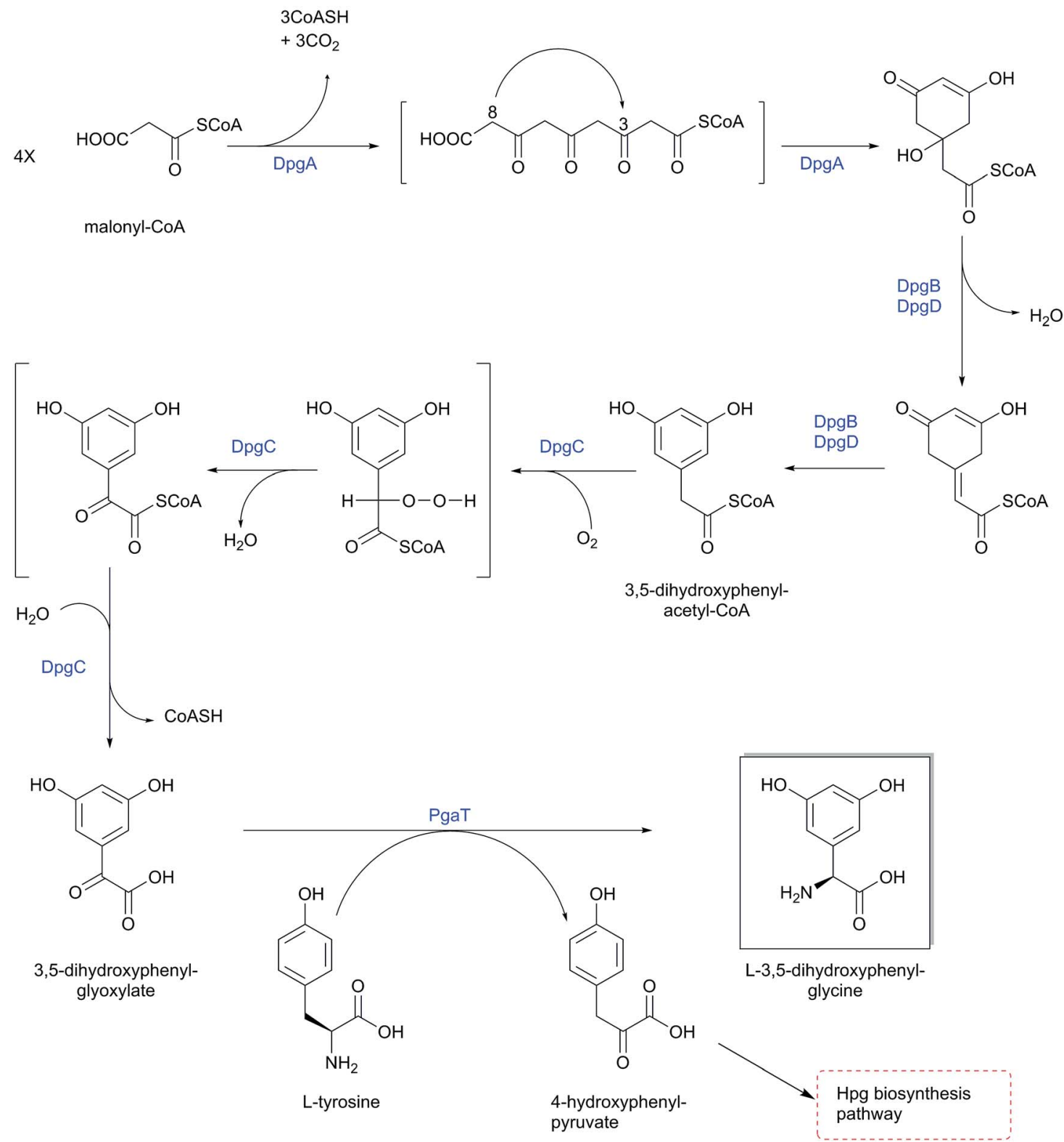

Scheme 12 Biosynthesis pathway of 3,5-dihydroxyphenylglycine (Dpg). (a) Balhimycin biosynthesis gene cluster from Amycolatopsis mediterranei DSM5908 indicating genes responsible for 3,5-dihydroxyphenylglycine (Dpg) assembly $(d p g A, d p g B, d p g C, d p g D$ and pgaT). Numbers indicate ORFs starting from the first gene in the gene cluster; (b) catalytic cycle of 3,5-dihydroxyphenylglycine (Dpg) biosynthesis.

accelerated 17 -fold by addition of DpgB. This conversion rate was again doubled by the addition of DpgD to DpgA/DpgB, although the addition of DpgD alone to DpgA did not increase DpgA activity. In total, the formation of DPA-CoA was accelerated 35-fold by the addition of DpgB/DpgD to DpgA. ${ }^{\mathbf{1 8 6 , 1 8 7}}$ Hence, DpgB and DpgD likely work as dehydratases on (1,3dihydroxy-5-oxo-cyclohex-3-enyl)acetyl-CoA to produce DPA-
CoA, probably while DpgA is still bound to the CoAsubstrate. ${ }^{186,187}$

In vitro studies on DpgC confirmed its role as a metal- and redox cofactor-independent oxygenase in converting 3,5-dihydroxyphenylacetyl-CoA (DPA-CoA) into 3,5-dihydroxyphenylglyoxylate. This was proven by addition of DpgC to the above mentioned DpgA/DpgB incubation mixture. Likewise 3,5- 
dihydroxyphenylglyoxylate was also obtained after incubation of synthetic DPA-CoA with DpgC alone. Addition of DpgB and/or DpgD to incubations of DpgC with DPA-CoA did not cause any effect on the CoASH formation rate. Furthermore, DpgC alone was able to yield phenylglyoxylate after incubation with the nonsubstituted phenylacetyl-CoA (PA-CoA). ${ }^{186,187}$ Anaerobic incubation of DpgC with DPA-CoA revealed no product formation or detectable loss of substrate. This behavior changed upon admission of air to the reaction vials, revealing molecular oxygen as a likely source for the keto oxygen introduced into 3,5dihydroxyphenylglyoxylate. Further investigations with mandelyl-CoA as a substrate showed that water can act as a source for the keto oxygen introduced into phenylglyoxylate by DpgC, since the anaerobic incubations did not indicate an absolute requirement for molecular oxygen. ${ }^{\mathbf{1 8 6 , 1 8 7}}$ In-frame deletion mutation confirmed phenylglycine aminotransferase (PgaT) to perform transamination of 3,5-dihydroxyphenylglyoxylate to yield 3,5-dihydroxyphenylglycine. ${ }^{175} \quad$ 4-Hydroxyphenylglycine transaminase HpgT was found to be corresponding with PgaT, and have the ability of catalyzing the transamination of $\mathrm{L}-\mathrm{Hpg}$ and L-Phg from 4-hydroxyphenylglyoxylic acid and phenylglyoxylic acid respectively. ${ }^{\mathbf{1 6 4}}$ This substrate promiscuity led to the assumption that both HpgT and PgaT have dual functional activities catalyzing the transamination reaction of L-Hpg and 3,5-dihydroxyphenylglycine (Dpg). ${ }^{175}$ PgaT uses L-tyrosine as an amino donor for the transamination conversion of 3,5-dihydroxyphenylglyoxylate into 3,5-dihydroxyphenylglycine, yielding 4-hydroxyphenylpyruvate (Scheme 12), which can undergo another cycle of Hpg biosynthesis (Scheme 10).

\section{Biosynthesis of phenylglycine- containing peptides}

The common element in the biosynthesis of all phenylglycine containing peptides is their origins in non-ribosomal peptide synthesis. This makes the presence of such residues in peptides a characteristic sign of non-ribosomal biosynthetic origins.

\subsection{Phenylglycine incorporation into non-ribosomal peptides}

5.1.1 Phenylglycine selection and epimerization. Within non-ribosomal peptide synthesis, the selection and activation of amino acid building blocks is performed by adenylation (A)domains. ${ }^{188,189}$ These domains have been studied in depth, including numerous structural, biochemical and bioinformatic approaches. This has resulted in the discovery of the "A-domain code", a series of 10 amino acid residues that contribute to the selection of the desired amino acid. This allows the prediction of peptide products from non-ribosomal peptide synthesis based upon a bioinformatics analysis, although novel amino acid precursors or non-linear NRPS assembly lines are resistant to this approach.

Based upon the reported non-ribosomal protein sequences available for the natural products discussed above, ${ }^{17,112,120,141,154,156-158,190-195}$ the A-domain selection pockets for phenylglycines L-Phg, L-Hpg and L-Dpg have been analysed
(Scheme 13, prepared using NRPSpredictor-2). ${ }^{\mathbf{1 9 6 , 1 9 7}}$ Hpg-activating domains fall into two broad classes (A-domain codes beginning with DIF (Scheme 13, upper left panel) and DAV/L (Scheme 13, upper right panel) respectively) that are typically conserved within a single NRPS assembly line. The exception is GPA biosynthesis, where both types are represented in the NRPS machinery in the Hpg-incorporating modules 4 and $1 / 5$ (Scheme 14). ${ }^{\mathbf{1 4 1 , 1 5 4 , 1 5 7 , 1 5 8 , 1 9 0 , 1 9 1}}$ Similar trends are seen for complestatin, although here the first class is found in modules 1,3 , 4 and 5 with the second class only found in module $7 .^{156}$ In both cases of these Hpg-activating A-domains the fourth residue present is a His, which is presumably involved in binding to the 4-hydroxyl group of Hpg.

The few examples of Phg activating A-domains characterised show a conserved A-domain code that is similar to that displayed by the Hpg-activating module 4 of GPA NRPS machineries (starting with DIF (Scheme 13, lower left panel)), albeit with the replacement of the His residue with a Leu residue and the subsequent Leu residue with a larger Trp residue. ${ }^{17} \mathrm{Dpg}$ activating A-domains show a selection pocket that maintains the His residue found in Hpg pockets, whilst reducing the general bulk of residues. ${ }^{141,154,157,158,190,191}$ These pockets also introduce a Thr residue capable of hydrogen bonding and replace the common Phe residue with a Tyr residue; presumably at least one of the His/Tyr/Thr residues are involved in coordinating to the phenol moieties of the Dpg residue (Scheme 13, lower right panel). The similarity of the A-domain codes in these systems argues against the direct activation of modified (e.g. chlorinated) $\mathrm{Phg} / \mathrm{Hpg} / \mathrm{Dpg}$ residues but rather implies their modification following activation by the NRPS machinery and transfer to a carrier protein domain. The same can also be argued for the incorporation of the initial p-hydroxybenzoylformate residue in complestatin biosynthesis, although this needs to be clarified experimentally. ${ }^{\mathbf{1 5 6}}$

In the vast majority of cases where the phenylglycine residue incorporated in the peptide is found to be the D-isomer, a corresponding epimerization (E)-domain can be found within the NRPS-module (see Scheme 14). ${ }^{188,198}$ These domains are structurally related to condensation domains that catalyse peptide bond formation and have been shown to epimerize the residue once it is contained within the peptide, with the exception of the first amino acid of the peptide. Epimerization after peptide bond formation is due to the selectivity of C-domains themselves, which are selective for L-configured amino acids in their donor sites. ${ }^{188}$ Two notable exceptions where there is a lack of an E-domain in spite of the final incorporation of a D-amino acid can be found for phenylglycine residues: one is found in the first module of GPA-biosynthesis (that incorporates Hpg in type III and IV GPAs) where the final peptide includes a D-amino acid at position 1 although there is no epimerization domain present within the NRPS. ${ }^{199}$ The second example is found in norcardicin A biosynthesis where epimerization activity of the terminal thioesterase (TE) domain is able to replace an Edomain (see below). ${ }^{67}$

5.1.2 Acceptance of alternative substrates by phenylglycine activating A-domains. The acceptance of natural as well as alternate amino acid substrates by NRPS A-domains has been 

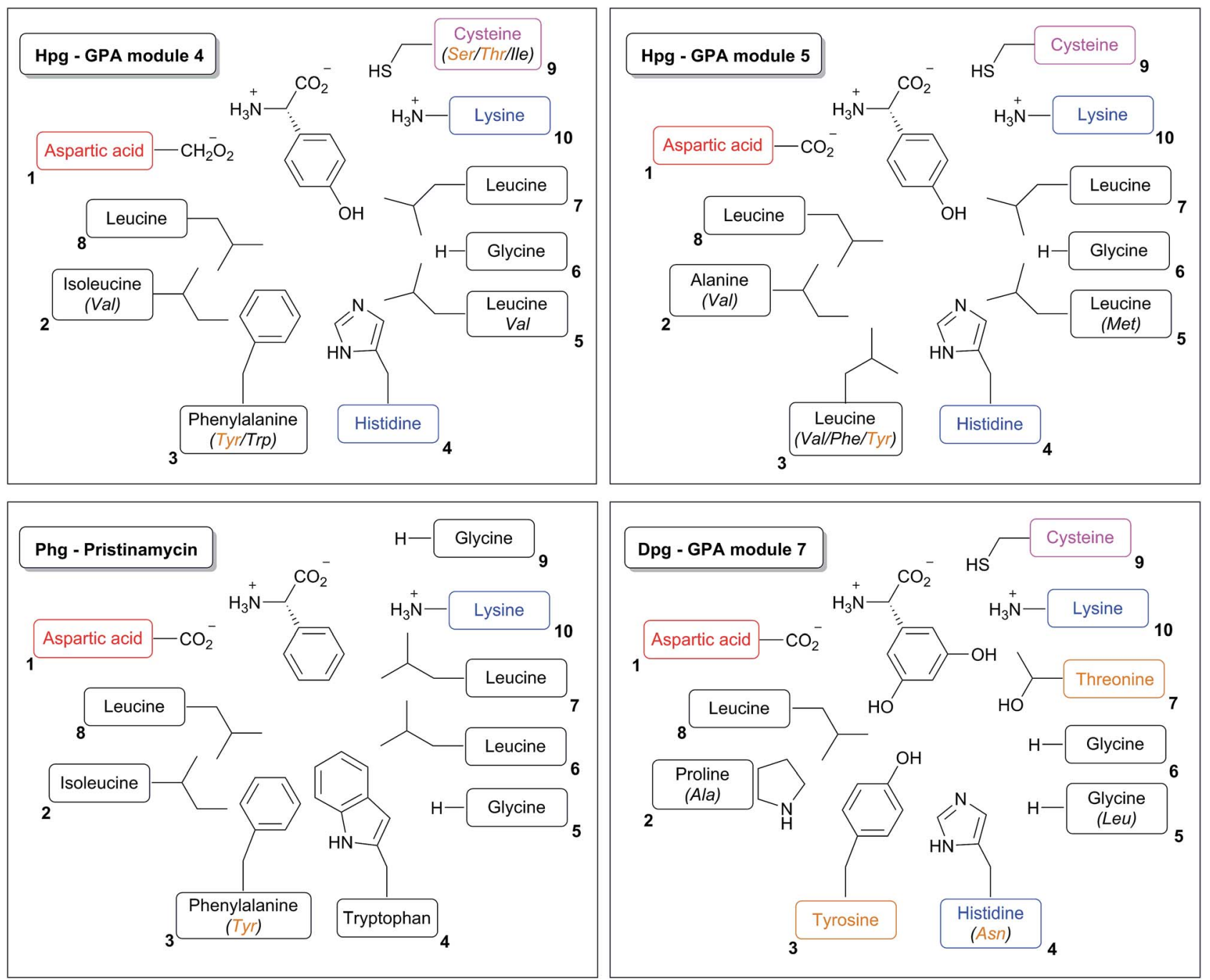

Scheme 13 Consensus adenylation selection pockets for phenylglycine residues (excluding ristocetin/ristomycin). Colour code: acidic residues (red), basic residues (blue), amide/alcohol containing residues (orange), cysteine residues (magenta).

extensively explored for the balhimycin system. The expression of isolated A-domains from modules $4-7$ of the balhimycin NRPS allowed the selectivity of these domains for their amino acid substrates to be quantified in vitro. ${ }^{166}$ Through the use of the standard ATP/PPi exchange assay, both the Hpg-activating modules 4 and 5 showed very high selectivity for L-Hpg; as expected, the $\mathrm{D}$-form was not well activated. Poor activation was also found for closely related amino acids to $\mathrm{L}-\mathrm{Hpg}$, including L-Phg, L-Dpg, L-Phe and L-Tyr. Module 7, which activates L-Dpg, did not display the selectivity that had been observed for modules $4 / 5$, although this was attributed to reduced activity of the recombinant A7 domain rather than a lowered specificity of this domain. ${ }^{166}$ The acceptance of altered amino acid substrates by the A7 domain was tested in vivo using a balhimycin producer strain that was incapable of producing L-Dpg due to gene deletion: this strain was supplemented with alternate amino acids to replace Dpg and their incorporation into modified derivatives of balhimycin was then assessed (Scheme 15 , left panel). ${ }^{200}$ Results indicated that there was significant potential for incorporation of modified residues into the peptide chain by the A7 domain: residues capable of being incorporated included 3-hydroxyphenylglycine, 3-methoxyphenylglycine, 3-hydroxy-5-methoxyphenylglycine and 3,5dimethoxyphenylglycine. The modified peptides thus produced were not always efficiently accepted by downstream crosslinking Cytochrome P450 (Oxy) enzymes (see Section 5.2.1); this was the case for the single 3 -substituted amino acids, which led to the isolation of partially crosslinked peptide aglycones as well as fully crosslinked aglycones. This same strain has also been shown to be able to incorporate Hpg into position 7 of a balhimycin type peptide, which in turn was able to be fully processed by downstream Oxy enzymes to yield a tricyclic aglycon (see below), albeit one that had an $\mathrm{AB}$ ring enlarged by one atom that then resulted in a loss of antibiotic activity. ${ }^{201}$

The acceptance of alternative substrates to Hpg has been assessed for calcium dependant antibiotic (CDA) biosynthesis via a similar gene knockout and amino acid supplementation strategy (Scheme 15, right panel). ${ }^{112}$ In this case, modified CDA 


\section{Glycopeptide antibiotic NRPS machinery}

module 1 module 2 module 3 module 4 module 5 module 6 module 7

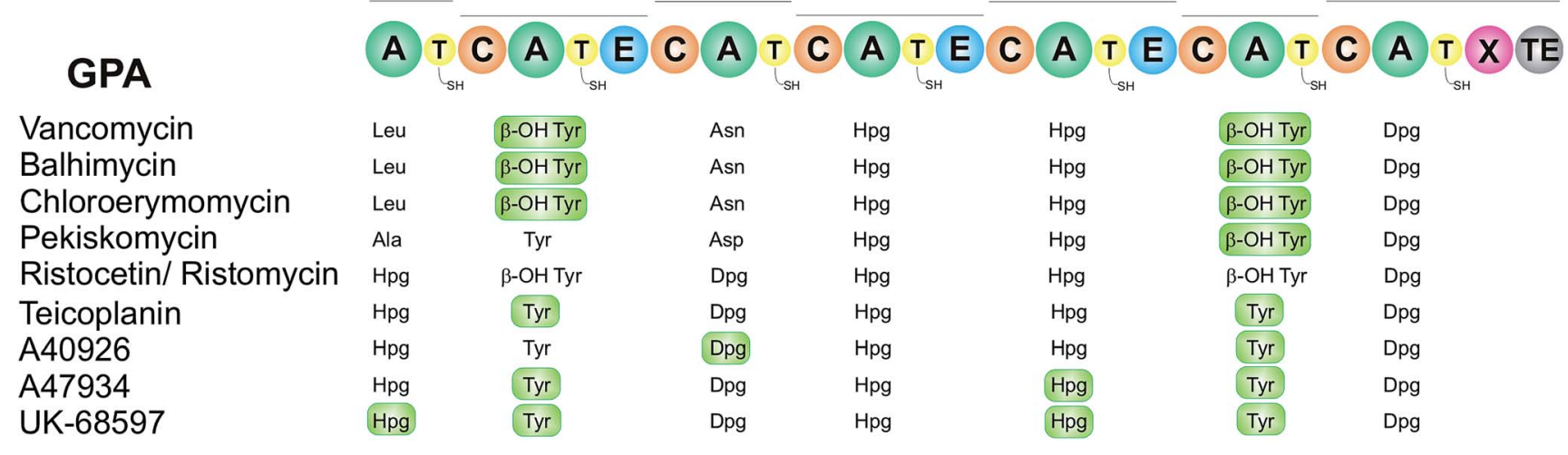

Scheme 14 Schematic representation of the NRPS machinery from glycopeptide antibiotic biosynthesis (type I-IV) displaying the amino acids activated by each A-domain of the seven individual modules for the compounds discussed within this review. Halogenation of the residues is indicated by a green box around the relevant residue. Abbreviations: $\mathrm{A}$ - adenylation domain, $\mathrm{C}-$ condensation domain, $\mathrm{T}-\mathrm{thiolation}$ (or peptidyl carrier protein (PCP) domain, $\mathrm{E}$ - epimerization domain, $\mathrm{X}$ - oxygenase recruitment domain, $\mathrm{TE}$ - thioesterase domain.
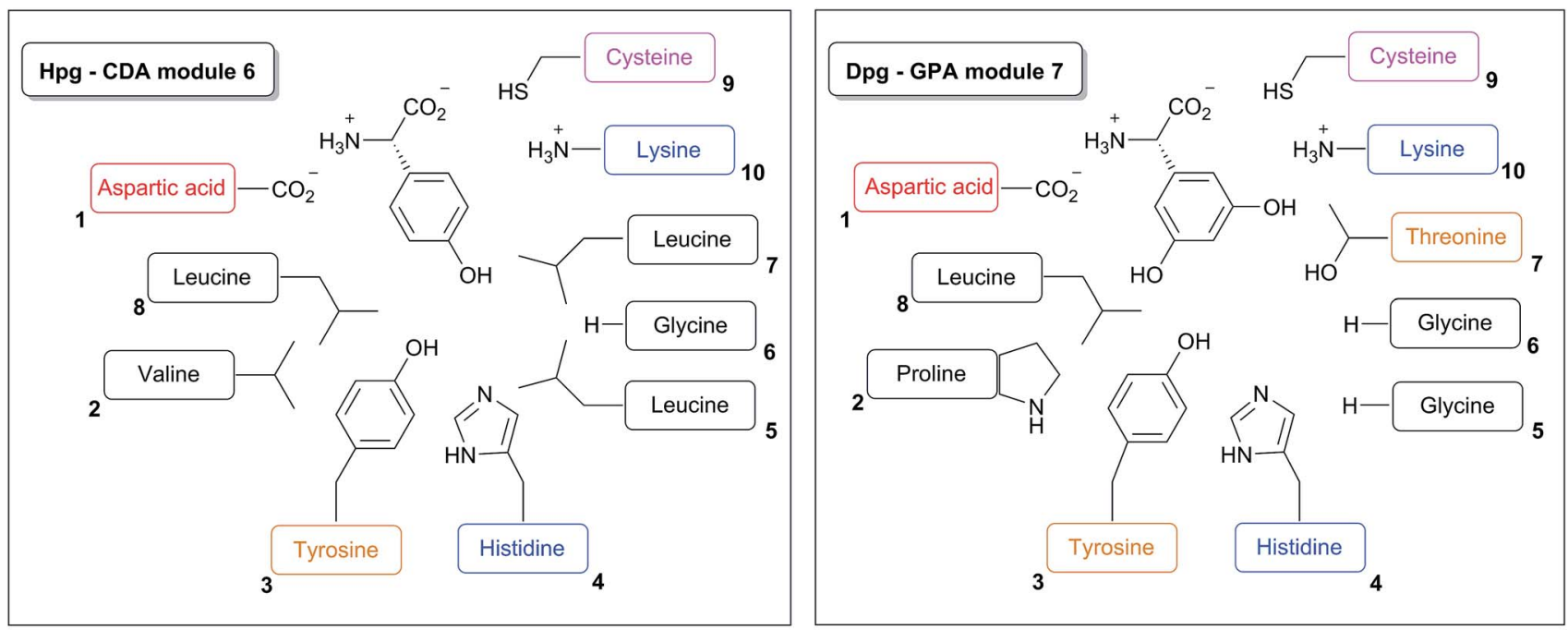
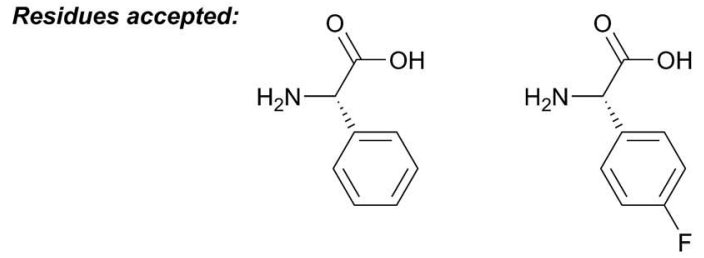

Residues not accepted:
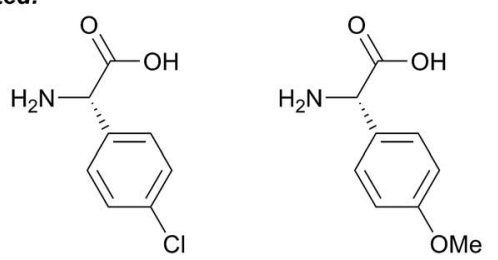

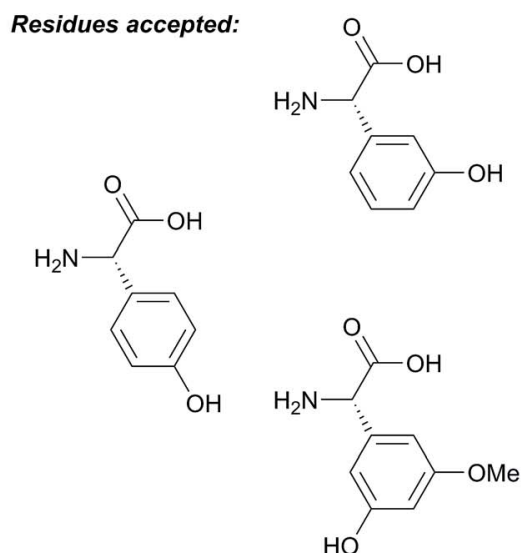

Scheme 15 Mutasynthesis potential of module 7 (Dpg incorporation) in balhimycin biosynthesis and module 6 (Hpg incorporation) in CDA biosynthesis through gene disruption and amino acid supplementation showing the incorporation potential of these residues by the respective A-domains. 
compounds were detected upon supplementation with either Phg or 4-fluorophenylglycine whilst 4-chlorophenylglycine and 4-methoxyphenylglycine were not able to be incorporated by the respective A-domain. This suggests tighter steric control during the incorporation of $\mathrm{Hpg}$ than Dpg in NRPS biosynthesis, although further examples of Dpg and $\mathrm{Hpg}$ activating Adomains would need to be examined to ascertain whether such trends are generally applicable. Finally it is worth mentioning that for all glycopeptides generated by mutasynthesis it was not possible to perform antibacterial profiling due to low production amounts. One possible reason for such reduced production may be that the modulated bioactivity causes problems for the organism by interfering with self-resistance. However, the basic export machinery, e.g. ABC transporters should be available. Production yield is a general problem inherent to many mutasynthesis applications, which needs to be addressed by future biotechnological and biosynthetic engineering efforts.

\subsection{Phenylglycine modifying enzymes}

Within the product peptides containing phenylglycine residues, many are subject to further modification during peptide assembly or following peptide synthesis. This includes numerous transformations such as alkylation, halogenation, oxidative coupling or glycosylation.

5.2.1 Oxidative coupling. The cyclisation of aromatic side chains in peptides involving phenylglycine residues is a common and important feature in such peptides: examples can be found in arylomycin, complestatin and kistamicin A as well as type I-IV glycopeptide antibiotics. The types of linkages formed include ether bridges and direct $\mathrm{C}-\mathrm{C}$ aryl bonds. Ether bridges are found between the phenol moiety of Tyr residues and the meta-position of Hpg residues (C-O-D and D-O-E rings of GPAs as well as the C-O-D rings of complestatin and kistamicin A), between the phenol moiety of $\mathrm{Hpg}$ residues and the metaposition of $\mathrm{Hpg}$ residues (A-O-B rings of kistamicin A) and between one phenol moiety of a Dpg residue and the $m$-position of Hpg residues (F-O-G rings of type III and IV GPAs). Aryl crosslinks are found between the $o$-position of Dpg residues and the $m$-position of Hpg residues (AB ring of GPAs), between the $m$-position of Tyr residues and the $m$-position of $\mathrm{Hpg}$ residues (arylomycin) and between positions six of the indole ring of Trp residues and the $m$-position of $\mathrm{Hpg}$ residues (kistamicin A and complestatin). In all cases where the gene clusters are known, the catalysts that perform the oxidative crosslinking reactions are members of the Cytochrome P450 superfamily of hemecontaining monooxygenases. ${ }^{\mathbf{1 2 2 0 2}}$ Mechanistically, numerous suggested alternatives have been made for these reactions, although experimental data is limited to showing that all phenolic oxygen atoms of $\mathrm{Hpg}$ residues are retained during aglycon maturation in vivo ${ }^{\mathbf{2 0 3}}$ and that there is no incorporation of ${ }^{18} \mathrm{O}_{2}$ into the crosslinked peptides by $\mathrm{P} 450$-catalysed oxidation in vitro. ${ }^{204}$

In the case of GPA biosynthesis, evidence is clear that these P450-catalysed reactions occur whilst the substrate peptides remain bound to the NRPS-machinery. Extensive in vivo experiments were not only able to imply the NRPS-bound nature of the peptide but could also elucidate both the identity of the enzymes responsible for the individual cross coupling steps (OxyA: D-O-E ring, OxyB: C-O-D ring, OxyC: AB ring, OxyE; F-O-G ring) as well as the order of oxidation for vancomycin-type (OxyB, OxyA, OxyC) ${ }^{205}$ and teicoplanin-type systems (OxyB, OxyE, OxyA, OxyC; there appears to be more flexibility in this case than in the vancomycin-type system). ${ }^{206}$ In vitro experiments have shown the acceptance of a range of peptide substrates on isolated carrier protein (PCP)-domains for OxyB from the vancomycin system, ${ }^{\mathbf{2 0 4 , 2 0 7 - 2 1 1}}$ with the selectivity of OxyB from the teicoplanin system for PCP-bound peptides proving significantly higher and with a reduced turnover yield. ${ }^{212}$ Other examples of a type-I (chloroerymomycin) and type-IV (A-47934) systems showed virtually no turnover of PCP-bound peptides, raising questions over the true nature of the $\mathrm{P} 450$ substrate. ${ }^{213}$ Recent in vitro data has now shown that the X-domain, a condensation-like domain of previously unknown function present in the final NRPS-module of all glycopeptide antibiotics (see Scheme 14), is able to recruit OxyA-C and thus present the adjacent PCP-bound peptide substrate to the P450 enzymes for oxidation. ${ }^{213}$ The activity of OxyB with peptide substrates bound to PCP-X constructs is significantly higher in all cases than the PCP alone; an additional point to support the importance of the $\mathrm{X}$-domain was the first demonstration of in vitro activity of a subsequent Oxy enzyme in the cascade (OxyA). ${ }^{213}$

In arylomycin, the $\mathrm{Hpg}^{4}$ residue of the linear precursor peptide is involved in the formation of an aryl bond with $\mathrm{Tyr}^{6}$ and the enzyme believed responsible for installation of the crosslink is AryC, a member of the Cytochrome P450 superfamily with a high degree of similarity to OxyC from the vancomycin gene cluster (49\%). ${ }^{\mathbf{2 1 4}}$ An arylomycin producer strain with AryC knocked out was shown to no longer produce crosslinked peptide products, supporting the assignment of the crosslinking function to this enzyme. ${ }^{215}$

5.2.2 Halogenation. The modification of phenylglycine residues by chlorination is a common modification observed in phenylglycine-containing natural products: these include examples such as the glycopeptide antibiotics, ${ }^{216}$ ramoplanin, enduracidin, complestatin, kistamicin and chlorocardicin. Identification of the halogenase genes from the gene clusters (in some cases more than one halogenase is present per gene cluster) of various glycopeptide antibiotics, enduracidin and complestatin all show that the gene products are highly similar ( $>70 \%$ identity), despite the large structural diversity of the final peptide products. ${ }^{205,217}$ It is not only phenylglycine derivatives that can be chlorinated in GPA biosynthesis: $\mathrm{Tyr}^{2 / 6}$ residues are typically chlorinated in GPAs (A40926 and pekiskomycin at $\mathrm{Tyr}^{6}$ only) ${ }^{158}$ whilst phenylglycine residues $\mathrm{Hpg}^{1 / 5}$ (UK-68597), ${ }^{195}$ $\mathrm{Hpg}^{5}$ (A47934) ${ }^{157}$ and $\mathrm{Dpg}^{3}$ (A40926) ${ }^{158}$ are only chlorinated in specific GPAs (see Scheme 14). Bromine supplementation studies have shown that such halogenases appear able to incorporate bromine instead of chlorine, which includes residue $\mathrm{Hpg}^{5}$ from $\mathrm{A} 47934 .^{218}$ Complestatin is heavily chlorinated, with two chlorine atoms added to Hpg residues 3 and 5 as well as the $p$-hydroxybenzoylformate residue at position $1 .^{156}$ Again, a single halogenase is believed responsible for the incorporation of all six chlorine atoms. The selection of amino 
acid residues by NRPS A-domains does not explain the selectivity of chlorination in these cases; rather it would appear that the modification of the residues occurs whilst they are bound to the NRPS machinery. Studies with vancomycin-type GPAs have shown that chlorinated amino acids are not accepted by the NRPS machinery in appropriate knockout strains, whilst the non-chlorinated residues are accepted by the appropriate Adomains. ${ }^{15,219}$ One exception is the replacement of the chlorine substitution with a fluorine atom - here, presumably the fluorine substituent is small enough not to perturb acceptance of the amino acid by the relevant A-domain; ${ }^{220}$ this also correlates with mutasynthesis studies performed with CDA (see above). ${ }^{\mathbf{1 1 2}}$

The exact nature of the halogenase substrate (i.e. peptide or amino acid) remains to be clarified, with in vitro and in vivo results from vancomycin ${ }^{221}$ and balhimycin biosynthesis ${ }^{178,180,201}$ implicating different substrates. Through the removal of the halogenase from producer strains dechloro forms of the natural products can be isolated: this has been shown for both balhimycin ${ }^{15}$ and enduracidin. ${ }^{103}$ A strain producing the GPA A40926 has also been evolved that demonstrates a reduced capacity to produce chlorinated compounds. ${ }^{222}$ The complementation of a halogenase deletion mutant of the enduracidin producing strain with the halogenase from the ramoplanin gene cluster allowed the isolation of novel halogenated enduracidins, bearing either a single chlorine substituent on $\mathrm{Hpg}^{13}$ or a triple chlorinated compound, with two chlorine atoms on $\mathrm{Hpg}^{13}$ and an additional chlorine substituent on $\mathrm{Hpg}^{11} \cdot{ }^{103}$ This cross complementation does suggest that the target of such halogenase enzymes is the NRPS-bound amino acids: targeting such substrates has precedence in both the hydroxylation of Tyr residues in teicoplanin-type GPA biosynthesis by non-heme iron oxygenases $^{223}$ as well as the hydroxylation of several hydrophobic residues by one cytochrome P450 in skyllamycin biosynthesis. $^{224-226}$

5.2.3 Alkylation. The modification of phenylglycine residues by alkylation typically involves the methylation of phenol residues (xanthostatin), the amine moiety (GPA A40926) and in some cases the carboxyl group to afford the methyl ester (ristocetin/ristomycin). ${ }^{227,228}$ Modification of nitrogen residues involved in amide bonds typically is catalysed by cis-domains within the NRPS machinery, such as the $\mathrm{Hpg}^{4}$ residue in arylomycin, using $S$-adenosylmethionine (AdoMet) as the source of the methyl group. ${ }^{\mathbf{1 8 8 , 2 1 4}}$ The GPA ristocetin/ristomycin alone has a modified structure that bears no chlorinations but rather displays a unique para-methylated $\mathrm{Dpg}^{3}$ residue in addition to a methyl ester formed at the terminal $\mathrm{Dpg}^{7}$ residue; ORF 19 has been implicated in the C-terminal methyl ester formation due to homology with a methyltransferase isolated from a different glycopeptide gene cluster (VEG), ${ }^{194,229}$ which thus implies a role in C-methylation for the remaining methyltransferase ORF $23 .^{227}$

In the case of salinamide A, the phenol moiety of the Hpg residue of desmethylsalinamide $\mathrm{C}$ is involved in oxidation/cyclisation with the seven-carbon moiety derived from $(2 E, 4 E)-4$ methylhexa-2,4-dienoyl coenzyme A to afford salinamide A. ${ }^{\mathbf{1 3 3 , 2 3 0}}$ The exact mechanistic details have yet to be determined, however it has been postulated that the cyclisation/oxidation proceeds either via initial attack of an epoxide by the Hpg phenol moiety that is followed by dehydration and epoxidation, or via an oxygenase-mediated [2+2] cycloaddition/dehydration cascade. ${ }^{230}$ Formation of salinamides $\mathrm{C}$ and $\mathrm{E}$, bearing a methylated Hpg phenol have been described as dead-end products in salinamide biosynthesis, where methylation via AdoMet prevents their final conversion into salinamide A. ${ }^{\mathbf{1 3 3}}$

5.2.4 Glycosylation. The modification of $\mathrm{Hpg}$ and Dpg residues through the attachment of glycosyl units has been identified for the formadicins, ${ }^{70}$ ramoplanin, ${ }^{\mathbf{8 1}}$ the lipoglycopeptides possessing an arylomycin core ${ }^{117}$ and for the glycopeptide antibiotics. ${ }^{141,154,158,195,216,227,228,231,232}$ Formadicins A and $\mathrm{B}$ are the only sugar-containing $\beta$-lactam antibiotics identified to date, bearing a D-glucuronic acid moiety ligated to the phenol group of the Hpg residue involved in the $\beta$-lactam ring (Scheme 4). ${ }^{70}$ In the ramoplanins, a dimannosyl group (comprising two $\alpha$-D-mannose units linked $\alpha(1 \rightarrow 2)$ ) is attached to the phenol of $\mathrm{Hpg}^{11} ;^{77,79}$ ramoplanose differs in having a branched mannose trisaccharide attached to this residue (Scheme 5). ${ }^{86}$ No glycosyl transferases were identified in the gene cluster of ramoplanin, and thus the enzymatic partner performing the glycosylation reactions in ramoplanin biosynthesis is unknown. ${ }^{81}$ The configuration of the sugar attached to the phenol group of $\mathrm{Hpg}^{4}$ in the arylomycin-derived lipoglycopeptides was confirmed as deoxy- $\alpha$-mannose, ${ }^{117}$ whilst the effect of the sugar moiety on antibiotic efficacy does not appear to be pronounced (Scheme 6). ${ }^{117,123,233}$

The glycosylation of glycopeptide antibiotics has been extensively characterised as most GPAs bear glycosylations; one important exception is the sulfated compound A47934. ${ }^{157}$ Glycosylation have been identified to occur on phenylglycine residues $\mathrm{Hpg}^{4}$ and $\mathrm{Dpg}^{7}$ as well as the $\beta$-hydroxytyrosine residue at position 6 . Whilst the glycosylation at position 6 contains a range of sugar moieties, initial modification of $\mathrm{Hpg}^{4}$ is restricted to glucose or glucosamine and $\mathrm{Dpg}^{7}$ displays a mannose group (teicoplanin, ristocetin, A40926). ${ }^{158,227,228,231,232}$ The glycosyl transferases responsible for the addition of glycosyl groups have been identified and investigated for chloroerymomycin (GftA, GftB, GftC) and vancomycin (GftD, GftE). ${ }^{234-237}$ GftB and GftE have been shown to be responsible for the glycosylation of $\mathrm{Hpg}^{4}$ using UDP-glucose. GftE in particular has shown potential for the acceptance of alternate aglycon substrates, ${ }^{234}$ alternative sugar units ${ }^{235,238}$ and has been shown to be able to glycosylate $\mathrm{A} 47934$ at $\mathrm{Hpg}^{4}$ in vivo. ${ }^{235} \mathrm{GftC}$ and $\mathrm{GftD}$ were shown to be responsible for further glycosylation of the mono-glycosylated aglycones by 4-epi-vancosamine; GftD was thus able to use an unnatural glycosyl donor and could also catalyse the modification of a teicoplanin mono-glycosylated aglycon. ${ }^{234}$ Further modification of unnatural mono-glycosylated aglycones produced by GftE was enabled by GftD. ${ }^{238} \mathrm{GftA}$ has been shown to be responsible for the glycosylation of $\beta$ hydroxytyrosine residue at position 6 , with a substrate preference for the singly glycosylated products of $\mathrm{GftB} / \mathrm{GftE} .^{236} \mathrm{GftA}$, GftB and GftD have also been structurally characterised. ${ }^{239-241}$

The teicoplanin glycosyltransferases tGftA and tGftB can both utilise UDP- $N$-acetylglucosamine as a donor, with tGftB also able to utilise UDP-glucose and UDP-glucosamine. ${ }^{231,232}$ The 
deletion of ORF 9 (with similarity to GftB) from the A40926 producer strain has allowed the isolation of an aglycon with only the mannosyl group present on $\mathrm{Dpg}^{7} ;^{242}$ the mannosyl transferase is implicated as ORF 20 (tcp15 in teicoplanin biosynthesis). ${ }^{158,231}$ Further modifications of the initial glucose $^{243}$ and second glycosyl moiety attached to $\mathrm{Hpg}^{4}$ have been demonstrated in GPA biosyntheses, ${ }^{\mathbf{2 4 4}}$ as well as being exploited to generate novel compounds. ${ }^{245}$

Glycosyltransferases have been employed in the synthesis of GPAs in vitro: completion of the synthesis of vancomycin and modified forms of vancomycin from synthetic aglycones have exploited the glycosyltransferases GftE and GftD to add the sugar moieties, with GftE first adding a glucose unit to $\mathrm{Hpg}^{4}{ }^{246}$ The tolerance of these enzymes for aglycon modifications was assessed, revealing that modification of the carboxylic acid moiety was poorly tolerated by GftE, with $N$-terminal modifications causing a moderate reduction in activity; GftD was less sensitive for these modifications. ${ }^{246}$ The alteration of the vancomycin backbone amide group of residue $\mathrm{Hpg}^{4}$ to thioamide moieties was more efficiently tolerated by these enzymes. ${ }^{247}$ The introduction of alkoxyamine-bearing sugars by GftE has also been demonstrated in vitro, allowing neoglycosylation to then produce novel disaccharide substituted aglycones, ${ }^{248}$ whilst azide-containing sugars introduced using GftE have been used together with a library of alkynes to create a range of modified GPA aglycones using chemoselective Huisgen 1,3-dipolar cycloaddition reactions. ${ }^{249}$

5.2.5 Sulfation. The modification of Hpg and Dpg residues by sulfation is relatively rare and occurs in the biosynthesis of the GPAs A47934 ( $\left.\mathrm{Hpg}^{1}\right)$ and UK-68597 (Dpg $\left.{ }^{3}\right)$. The sulfotransferase from the A47934 cluster has been extensively characterised, including an examination of the substrate tolerance of the enzyme as well as structural analysis. ${ }^{250-252}$ Other sulfotransferases that act on phenylglycine residues in GPA biosynthesis have been identified from metagenomics studies, with the residues modified being $\mathrm{Hpg}^{4}$ and $\mathrm{Dpg}^{3}$ of teicoplanin-type aglycones. ${ }^{194,229}$

5.2.6 Miscellaneous/combined tailoring reactions: nocardicin A. The two Hpg residues flanking the $\beta$-lactam ring in norcardicin $\mathrm{G}$ (corresponding to positions 3 and 5 in the initial NRPS-pentapeptide product) undergo several modifications during the biosynthesis to produce norcardicin A (Scheme 4). ${ }^{\mathbf{1 9 3}}$ Initially, the NRPS-mediated synthesis has several unusual features: firstly, the formation of the $\beta$-lactam ring that includes the amine of $\mathrm{Hpg}^{5}$ has been shown to be catalysed by the C5 domain of the NRPS machinery. ${ }^{253}$ Additionally, the stereochemistry of $\mathrm{Hpg}^{5}$ undergoes epimerization from the (L)- to the (D)configuration prior to hydrolysis from the NRPS - this epimerization has been attributed to the thioesterase domain of the NRPS machinery, representing another deviation from typical NRPSdomain chemistry. ${ }^{67}$ Based upon comprehensive in vitro experiments, the conversion of norcardicin $\mathrm{G}$ to norcardicin A proceeds via initial conversion to norcardicin $\mathrm{C}$, catalysed by the AdoMet: nocardicin 3-amino-3-carboxypropyltransferase NocC. ${ }^{254}$ This enzyme transfers the 3-amino-3-carboxypropyl moiety from AdoMet to the phenol group of $\mathrm{Hpg}^{3}$, which is highly unusual given that the majority of transferases employing AdoMet are involved in methylation. ${ }^{254}$ Following this, and epimerization of the $\mathrm{C}^{\prime}$ position of the 3-amino-3-carboxypropyl moiety, ${ }^{255}$ the amine of $\mathrm{Hpg}^{3}$ undergoes Cytochrome P450-catalysed oxidation to form the oxime. ${ }^{256}$ This reaction has been suggested to proceed via a twostep oxidation of the nitrogen atom, subsequent dehydration to the nitroso species and tautomerization to the oxime, although the direct dehydration of a hydroxylamine intermediate would also be a possible route to the final oxime product norcardicin A. ${ }^{256}$ This makes the $\mathrm{P} 450$ responsible, NocL, an unusual member of the P450 superfamily by catalysing the oxidation of a nitrogen atom as opposed to more typical P450-catalysed reactions involving oxygen insertion into $\mathrm{C}-\mathrm{H}$ bonds..$^{12,202,256}$

\section{Significance, importance and occurrence in medicinal chemistry}

The amino acid 4-hydroxyphenylglycine (Hpg) is a valuable pharmaceutical building block used for production of semisynthetic $\beta$-lactam antibiotics, such as the penicillins, cephalosporins, i.e. amoxicillin and cefadroxil. ${ }^{257-259}$ Scheme 16 shows the use of penicillin acylase as a catalyst for the synthesis of $\beta$ lactam antibiotics ampicillin, amoxicillin, and cephalexin starting from D-hydroxyphenylglycine amide (D-Hpga) and Dphenylglycine amide (D-Phga) together with 6-aminopenicillanic (6-APA) and 7-aminodesacetoxycephalosporanic (7ADCA) acid as substrates. ${ }^{260}$ In addition, D-4-hydroxyphenylglycine (Hpg) has also efficiently been used for the synthesis of polyxamic acid, which is an essential moiety of the antifungal antibiotics polyoxins. ${ }^{261}$

L-3,5-Dpg was found to be a specific agonist of group I metabotropic glutamate receptors mGluRs $^{262}$ with significantly low $\mathrm{EC}_{50}$ values. ${ }^{\mathbf{2 6 3 , 2 6 4}}$ It has the potency of phosphoinositide hydrolysis stimulation in neonatal $\left(\mathrm{EC}_{50} \sim 7 \mu \mathrm{M}\right)$ and adult $\left(\mathrm{EC}_{50} \sim 28 \mu \mathrm{M}\right)$ rat hippocampus and cerebellum in a dosedependent manner. ${ }^{264}$ L-3,5-Dpg application causes an agonist response elicitation in non-neuronal cells and Xenopus oocytes expressing recombinant $\mathrm{mGlu}_{1 \mathrm{a}}\left(\mathrm{EC}_{50} \sim 6-10 \mu \mathrm{M}\right)$ or $\mathrm{mGlu}_{5}$ $\left(\mathrm{EC}_{50} \sim 2 \mu \mathrm{M}\right)$ receptor subtypes. ${ }^{262,265-267}$ The stimulated cAMP levels in the adult can be inhibited by $\mathrm{L}-3,5-\mathrm{Dpg}$, while the application of such an amino acid can cause enhancement in the basal cAMP levels in the neonatal brain tissue. ${ }^{264}$

Interestingly, rac-3,5-Dpg has the ability to stimulate phospholipase C (PLC) but not phospholipase D (PLD), so it works as an antagonist of mGluRs linked to PLD in adult hippocampus but as an agonist in the neonatal brain or astrocyte cultures. ${ }^{268,269}$ The usage of $\mathrm{L}-3,5-\mathrm{Dpg}$ as a metabotropic glutamate receptors-group I-agonist induces an elevation in the intracellular calcium concentration $\left[\mathrm{Ca}^{2+}\right]_{\mathrm{i}}$ which plays an important role in controlling neuronal development and necrosis. ${ }^{270}$ mGluRs activated by L-3,5-Dpg were found to inhibit voltage dependent $\mathrm{Ca}^{2+}$ channels, and to regulate multiple subtypes of the $\mathrm{Ca}^{2+}$ channels including L-, $\mathrm{N}$ - and $\mathrm{P}$ subtypes, but not the resistant R-subtype. ${ }^{271}$

The affinity of the high affinity state of D2 receptors for dopamine in striatum was significantly decreased upon the application of $\mathrm{L}-3,5-\mathrm{Dpg},{ }^{272}$ and this application causes an inhibition in the basal and stimulated dopamine release. ${ }^{273}$ 
<smiles>CC1(C)S[C@@H]2[C@H](N)C(=O)N2C1C(=O)O</smiles><smiles>CC1(C)S[C@@H]2[C@H](N)C(=O)N2C1C(=O)O</smiles><smiles>CC1(C)S[C@@H]2C(NC(=O)[C@@H](N)c3ccc(O)cc3)C(=O)N2C1C(=O)O</smiles><smiles>N[C@@H](C(=O)O)c1ccc(O)cc1</smiles><smiles>NC(=O)[C@H](N)c1ccccc1</smiles><smiles>CC1=C(C(=O)O)N2C(=O)[C@@H](N)[C@H]2SC1</smiles>

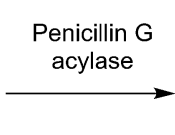<smiles>CC1=C(C(=O)O)N2C(=O)[C@@H](NC(=O)[C@H](N)c3ccccc3)[C@H]2SC1</smiles>

Cephalexin<smiles>N[C@@H](C(=O)O)c1ccccc1</smiles>

D-Phg

Scheme 16 Synthesis of $\beta$-lactam antibiotics ampicillin, amoxicillin and cephalexin starting from $D$-hydroxyphenylglycine amide (D-Hpga) and D-phenylglycine amide (D-Phga) together with 6-aminopenicillanic (6-APA) and 7-aminodesacetoxycephalosporanic (7-ADCA) acids. This reaction is performed by the mediation of penicillin $\mathrm{G}$ acylase as a catalyst.

Furthermore, the inhibition of $[3 H]$-acetylcholine $([3 H]$ Ach) release by L-AP4 (an agonist from group III mGluRs) was reversed upon treatment with $\mathrm{L}-3,5-\mathrm{Dpg}$ in retinal amacrine cells, even the later did not show a significant effect on the $([3 H]$ Ach) release. ${ }^{274}$

L-3,5-Dpg was reported to enhance or decrease excitatory postsynaptic potentials (EPSP's) in a dose dependent manner, and to have the ability of induction long-term depression (LTD) and long-term potentiation (LTP), which are thought to underpin learning and memory formation. ${ }^{275-279}$ Some other studies suggested $\mathrm{L}-3,5-\mathrm{Dpg}$ as a therapeutic agent for epileptogenesis and neuronal injury, ${ }^{280}$ hypoxia, ${ }^{281}$ regulation of intestinal motility and secretion, ${ }^{282}$ antidepression ${ }^{283,284}$ and in cardiovascular system. ${ }^{285,286}$

\section{Conclusions}

Phenylglycines comprise an important and structurally unique class of non-proteinogenic amino acids that occur in natural products but also find broad application in synthetic compounds. The main representatives are the amino acids phenylglycine (Phg), 4-hydroxyphenylglycine ( $\mathrm{Hpg}$ ), and 3,5dihydroxyphenylglycine (Dpg), which are building blocks for non-ribosomal peptide biosynthesis assembly lines of highly important and clinically used natural products. This includes linear and cyclic peptides, e.g. feglymycin, pristinamycin, arylomycin, CDA, enduracidin, ramoplanin as well as the complete group of glycopeptide antibiotics, like vancomycin and teicoplanin. The unique combination of properties in phenylglycines - restricted side chain flexibility in comparison to the proteinogenic amino acids Tyr or Phe combined with the ability for hydrogen bonding as well as hydrophobic interactions such as $\pi$-stacking - makes these amino acids crucial structural and functional elements in these groups of natural products. Interestingly, nature provides two independent solutions for the assembly of phenylglycine-type amino acids: the chorismate pathway (Phg, Hpg) and acetyl-CoA mediated by a chalcone synthase (Dpg). Peptides containing phenylglycine residues assembled on non-ribosomal peptide synthetases undergo a variety of modifications by tailoring enzymes, including those that perform alkylation, oxidation, sulfation, halogenation and glycosylation. Thus, phenylglycines constitute central building blocks of NRPS biosynthesis machineries and futures discoveries of novel peptide natural products containing these amino acids are expected.

\section{Acknowledgements}

This work was supported by the Cluster of Excellence "Unifying Concepts in Catalysis UniCat" funded by the DFG and coordinated by the TU Berlin, and by the StrepSynth project (FP7KBBE-2013-7-613887) within the 7th Framework program of the European Union. M.J.C. is grateful to the Deutsche Forschungsgemeinschaft (Emmy-Noether Program, CR 392/1-1) for financial support. R. Al Toma gratefully acknowledges support from the EMECW (Erasmus Mundus External Cooperation Window) for a fellowship.

\section{Notes and references}

1 P. G. Arnison, M. J. Bibb, G. Bierbaum, A. A. Bowers, T. S. Bugni, G. Bulaj, J. A. Camarero, D. J. Campopiano, 
G. L. Challis, J. Clardy, P. D. Cotter, D. J. Craik, M. Dawson, E. Dittmann, S. Donadio, P. C. Dorrestein, K. D. Entian, M. A. Fischbach, J. S. Garavelli, U. Goransson, C. W. Gruber, D. H. Haft, T. K. Hemscheidt, C. Hertweck, C. Hill, A. R. Horswill, M. Jaspars, W. L. Kelly, J. P. Klinman, O. P. Kuipers, A. J. Link, W. Liu, M. A. Marahiel, D. A. Mitchell, G. N. Moll, B. S. Moore, R. Muller, S. K. Nair, I. F. Nes, G. E. Norris, B. M. Olivera, H. Onaka, M. L. Patchett, J. Piel, M. J. Reaney, S. Rebuffat, R. P. Ross, H. G. Sahl, E. W. Schmidt, M. E. Selsted, K. Severinov, B. Shen, K. Sivonen, L. Smith, T. Stein, R. D. Süssmuth, J. R. Tagg, G. L. Tang, A. W. Truman, J. C. Vederas, C. T. Walsh, J. D. Walton, S. C. Wenzel, J. M. Willey and W. A. van der Donk, Nat. Prod. Rep., 2013, 30, 108-160.

2 L. Johansson, G. Gafvelin and E. S. Arner, Biochim. Biophys. Acta, 2005, 30, 1-13.

3 G. Srinivasan, C. M. James and J. A. Krzycki, Science, 2002, 296, 1459-1462.

4 B. Hao, W. Gong, T. K. Ferguson, C. M. James, J. A. Krzycki and M. K. Chan, Science, 2002, 296, 1462-1466.

5 R. S. Al Toma, A. Kuthning, M. P. Exner, A. Denisiuk, J. Ziegler, N. Budisa and R. D. Süssmuth, ChemBioChem, 2014, 11, 201402558.

6 Y. Zhang, P. V. Baranov, J. F. Atkins and V. N. Gladyshev, J. Biol. Chem., 2005, 280, 20740-20751.

7 F. H. Vaillancourt, E. Yeh, D. A. Vosburg, S. E. O'Connor and C. T. Walsh, Nature, 2005, 436, 1191-1194.

8 M. A. Fischbach and C. T. Walsh, Chem. Rev., 2006, 106, 3468-3496.

9 J. He, N. Magarvey, M. Piraee and L. C. Vining, Microbiology, 2001, 147, 2817-2829.

10 J. M. Neary, A. Powell, L. Gordon, C. Milne, F. Flett, B. Wilkinson, C. P. Smith and J. Micklefield, Microbiology, 2007, 153, 768-776.

11 M. Strieker, E. M. Nolan, C. T. Walsh and M. A. Marahiel, J. Am. Chem. Soc., 2009, 131, 13523-13530.

12 M. J. Cryle, C. Brieke and K. Haslinger, in Amino Acids, Peptides and Proteins, The Royal Society of Chemistry, 2014, vol. 38, pp. 1-36.

13 H. Chen and C. T. Walsh, Chem. Biol., 2001, 8, 301-312.

14 M. J. Cryle, A. Meinhart and I. Schlichting, J. Biol.Chem., 2010, 285, 24562-24574.

15 O. Puk, P. Huber, D. Bischoff, J. Recktenwald, G. Jung, R. D. Süssmuth, K. H. van Pee, W. Wohlleben and S. Pelzer, Chem. Biol., 2002, 9, 225-235.

16 V. Blanc, P. Gil, N. Bamas-Jacques, S. Lorenzon, M. Zagorec, J. Schleuniger, D. Bisch, F. Blanche, L. Debussche, J. Crouzet and D. Thibaut, Mol. Microbiol., 1997, 23, 191202.

17 Y. Mast, T. Weber, M. Golz, R. Ort-Winklbauer, A. Gondran, W. Wohlleben and E. Schinko, Microb. Biotechnol., 2011, 4, 192-206.

18 D. Seebach, A. K. Beck, S. Capone, G. Deniau, U. Groselj and E. Zass, Synthesis, 2009, 1-32.

19 L. Liu, D. W. Bearden and K. S. Rein, J. Nat. Prod., 2011, 74, 1535-1538.
$20 \mathrm{H}$. S. Okumura, B. Philmus, C. Portmann and T. K. Hemscheidt, J. Nat. Prod., 2009, 72, 172-176.

21 C. Keller-Juslén, M. Kuhn, H. R. Loosli, T. J. Petcher, H. P. Weber and A. von Wartburg, Tetrahedron Lett., 1976, 17, 4147-4150.

22 M. Sato, T. Tatsuno and H. Matsuo, Yakugaku Zasshi, 1970, 90, 1160-1163.

23 K. C. Nicolaou, C. N. Boddy, S. Brase and N. Winssinger, Angew. Chem., Int. Ed. Engl., 1999, 38, 2096-2152.

24 M. A. Elsawy, C. Hewage and B. Walker, J. Pept. Sci., 2012, 18, 302-311.

25 J. Nam, D. Shin, Y. Rew and D. L. Boger, J. Am. Chem. Soc., 2007, 129, 8747-8755.

26 A. Hänchen, S. Rausch, B. Landmann, L. Toti, A. Nusser and R. D. Süssmuth, ChemBioChem, 2013, 14, 625-632.

27 H. Vanderhaeghe, G. Janssen and F. Compernolle, Tetrahedron Lett., 1971, 12, 2687-2688.

28 C. Cocito, Microbiol. Rev., 1979, 43, 145-192.

29 J. C. Barriere, D. H. Bouanchaud, J. F. Desnottes and J. M. Paris, Expert Opin. Invest. Drugs, 1994, 3, 115-131.

30 P. Crooy and R. De Neys, J. Antibiot., 1972, 25, 371-372.

31 C. Cocito, Antibiotics, 1983, 6, 296-332.

32 C. Cocito, M. Di Giambattista, E. Nyssen and P. Vannuffel, J. Antimicrob. Chemother., 1997, 39, 7-13.

33 D. Vazquez, J. Gen. Microbiol., 1966, 42, 93-106.

34 Y. Mast and W. Wohlleben, Int. J. Med. Microbiol., 2014, 304, 44-50.

35 T. A. Mukhtar and G. D. Wright, Chem. Rev., 2005, 105, 529542.

36 Y. A. Chabbert and J. F. Acar, Ann. Inst. Pasteur, 1964, 107, 777-790.

37 D. Vazquez, in Mechanism of Action of Antimicrobial and Antitumor Agents, ed. J. Corcoran, F. Hahn, J. F. Snell and K. L. Arora, Springer Berlin Heidelberg, 1975, vol. 3, pp. 521-534.

38 J. Preudhomme, A. Belloc, Y. Charpentie and P. Tarridec, $C$. R. Hebd. Seances Acad. Sci., 1965, 260, 1309-1312.

39 J. Preud'homme, P. Tarridec and A. Belloc, Bull. Soc. Chim. Fr., 1968, 2, 585-591.

40 G. P. G. Jolies, J. Robert, B. Terlain and J. P. Thomas, Bull. Soc. Chim. Fr., 1965, 8, 2252-2259.

41 A. A. Kiryushkin, V. M. Burikov and B. V. Rozynov, Tetrahedron Lett., 1967, 2675-2678.

42 B. V. Rozynov, V. M. Burikov, I. A. Bogdanova and A. A. Kiryushkin, Zh. Obshch. Khim., 1969, 39, 891-905.

43 J. P. Declercq, G. Germain, M. Van Meerssche, S. E. Hull and M. J. Irwin, Acta Crystallogr., Sect. B: Struct. Crystallogr. Cryst. Chem., 1978, 34, 3644-3648.

44 J. D. Yates and P. J. Schaible, Nature, 1962, 194, 183-184. 45 H. Eyssen and P. de Somer, J. Exp. Med., 1963, 117, 127-138. 46 F. M. Aarestrup, A. M. Seyfarth, H.-D. Emborg, K. Pedersen, R. S. Hendriksen and F. Bager, Antimicrob. Agents Chemother., 2001, 45, 2054-2059.

47 F. M. Aarestrup, H. Kruse, E. Tast, A. M. Hammerum and L. B. Jensen, Microb. Drug Resist., 2000, 6, 63-70.

48 G. M. Elipoulos, Clin. Infect. Dis., 2003, 36, 473-481.

49 P. Weber, Pathol. Biol., 2001, 49, 840-845. 
50 R. Leclercq, C. J. Soussy, P. Weber, N. Moniot-Ville and C. Dib, Pathol. Biol., 2003, 51, 400-404.

51 Martindale: The Complete Drug Reference, ed. S. C. Sweetman, Pharmaceutical Press, 2005.

52 D. Nathwani, P. G. Davey and C. A. Marwick, Clin. Evid., 2010, 0922.

53 T. Teshima, M. Nishikawa, I. Kubota, T. Shiba, Y. Iwai and S. Ōmura, Tetrahedron Lett., 1988, 29, 1963-1966.

54 L. Brandi, S. Maffioli, S. Donadio, F. Quaglia, M. Sette, P. Milón, C. O. Gualerzi and A. Fabbretti, FEBS Lett., 2012, 586, 3373-3378.

55 S. Omura, Y. Iwai, A. Hirano, J. Awaya, Y. Suzuki and K. Matsumoto, Agric. Biol. Chem., 1977, 41, 1827-1828.

56 L. Brandi, A. Fabbretti, M. Di Stefano, A. Lazzarini, M. Abbondi and C. O. Gualerzi, RNA, 2006, 12, 1262-1270.

57 D. Bulkley, L. Brandi, Y. S. Polikanov, A. Fabbretti, M. O'Connor, C. O. Gualerzi and T. A. Steitz, Cell Rep., 2014, 6, 357-365.

58 T. Kawahara, M. Itoh, M. Izumikawa, J. Hashimoto, N. Sakata, T. Tsuchida and K. Shin-ya, J. Antibiot., 2015, 68, 67-70.

59 T. Yamamoto, K. Kojiri, H. Morishima, H. Naganawa, T. Aoyagi and H. Umezawa, J. Antibiot., 1978, 31, 483-484.

60 T. Aoyagi, T. Yamamoto, K. Kojiri, F. Kojima, M. Hamada, T. Takeuchi and H. Umezawa, J. Antibiot., 1978, 31, 244246.

61 P. Friis and A. Kjaer, Acta Chem. Scand., 1963, 17, 23912396.

62 M. Hashimoto, T. Komori and T. Kamiya, J. Antibiot., 1976, 29, 890-901.

63 H. Aoki, H. Sakai, M. Kohsaka, T. Konomi and J. Hosoda, J. Antibiot., 1976, 29, 492-500.

64 J. Hosoda, T. Konomi, N. Tani, H. Aoki and H. Imanaka, Agric. Biol. Chem., 1977, 41, 2013-2020.

65 G. M. Salituro and C. A. Townsend, J. Am. Chem. Soc., 1990, 112, 760-770.

66 C. A. Townsend and B. A. Wilson, J. Am. Chem. Soc., 1988, 110, 3320-3321.

67 N. M. Gaudelli and C. A. Townsend, Nat. Chem. Biol., 2014, 10, 251-258.

68 L. J. Nisbet, R. J. Mehta, Y. Oh, C. H. Pan, C. G. Phelen, M. J. Polansky, M. C. Shearer, A. J. Giovenella and S. F. Grappel, J. Antibiot., 1985, 38, 133-138.

69 J. A. Chan, E. A. Shultis, J. J. Dingerdissen, C. W. DeBrosse, G. D. Roberts and K. M. Snader, J. Antibiot., 1985, 38, 139144.

70 N. Katayama, Y. Nozaki, K. Okonogi, H. Ono, S. Harada and H. Okazaki, J. Antibiot., 1985, 38, 1117-1127.

71 T. Hida, S. Tsubotani, N. Katayama, H. Okazaki and S. Harada, J. Antibiot., 1985, 38, 1128-1140.

72 L. Vertesy, W. Aretz, M. Knauf, A. Markus, M. Vogel and J. Wink, J. Antibiot., 1999, 52, 374-382.

73 F. Dettner, A. Hänchen, D. Schols, L. Toti, A. Nusser and R. D. Süssmuth, Angew. Chem., Int. Ed. Engl., 2009, 48, 1856-1861.

74 G. Bunkoczi, L. Vertesy and G. M. Sheldrick, Angew. Chem., Int. Ed. Engl., 2005, 44, 1340-1342.
75 G. Férir, A. Hänchen, K. O. François, B. Hoorelbeke, D. Huskens, F. Dettner, R. D. Süssmuth and D. Schols, Virology, 2012, 433, 308-319.

76 B. Cavalleri, H. Pagani, G. Volpe, E. Selva and F. Parenti, J. Antibiot., 1984, 37, 309-317.

77 R. Ciabatti, J. K. Kettenring, G. Winters, G. Tuan, L. Zerilli and B. Cavalleri, J. Antibiot., 1989, 42, 254-267.

78 R. Pallanza, M. Berti, R. Scotti, E. Randisi and V. Arioli, J. Antibiot., 1984, 37, 318-324.

79 J. K. Kettenring, R. Ciabatti, G. Winters, G. Tamborini and B. Cavalleri, J. Antibiot., 1989, 42, 268-275.

80 S. Walker, L. Chen, Y. Hu, Y. Rew, D. Shin and D. L. Boger, Chem. Rev., 2005, 105, 449-476.

81 D. G. McCafferty, P. Cudic, B. A. Frankel, S. Barkallah, R. G. Kruger and W. Li, Biopolymers, 2002, 66, 261-284.

82 P. Cudic, J. K. Kranz, D. C. Behenna, R. G. Kruger, H. Tadesse, A. J. Wand, Y. I. Veklich, J. W. Weisel and D. G. McCafferty, Proc. Natl. Acad. Sci. U. S. A., 2002, 99, 7384-7389.

83 N. Bionda, J. P. Pitteloud and P. Cudic, Future Med. Chem., 2013, 5, 1311-1330.

84 P. Fulco and R. P. Wenzel, Expert Rev. Anti-Infect. Ther., 2006, 4, 939-945.

85 D. K. Farver, D. D. Hedge and S. C. Lee, Ann. Pharmacother, 2005, 39, 863-868.

86 N. J. Skelton, M. M. Harding, R. J. Mortishire-Smith, S. K. Rahman, D. H. Williams, M. J. Rance and J. C. Ruddock, J. Am. Chem. Soc., 1991, 113, 7522-7530.

87 M. Kurz and W. Guba, Biochemistry, 1996, 35, 12570-12575.

88 W. Jiang, J. Wanner, R. J. Lee, P. Y. Bounaud and D. L. Boger, J. Am. Chem. Soc., 2002, 124, 5288-5290.

89 F. Castiglione, A. Marazzi, M. Meli and G. Colombo, Magn. Reson. Chem., 2005, 43, 603-610.

90 E. Higashide, K. Hatano, M. Shibata and K. Nakazawa, J. Antibiot., 1968, 21, 126-137.

91 E. Meyers, F. L. Weisenborn, F. E. Pansy, D. S. Slusarchyk, M. H. Von Saltza, M. L. Rathnum and W. L. Parker, J. Antibiot., 1970, 23, 502-507.

92 P. E. Linnett and J. L. Strominger, Antimicrob. Agents Chemother., 1973, 4, 231-236.

93 M. Hori, N. Sugita and M. Miyazaki, Chem. Pharm. Bull., 1973, 21, 1171-1174.

94 M. Hori, H. Iwasaki, S. Horii, I. Yoshida and T. Hongo, Chem. Pharm. Bull., 1973, 21, 1175-1183.

95 H. Iwasaki, S. Horii, M. Asai, K. Mizuno, J. Ueyanagi and A. Miyake, Chem. Pharm. Bull., 1973, 21, 1184-1191.

96 S. Tsuji, S. Kusumoto and T. Shiba, Chem. Lett., 1975, 12811284.

97 M. Peromet, E. Schoutens and E. Yourassowsky, Chemotherapy, 1973, 19, 53-61.

98 S. Goto, S. Kuwahara, N. Okubo and H. Zenyoji, J. Antibiot., 1968, 21, 119-125.

99 K. Tsuchiya, M. Kondo, T. Oishi and T. Yamazaki, J. Antibiot., 1968, 21, 147-153.

100 M. Kawakami, Y. Nagai, T. Fuji and S. Mitsuhashi, J. Antibiot., 1971, 24, 583-586.

101 E. Yourassowsky and R. Monsieur, Chemotherapy, 1972, 17, 182-187. 
102 H. Komatsuzawa, J. Suzuki, M. Sugai, Y. Miyake and H. Suginaka, J. Antimicrob. Chemother., 1994, 33, 1155-1163.

103 X. Yin, Y. Chen, L. Zhang, Y. Wang and T. M. Zabriskie, J. Nat. Prod., 2010, 73, 583-589.

104 J.-M. Du, L. Li and J.-M. Du, Siliao Yanjiu, 2013, 18-20.

105 W. E. Brown, V. Seinerova, W. M. Chan, A. I. Laskin, P. Linnett and J. L. Strominger, Ann. N. Y. Acad. Sci., 1974, 235, 399-405.

106 E. Meyers, F. L. Weisenborn, F. E. Pansy, D. S. Slusarchyk, M. H. Von Saltza, M. L. Rathnum and W. L. Parker, J. Antibiot., 1970, 23, 502-507.

107 B. A. M. Rudd, Ph.D. thesis, University of East Anglia, Norwich, U.K., 1978.

108 J. H. Lakey, E. J. Lea, B. A. Rudd, H. M. Wright and D. A. Hopwood, J. Gen. Microbiol., 1983, 129, 3565-3573.

109 D. A. Hopwood and H. M. Wright, J. Gen. Microbiol., 1983, 129, 3575-3579.

110 C. Kempter, D. Kaiser, S. Haag, G. Nicholson, V. Gnau, T. Walk, K. H. Gierling, H. Decker, H. Zähner, G. Jung and J. W. Metzger, Angew. Chem., Int. Ed. Engl., 1997, 36, 498-501.

111 M. Strieker, F. Kopp, C. Mahlert, L.-O. Essen and M. A. Marahiel, ACS Chem. Biol., 2007, 2, 187-196.

112 Z. Hojati, C. Milne, B. Harvey, L. Gordon, M. Borg, F. Flett, B. Wilkinson, P. J. Sidebottom, B. A. Rudd, M. A. Hayes, C. P. Smith and J. Micklefield, Chem. Biol., 2002, 9, 11751187.

113 D. Jung, A. Rozek, M. Okon and R. E. W. Hancock, Chem. Biol., 2004, 11, 949-957.

114 L. Vertesy, E. Ehlers, H. Kogler, M. Kurz, J. Meiwes, G. Seibert, M. Vogel and P. Hammann, J. Antibiot., 2000, 53, 816-827.

115 A. Holtzel, D. G. Schmid, G. J. Nicholson, S. Stevanovic, J. Schimana, K. Gebhardt, H.-P. Fiedler and G. Jung, J. Antibiot., 2002, 55, 571-577.

116 J. Schimana, K. Gebhardt, A. Holtzel, D. G. Schmid, R. Süssmuth, J. Muller, R. Pukall and H.-P. Fiedler, J. Antibiot., 2002, 55, 565-570.

117 P. Kulanthaivel, A. J. Kreuzman, M. A. Strege, M. D. Belvo, T. A. Smitka, M. Clemens, J. R. Swartling, K. L. Minton, F. Zheng, E. L. Angleton, D. Mullen, L. N. Jungheim, V. J. Klimkowski, T. I. Nicas, R. C. Thompson and S. B. Peng, J. Biol. Chem., 2004, 279, 36250-36258.

118 M. Paetzel, J. J. Goodall, M. Kania, R. E. Dalbey and M. G. P. Page, J. Biol. Chem., 2004, 279, 30781-30790.

119 T. C. Roberts, P. A. Smith, R. T. Cirz and F. E. Romesberg, J. Am. Chem. Soc., 2007, 129, 15830-15838.

120 J. Liu, C. Luo, P. A. Smith, J. K. Chin, M. G. P. Page, M. Paetzel and F. E. Romesberg, J. Am. Chem. Soc., 2011, 133, 17869-17877.

121 T. C. Roberts, P. A. Smith and F. E. Romesberg, J. Nat. Prod., 2011, 74, 956-961.

122 P. A. Smith, T. C. Roberts and F. E. Romesberg, Chem. Biol., 2010, 17, 1223-1231.

123 P. A. Smith, M. E. Powers, T. C. Roberts and F. E. Romesberg, Antimicrob. Agents Chemother., 2011, 55, 1130-1134.
124 P. A. Smith and F. E. Romesberg, Antimicrob. Agents Chemother., 2012, 56, 5054-5060.

125 M. Rao, W. Wei, M. Ge, D. Chen and X. Sheng, Nat. Prod. Res., 2013, 27, 2190-2195.

126 B. Hellmark, M. Unemo, A. Nilsdotter-Augustinsson and B. Soderquist, Clin. Microbiol. Infect., 2009, 15, 238-244.

127 Y. K. Lam, D. L. Williams Jr, J. M. Sigmund, M. Sanchez, O. Genilloud, Y. L. Kong, S. Stevens-Miles, L. Huang and G. M. Garrity, J. Antibiot., 1992, 45, 1709-1716.

128 D. Zink, O. D. Hensens, Y. K. Lam, R. Reamer and J. M. Liesch, J. Antibiot., 1992, 45, 1717-1722.

129 X. C. Cheng, T. Kihara, H. Kusakabe, R. Fang, Z. Ni, Y. Shen, K. Ko, I. Yamaguchi and K. Isono, Agric. Biol. Chem., 1987, 51, 279-281.

130 S. Kim, M. Ubukata, K. Kobayashi and K. Isono, Tetrahedron Lett., 1992, 33, 2561-2564.

131 S.-K. Kim, M. Ubukata and K. Isono, J. Microbiol. Biotechnol., 2003, 13, 998-1000.

132 J. A. Trischman, D. M. Tapiolas, P. R. Jensen, R. Dwight, W. Fenical, T. C. McKee, C. M. Ireland, T. J. Stout and J. Clardy, J. Am. Chem. Soc., 1994, 116, 757-758.

133 B. S. Moore, J. A. Trischman, D. Seng, D. Kho, P. R. Jensen and W. Fenical, J. Org. Chem., 1999, 64, 1145-1150.

134 H. M. Hassan, D. Degen, K. H. Jang, R. H. Ebright and W. Fenical, J. Antibiot., 2015, 68, 206-209.

135 L. Tan and D. Ma, Angew. Chem., Int. Ed. Engl., 2008, 47, 3614-3617.

136 S. Miao, M. R. Anstee, K. LaMarco, J. Matthew, L. H. T. Huang and M. M. Brasseur, J. Nat. Prod., 1997, 60, 858-861.

137 D. Degen, Y. Feng, Y. Zhang, K. Y. Ebright, Y. W. Ebright, M. Gigliotti, H. Vahedian-Movahed, S. Mandal, M. Talaue, N. Connell, E. Arnold, W. Fenical and R. H. Ebright, eLife, 2014, 3, DOI: 10.7554/eLife.02451.

138 B. K. Hubbard and C. T. Walsh, Angew. Chem., Int. Ed. Engl., 2003, 42, 730-765.

139 M. H. McCormick, J. M. McGuire, G. E. Pittenger, R. C. Pittenger and W. M. Stark, Antibiot. Annu., 1955, 3, 606-611.

140 G. M. Sheldrick, E. Paulus, L. Vertesy and F. Hahn, Acta Crystallogr., Sect. B: Struct. Sci., 1995, 51, 89-98.

141 A. M. van Wageningen, P. N. Kirkpatrick, D. H. Williams, B. R. Harris, J. K. Kershaw, N. J. Lennard, M. Jones, S. J. Jones and P. J. Solenberg, Chem. Biol., 1998, 5, 155-162.

142 N. N. Lomakina, M. S. Iurina, M. F. Lavrova and M. G. Brazhnikova, Antibiotiki, 1961, 6, 609-618.

143 S. L. Heald, L. Mueller and P. W. Jeffs, J. Antibiot., 1987, 40, 630-645.

144 W. E. Grundy, A. C. Sinclair, R. J. Theriault, A. W. Goldstein, C. J. Rickher, H. B. Warren Jr, T. J. Oliver and J. C. Sylvester, Antibiot. Annu., 1956, 687-692.

145 J. E. Philip, J. R. Schenck and M. P. Hargie, Antibiot. Annu., 1956, 699-705.

146 M. R. Bardone, M. Paternoster and C. Coronelli, J. Antibiot., 1978, 31, 170-177.

147 H. Seto, T. Fujioka, K. Furihata, I. Kaneko and S. Takahashi, Tetrahedron Lett., 1989, 30, 4987-4990. 
148 K. Matsuzaki, H. Ikeda, T. Ogino, A. Matsumoto, H. B. Woodruff, H. Tanaka and S. Omura, Chloropeptins I and II, novel inhibitors against gp120-CD4 binding from Streptomyces sp, J. Antibiot., 1994, 47(10), 1173-1174.

149 S. B. Singh, H. Jayasuriya, G. M. Salituro, D. L. Zink, A. Shafiee, B. Heimbuch, K. C. Silverman, R. B. Lingham, O. Genilloud, A. Teran, D. Vilella, P. Felock and D. Hazuda, J. Nat. Prod., 2001, 64, 874-882.

150 M. N. Preobrazhenskaya and E. N. Olsufyeva, Antiviral Res., 2006, 71, 227-236.

151 N. Naruse, O. Tenmyo, S. Kobaru, M. Hatori, K. Tomita, Y. Hamagishi and T. Oki, J. Antibiot., 1993, 46, 18041811.

152 D. H. Williams and B. Bardsley, Angew. Chem., Int. Ed. Engl., 1999, 38, 1172-1193.

153 R. D. Süssmuth and W. Wohlleben, Appl. Microbiol. Biotechnol., 2004, 63, 344-350.

154 S. Pelzer, R. Süssmuth, D. Heckmann, J. Recktenwald, P. Huber, G. Jung and W. Wohlleben, Antimicrob. Agents Chemother., 1999, 43, 1565-1573.

155 M. Sosio, A. Bianchi, E. Bossi and S. Donadio, Antonie Van Leeuwenhoek, 2000, 78, 379-384.

156 H. T. Chiu, B. K. Hubbard, A. N. Shah, J. Eide, R. A. Fredenburg, C. T. Walsh and C. Khosla, Proc. Natl. Acad. Sci. U. S. A., 2001, 98, 8548-8553.

157 J. Pootoolal, M. G. Thomas, C. G. Marshall, J. M. Neu, B. K. Hubbard, C. T. Walsh and G. D. Wright, Proc. Natl. Acad. Sci. U. S. A., 2002, 99, 8962-8967.

158 M. Sosio, S. Stinchi, F. Beltrametti, A. Lazzarini and S. Donadio, Chem. Biol., 2003, 10, 541-549.

159 Y. J. Mast, W. Wohlleben and E. Schinko, J. Biotechnol., 2011, 155, 63-67.

160 L. Li, J. P. Bannantine, Q. Zhang, A. Amonsin, B. J. May, D. Alt, N. Banerji, S. Kanjilal and V. Kapur, Proc. Natl. Acad. Sci. U. S. A., 2005, 102, 12344-12349.

161 S. F. Altschul, W. Gish, W. Miller, E. W. Myers and D. J. Lipman, J. Mol. Biol., 1990, 215, 403-410.

162 P. F. Widboom, E. N. Fielding, Y. Liu and S. D. Bruner, Nature, 2007, 447, 342-345.

163 O. W. Choroba, D. H. Williams and J. B. Spencer, J. Am. Chem. Soc., 2000, 122, 5389-5390.

164 B. K. Hubbard, M. G. Thomas and C. T. Walsh, Chem. Biol., 2000, 7, 931-942.

165 T. L. Li, O. W. Choroba, H. Hong, D. H. Williams and J. B. Spencer, Chem. Commun., 2001, 2156-2157.

166 J. Recktenwald, R. Shawky, O. Puk, F. Pfennig, U. Keller, W. Wohlleben and S. Pelzer, Microbiology, 2002, 148, 1105-1118.

167 M. Gunsior, S. D. Breazeale, A. J. Lind, J. Ravel, J. W. Janc and C. A. Townsend, Chem. Biol., 2004, 11, 927-938.

168 S. J. Hammond, M. P. Williamson, D. H. Williams, L. D. Boeck and G. G. Marconi, J. Chem. Soc., Chem. Commun., 1982, 344-346.

169 S. J. Hammond, D. H. Williams and R. V. Nielsen, J. Chem. Soc., Chem. Commun., 1983, 116-117.

170 S. K. Chung, P. Taylor, Y. K. Oh, C. DeBrosse and P. W. Jeffs, J. Antibiot., 1986, 39, 642-651.
171 T. I. Nicas and R. D. G. Cooper, Drugs Pharm. Sci., 1997, 82, 363-392.

172 J. A. Conrad and G. R. Moran, Inorg. Chim. Acta, 2008, 361, 1197-1201.

173 L. Que Jr and R. Y. Ho, Chem. Rev., 1996, 96, 2607-2624.

174 L. Serre, A. Sailland, D. Sy, P. Boudec, A. Rolland, E. PebayPeyroula and C. Cohen-Addad, Structure, 1999, 7, 977-988.

175 V. Pfeifer, G. J. Nicholson, J. Ries, J. Recktenwald, A. B. Schefer, R. M. Shawky, J. Schroder, W. Wohlleben and S. Pelzer, J. Biol. Chem., 2001, 276, 38370-38377.

176 J. Brownlee, P. He, G. R. Moran and D. H. Harrison, Biochemistry, 2008, 47, 2002-2013.

177 P. He and G. R. Moran, J. Inorg. Biochem., 2011, 105, 12591272.

178 D. Bischoff, S. Pelzer, B. Bister, G. J. Nicholson, S. Stockert, M. Schirle, W. Wohlleben, G. Jung and R. D. Süssmuth, Angew. Chem., Int. Ed. Engl., 2001, 40, 4688-4691.

179 D. Bischoff, S. Pelzer, A. Holtzel, G. J. Nicholson, S. Stockert, W. Wohlleben, G. Jung and R. D. Süssmuth, Angew. Chem., Int. Ed. Engl., 2001, 40, 1693-1696.

180 R. D. Süssmuth, S. Pelzer, G. Nicholson, T. Walk, W. Wohlleben and G. Jung, Angew. Chem., Int. Ed. Engl., 1999, 38, 1976-1979.

181 A. M. Sandercock, E. H. Charles, W. Scaife, P. N. Kirkpatrick, S. W. O'Brien, E. A. Papageorgiou, J. B. Spencer and D. H. Williams, Chem. Commun., 2001, 1252-1253.

182 S. Eckermann, G. Schroder, J. Schmidt, D. Strack, R. A. Edrada, Y. Helariutta, P. Elomaa, M. Kotilainen, I. Kilpelainen, P. Proksch, T. H. Teeri and J. Schroder, Nature, 1998, 396, 387-390.

183 S. Pelzer, P. Huber, R. D. Süssmuth, J. Recktenwald, D. Heckmann and W. Wohlleben, International Patent, WO0077182A1, 2000.

184 B. S. Moore and J. N. Hopke, ChemBioChem, 2001, 2, 35-38.

185 M. Redenbach, H. M. Kieser, D. Denapaite, A. Eichner, J. Cullum, H. Kinashi and D. A. Hopwood, Mol. Microbiol., 1996, 21, 77-96.

186 H. Chen, C. C. Tseng, B. K. Hubbard and C. T. Walsh, Proc. Natl. Acad. Sci. U. S. A., 2001, 98, 14901-14906.

187 C. C. Tseng, S. M. McLoughlin, N. L. Kelleher and C. T. Walsh, Biochemistry, 2004, 43, 970-980.

188 G. H. Hur, C. R. Vickery and M. D. Burkart, Nat. Prod. Rep., 2012, 29, 1074-1098.

189 G. L. Challis, J. Ravel and C. A. Townsend, Chem. Biol., 2000, 7, 211-224.

190 M. Sosio, H. Kloosterman, A. Bianchi, P. de Vreugd, L. Dijkhuizen and S. Donadio, Microbiology, 2004, 150, 95-102.

191 T.-L. Li, F. Huang, S. F. Haydock, T. Mironenko, P. F. Leadlay and J. B. Spencer, Chem. Biol., 2004, 11, 107119.

192 X. Yin and T. M. Zabriskie, Microbiology, 2006, 152, 29692983.

193 M. Gunsior, S. D. Breazeale, A. J. Lind, J. Ravel, J. W. Janc and C. A. Townsend, Chem. Biol., 2004, 11, 927-938.

194 J. J. Banik and S. F. Brady, Proc. Natl. Acad. Sci. U. S. A., 2008, 105, 17273-17277. 
195 G. Yim, L. Kalan, K. Koteva, M. N. Thaker, N. Waglechner, I. Tang and G. D. Wright, ChemBioChem, 2014, 15, 26132623.

196 M. Röttig, M. H. Medema, K. Blin, T. Weber, C. Rausch and O. Kohlbacher, Nucleic Acids Res., 2011, 39, W362-W367.

197 C. Rausch, T. Weber, O. Kohlbacher, W. Wohlleben and D. H. Huson, Nucleic Acids Res., 2005, 33, 5799-5808.

198 S. A. Samel, P. Czodrowski and L.-O. Essen, Acta Crystallogr., Sect. D: Biol. Crystallogr., 2014, 70, 1442-1452.

199 J. W. Trauger and C. T. Walsh, Proc. Natl. Acad. Sci. U. S. A., 2000, 97, 3112-3117.

200 S. Weist, C. Kittel, D. Bischoff, B. Bister, V. Pfeifer, G. J. Nicholson, W. Wohlleben and R. D. Süssmuth, J. Am. Chem. Soc., 2004, 126, 5942-5943.

201 D. Bischoff, B. Bister, M. Bertazzo, V. Pfeifer, E. Stegmann, G. J. Nicholson, S. Keller, S. Pelzer, W. Wohlleben and R. D. Süssmuth, ChemBioChem, 2005, 6, 267-272.

202 M. J. Cryle, J. E. Stok and J. J. De Voss, Aust. J. Chem., 2003, 56, 749-762.

203 A. N. Holding and J. B. Spencer, ChemBioChem, 2008, 9, 2209-2214.

204 N. Geib, K. Woithe, K. Zerbe, D. B. Li and J. A. Robinson, Bioorg. Med. Chem. Lett., 2008, 18, 3081-3084.

205 E. Stegmann, S. Pelzer, D. Bischoff, O. Puk, S. Stockert, D. Butz, K. Zerbe, J. Robinson, R. D. Süssmuth and W. Wohlleben, J. Biotechnol., 2006, 124, 640-653.

206 B. Hadatsch, D. Butz, T. Schmiederer, J. Steudle, W. Wohlleben, R. Süssmuth and E. Stegmann, Chem. Biol., 2007, 14, 1078-1089.

207 P. C. Schmartz, K. Wölfel, K. Zerbe, E. Gad, E. S. El Tamany, H. K. Ibrahim, K. Abou-Hadeed and J. A. Robinson, Angew. Chem., Int. Ed. Engl., 2012, 51, 11468-11472.

208 K. Woithe, N. Geib, O. Meyer, T. Wortz, K. Zerbe and J. A. Robinson, Org. Biomol. Chem., 2008, 6, 2861-2867.

209 K. Woithe, N. Geib, K. Zerbe, D. B. Li, M. Heck, S. FournierRousset, O. Meyer, F. Vitali, N. Matoba, K. Abou-Hadeed and J. A. Robinson, J. Am. Chem. Soc., 2007, 129, 6887-6895.

210 K. Zerbe, K. Woithe, D. B. Li, F. Vitali, L. Bigler and J. A. Robinson, Angew. Chem., Int. Ed. Engl., 2004, 43, 6709-6713.

211 C. Brieke, V. Kratzig, K. Haslinger, A. Winkler and M. J. Cryle, Org. Biomol. Chem., 2015, 13, 2012-2021.

212 K. Haslinger, E. Maximowitsch, C. Brieke, A. Koch and M. J. Cryle, ChemBioChem, 2014, 15, 2719-2728.

213 K. Haslinger, M. Peschke, C. Brieke, E. Maximowitsch and M. J. Cryle, Nature, 2015, DOI: 10.1038/nature14141.

214 W.-T. Liu, R. D. Kersten, Y.-L. Yang, B. S. Moore and P. C. Dorrestein, J. Am. Chem. Soc., 2011, 133, 1801018013.

215 X. Jin, M. Rao, W. Wei, M. Ge, J. Liu, D. Chen and Y. Liang, Biotechnol. Lett., 2012, 34, 2283-2289.

216 G. Yim, M. N. Thaker, K. Koteva and G. Wright, J. Antibiot., 2014, 67, 31-41.

217 A. Hornung, M. Bertazzo, A. Dziarnowski, K. Schneider, K. Welzel, S.-E. Wohlert, M. Holzenkämpfer, G. J. Nicholson, A. Bechthold, R. D. Süssmuth, A. Vente and S. Pelzer, ChemBioChem, 2007, 8, 757-766.
218 B. Bister, D. Bischoff, G. J. Nicholson, S. Stockert, J. Wink, C. Brunati, S. Donadio, S. Pelzer, W. Wohlleben and R. D. Süssmuth, ChemBioChem, 2003, 4, 658-662.

219 O. Puk, D. Bischoff, C. Kittel, S. Pelzer, S. Weist, E. Stegmann, R. D. Süssmuth and W. Wohlleben, J. Bacteriol., 2004, 186, 6093-6100.

220 S. Weist, B. Bister, O. Puk, D. Bischoff, S. Pelzer, G. J. Nicholson, W. Wohlleben, G. Jung and R. D. Süssmuth, Angew. Chem., Int. Ed. Engl., 2002, 41, 3383-3385.

221 P. C. Schmartz, K. Zerbe, K. Abou-Hadeed and J. A. Robinson, Org. Biomol. Chem., 2014, 12, 5574-5577.

222 F. Beltrametti, A. Lazzarini, C. Brunati, A. Marazzi, S. Jovetic, E. Selva and F. Marinelli, J. Antibiot., 2003, 56, 773-782.

223 S. Stinchi, L. Carrano, A. Lazzarini, M. Feroggio, A. Grigoletto, M. Sosio and S. Donadio, FEMS Microbiol. Lett., 2006, 256, 229-235.

224 K. Haslinger, C. Brieke, S. Uhlmann, L. Sieverling, R. D. Süssmuth and M. J. Cryle, Angew. Chem., Int. Ed. Engl., 2014, 53, 1-6.

225 S. Uhlmann, R. D. Süssmuth and M. J. Cryle, ACS Chem. Biol., 2013, 8, 2586-2596.

226 S. Pohle, C. Appelt, M. Roux, H.-P. Fiedler and R. D. Süssmuth, J. Am. Chem. Soc., 2011, 133, 6194-6205.

227 A. W. Truman, M. J. Kwun, J. Cheng, S. H. Yang, J.-W. Suh and H.-J. Hong, Antimicrob. Agents Chemother., 2014, 58, 5687-5695.

228 M. Spohn, N. Kirchner, A. Kulik, A. Jochim, F. Wolf, P. Muenzer, O. Borst, H. Gross, W. Wohlleben and E. Stegmann, Antimicrob. Agents Chemother., 2014, 58, 6185-6196.

229 J. J. Banik, J. W. Craig, P. Y. Calle and S. F. Brady, J. Am. Chem. Soc., 2010, 132, 15661-15670.

230 B. S. Moore and D. Seng, Tetrahedron Lett., 1998, 39, 39153918.

231 M. Sosio, H. Kloosterman, A. Bianchi, V. P. de, L. Dijkhuizen and S. Donadio, Microbiology, 2004, 150, 95-102.

232 T.-L. Li, F. Huang, S. F. Haydock, T. Mironenko, P. F. Leadlay and J. B. Spencer, Chem. Biol., 2004, 11, 107-119.

233 T. C. Roberts, M. A. Schallenberger, J. Liu, P. A. Smith and F. E. Romesberg, J. Med. Chem., 2011, 54, 4954-4963.

234 H. C. Losey, M. W. Peczuh, Z. Chen, U. S. Eggert, S. D. Dong, I. Pelczer, D. Kahne and C. T. Walsh, Biochemistry, 2001, 40, 4745-4755.

235 P. J. Solenberg, P. Matsushima, D. R. Stack, S. C. Wilkie, R. C. Thompson and R. H. Baltz, Chem. Biol., 1997, 4, 195-202.

236 W. Lu, M. Oberthür, C. Leimkuhler, J. Tao, D. Kahne and C. T. Walsh, Proc. Natl. Acad. Sci. U. S. A., 2004, 101, 4390-4395.

237 M. Oberthür, C. Leimkuhler, R. G. Kruger, W. Lu, C. T. Walsh and D. Kahne, J. Am. Chem. Soc., 2005, 127, 10747-10752.

238 H. C. Losey, J. Jiang, J. B. Biggins, M. Oberthür, X.-Y. Ye, S. D. Dong, D. Kahne, J. S. Thorson and C. T. Walsh, Chem. Biol., 2002, 9, 1305-1314. 
239 A. M. Mulichak, H. C. Losey, C. T. Walsh and R. M. Garavito, Structure, 2001, 9, 547-557.

240 A. M. Mulichak, W. Lu, H. C. Losey, C. T. Walsh and R. M. Garavito, Biochemistry, 2004, 43, 5170-5180.

241 A. M. Mulichak, H. C. Losey, W. Lu, Z. Wawrzak, C. T. Walsh and R. M. Garavito, Proc. Natl. Acad. Sci. U. S. A., 2003, 100, 9238-9243.

242 M. Sosio, S. Stinchi, F. Beltrametti, A. Lazzarini and S. Donadio, Chem. Biol., 2003, 10, 541-549.

243 M. N. Thaker, W. Wang, P. Spanogiannopoulos, N. Waglechner, A. M. King, R. Medina and G. D. Wright, Nat. Biotechnol., 2013, 31, 922-927.

244 J.-Y. Ho, Y.-T. Huang, C.-J. Wu, Y.-S. Li, M.-D. Tsai and T.-L. Li, J. Am. Chem. Soc., 2006, 128, 13694-13695.

245 Y.-C. Liu, Y.-S. Li, S.-Y. Lyu, L.-J. Hsu, Y.-H. Chen, Y.-T. Huang, H.-C. Chan, C.-J. Huang, G.-H. Chen, C.-C. Chou, M.-D. Tsai and T.-L. Li, Nat. Chem. Biol., 2011, 7, 304-309.

246 A. Nakayama, A. Okano, Y. Feng, J. C. Collins, K. C. Collins, C. T. Walsh and D. L. Boger, Org. Lett., 2014, 16, 3572-3575.

247 A. Okano, A. Nakayama, A. W. Schammel and D. L. Boger, J. Am. Chem. Soc., 2014, 136, 13522-13525.

248 P. Peltier-Pain, K. Marchillo, M. Zhou, D. R. Andes and J. S. Thorson, Org. Lett., 2012, 14, 5086-5089.

249 X. Fu, C. Albermann, J. Jiang, J. Liao, C. Zhang and J. S. Thorson, Nat. Biotechnol., 2003, 21, 1467-1469.

250 R. Shi, C. Munger, L. Kalan, T. Sulea, G. D. Wright and M. Cygler, Proc. Natl. Acad. Sci. U. S. A., 2012, 109, 1182411829.

251 S. S. Lamb, T. Patel, K. P. Koteva and G. D. Wright, Chem. Biol., 2006, 13, 171-181.

252 R. Shi, S. S. Lamb, S. Bhat, T. Sulea, G. D. Wright, A. Matte and M. Cygler, J. Biol. Chem., 2007, 282, 13073-13086.

253 N. M. Gaudelli, D. H. Long and C. A. Townsend, Nature, 2015, 520, 383-387.

254 A. M. Reeve, S. D. Breazeale and C. A. Townsend, J. Biol. Chem., 1998, 273, 30695-30703.

255 B. A. Wilson, S. Bantia, G. M. Salituro, A. M. Reeve and C. A. Townsend, J. Am. Chem. Soc., 1988, 110, 8238-8239.

256 W. L. Kelly and C. A. Townsend, J. Am. Chem. Soc., 2002, 124, 8186-8187.

257 A. Bruggink, E. C. Roos and E. de Vroom, Org. Process Res. Dev., 1998, 2, 128-133.

258 R. V. Ulijn, L. De Martin, P. J. Halling, B. D. Moore and A. E. Janssen, J. Biotechnol., 2002, 99, 215-222.

259 I. Aranaz, N. Acosta and A. Heras, Enzyme Microb. Technol., 2006, 39, 215-221.

260 M. I. Youshko, H. M. Moody, A. L. Bukhanov, W. H. Boosten and V. K. Svedas, Biotechnol. Bioeng., 2004, 85, 323-329.

261 F. Matsuura, Y. Hamada and T. Shiori, Tetrahedron Lett., 1994, 35, 733-736.

262 K. Wisniewski and H. Car, CNS Drug Rev., 2002, 8, 101-116.
263 P. J. Conn and J. P. Pin, Annu. Rev. Pharmacol. Toxicol., 1997, 37, 205-237.

264 D. D. Schoepp, J. Goldsworthy, B. G. Johnson, C. R. Salhoff and S. R. Baker, J. Neurochem., 1994, 63, 769-772.

265 I. Brabet, S. Mary, J. Bockaert and J. P. Pin, Neuropharmacology, 1995, 34, 895-903.

266 M. A. Desai, J. P. Burnett, N. G. Mayne and D. D. Schoepp, Mol. Pharmacol., 1995, 48, 648-657.

267 I. Ito, A. Kohda, S. Tanabe, E. Hirose, M. Hayashi, S. Mitsunaga and H. Sugiyama, NeuroReport, 1992, 3, 1013-1016.

268 J.-M. Servitja, R. Masgrau, E. Sarri and F. Picatoste, J. Neurochem., 1999, 72, 1441-1447.

269 D. E. Pellegrini-Giampietro, S. A. Torregrossa and F. Moroni, Br. J. Pharmacol., 1996, 118, 1035-1043.

270 K. Maiese, I. Ahmad, M. Tenbroeke and J. Gallant, J. Neurosci. Res., 1999, 55, 472-485.

271 R. J. Sayer, J. Neurophysiol., 1998, 80, 1981-1988.

272 S. Ferre, P. Popoli, R. Rimondini, R. Reggio, J. Kehr and K. Fuxe, Neuropharmacology, 1999, 38, 129-140.

273 M. T. Taber and H. C. Fibiger, J. Neurosci., 1995, 15, 38963904.

274 O. L. Caramelo, P. F. Santos, A. P. Carvalho and C. B. Duarte, J. Neurosci. Res., 1999, 58, 505-514.

275 S. M. Fitzjohn, Z. A. Bortolotto, M. J. Palmer, A. J. Doherty, P. L. Ornstein, D. D. Schoepp, A. E. Kingston, D. Lodge and G. L. Collingridge, Neuropharmacology, 1998, 37, 14451458.

276 S. M. Fitzjohn, A. J. Irving, M. J. Palmer, J. Harvey, D. Lodge and G. L. Collingridge, Neurosci. Lett., 1996, 203, 211-213.

277 K. M. Huber, M. S. Kayser and M. F. Bear, Science, 2000, 288, 1254-1257.

278 M. J. Palmer, A. J. Irving, G. R. Seabrook, D. E. Jane and G. L. Collingridge, Neuropharmacology, 1997, 36, 15171532.

279 R. Schnabel, I. C. Kilpatrick and G. L. Collingridge, $B r . J$. Pharmacol., 2001, 132, 1095-1101.

280 A. I. Sacaan and D. D. Schoepp, Neurosci. Lett., 1992, 139, 77-82.

281 U. H. Schroder, T. Opitz, T. Jager, C. F. Sabelhaus, J. Breder and K. G. Reymann, Neuropharmacology, 1999, 38, 209-216.

282 H.-Z. Hu, J. Ren, S. Liu, C. Gao, Y. Xia and J. D. Wood, Br. J. Pharmacol., 1999, 128, 1631-1635.

283 K. P. Lesch, C. S. Aulakh, B. L. Wolozin and D. L. Murphy, Pharmacol. Toxicol., 1992, 71, 49-60.

284 A. Pilc, P. Branski, A. Palucha, K. Tokarski and M. Bijak, Eur. J. Pharmacol., 1998, 349, 83-87.

285 X. C. Li, P. M. Beart, J. A. Monn, N. M. Jones and R. E. Widdop, Br. J. Pharmacol., 1999, 128, 823-829.

286 T. Tsuchihashi, Y. Liu, S. Kagiyama, K. Matsumura, I. Abe and M. Fujishima, Brain Res. Bull., 2000, 52, 279-283. 